Nevada

Environmental

Restoration

Project

\title{
Corrective Action Investigation Plan for Corrective Action Unit 372: Area 20 Cabriolet/Palanquin \\ Unit Craters \\ Nevada Test Site, Nevada
}

Controlled Copy No.:

Revision No.: 0

June 2009

Approved for public release; further dissemination unlimited.

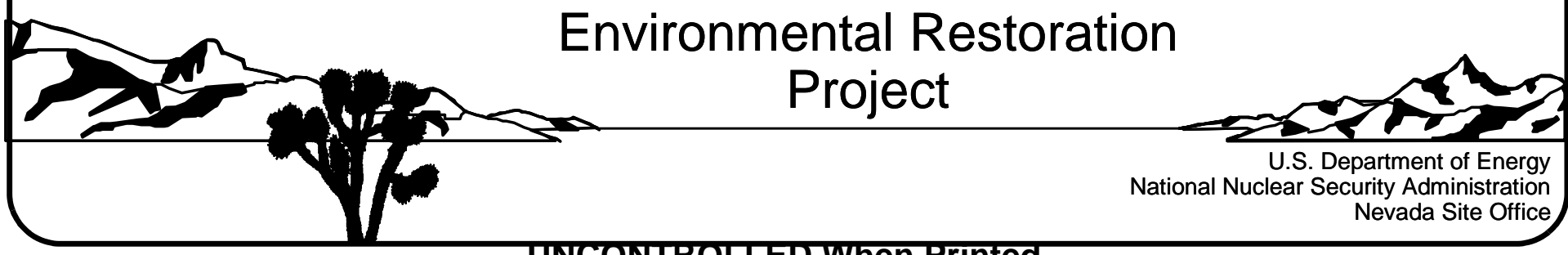


Available for sale to the public from:

U.S. Department of Commerce

National Technical Information Service

5285 Port Royal Road

Springfield, VA 22161

Phone: 800.553 .6847

Fax: 703.605.6900

Email: orders@ntis.gov

Online ordering: http://www.ntis.gov/ordering.htm

Available electronically at http://www.osti.gov/bridge

Available for a processing fee to U.S. Department of Energy and its contractors, in paper, from:

U.S. Department of Energy

Office of Scientific and Technical Information

P.O. Box 62

Oak Ridge, TN 37831-0062

Phone: 865.576.8401

Fax: 865.576.5728

Email: reports@adonis.osti.gov

Reference herein to any specific commercial product, process, or service by trade name, trademark, manufacturer, or otherwise, does not necessarily constitute or imply its endorsement, recommendation, or favoring by the United States Government or any agency thereof or its contractors or subcontractors. 


\title{
CORRECTIVE ACTION INVESTIGATION PLAN FOR CORRECTIVE ACTION UNIT 372: AREA 20 CABRIOLET/PALANQUIN UNIT CRATERS NEVADA TEST SITE, NEVADA
}

\author{
U.S. Department of Energy \\ National Nuclear Security Administration \\ Nevada Site Office \\ Las Vegas, Nevada
}

Controlled Copy No.:

Revision No.: 0

June 2009

Approved for public release; further dissemination unlimited.

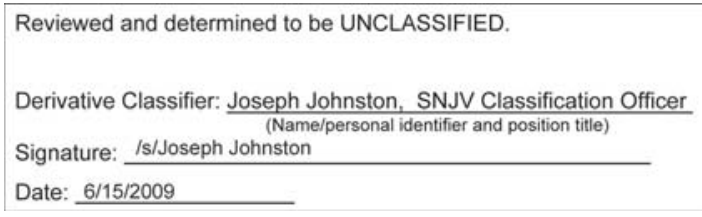




\section{CORRECTIVE ACTION INVESTIGATION PLAN \\ FOR CORRECTIVE ACTION UNIT 372: \\ AREA 20 CABRIOLET/PALANQUIN \\ UNIT CRATERS \\ NEVADA TEST SITE, NEVADA}

Approved by: /s/ Kevin J. Cabble

Date: 6/15/2009

Kevin J. Cabble

Acting Federal Sub-Project Director

Soils Sub-Project

Approved by: /s/ Robert F. Boehlecke

Date: 6/15/2009

Robert F. Boehlecke

Federal Project Director

Environmental Restoration Project 


\section{Table of Contents}

List of Figures $\ldots \ldots \ldots \ldots \ldots \ldots \ldots \ldots \ldots \ldots \ldots \ldots \ldots \ldots \ldots \ldots \ldots \ldots \ldots \ldots \ldots$

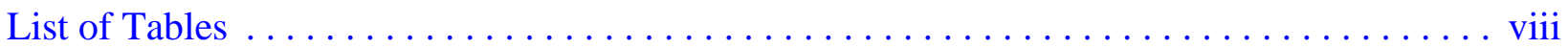

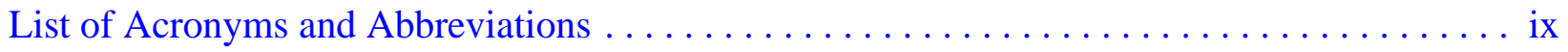

Executive Summary . . . . . . . . . . . . . . . . . . . . . . ES-1

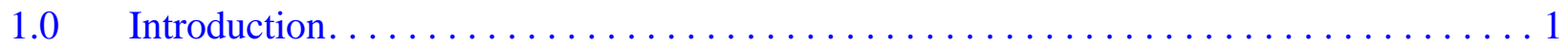

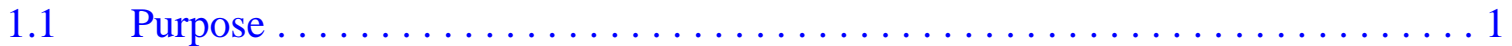

1.1.1 Corrective Action Unit 372 History and Description. . . . . . . . . . 4

1.1 .2 Data Quality Objective Summary .................. 4

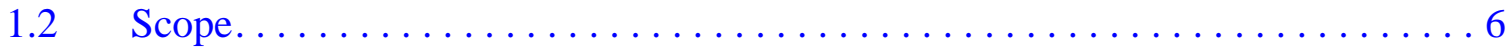

1.3 Corrective Action Investigation Plan Contents $\ldots \ldots \ldots \ldots \ldots \ldots \ldots \ldots$

$2.0 \quad$ Facility Description. . . . . . . . . . . . . . . . . . 8

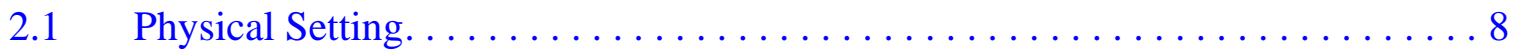

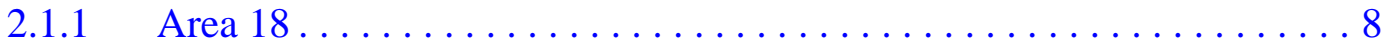

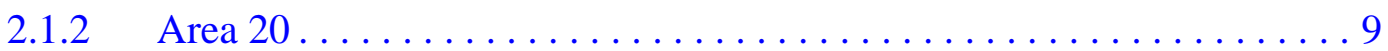

2.2 Operational History. . . . . . . . . . . . . . . . . . . . . 10

2.2.1 Corrective Action Site 18-45-02, Little Feller I Surface Crater. . . . . . . 10

2.2.2 Corrective Action Site 18-45-03, Little Feller II Surface Crater . . . . . . 11

2.2.3 Corrective Action Site 20-23-01, U-20k Contamination Area. . . . . . . . 11

2.2.4 Corrective Action Site 20-45-01, U-20L Crater (Cabriolet) . . . . . . . . 11

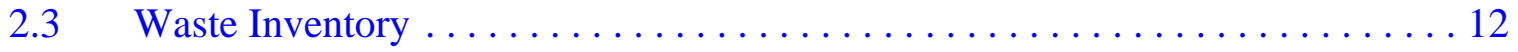

2.3.1 Corrective Action Site 18-45-02, Little Feller I Surface Crater. . . . . . . 12

2.3.2 Corrective Action Site 18-45-03, Little Feller II Surface Crater . . . . . . 12

2.3.3 Corrective Action Site 20-23-01, U-20k Contamination Area. . . . . . . . 12

2.3.4 Corrective Action Site 20-45-01, U-20L Crater (Cabriolet) . . . . . . . . 12

2.4 Release Information . . . . . . . . . . . . . . . . . . . . . . . 13

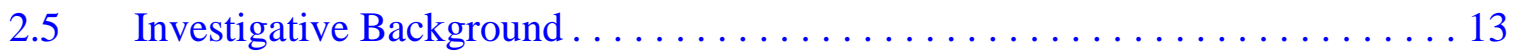

2.5.1 Corrective Action Site 18-45-02, Little Feller I Surface Crater. . . . . . 13

2.5.2 Corrective Action Site 18-45-03, Little Feller II Surface Crater . . . . . . 14

2.5.3 Corrective Action Site 20-23-01, U-20k Contamination Area. . . . . . . 16

2.5.4 Corrective Action Site 20-45-01, U-20L Crater (Cabriolet) . . . . . . . . 19

2.5.5 National Environmental Policy Act . . . . . . . . . . . . . 22

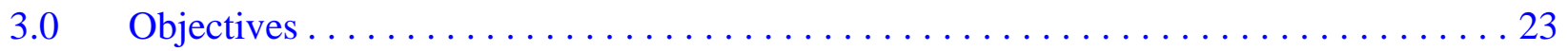

$3.1 \quad$ Conceptual Site Model . . . . . . . . . . . . . . . . . . . . 23

3.1.1 Land-Use and Exposure Scenarios. . . . . . . . . . . . . 23

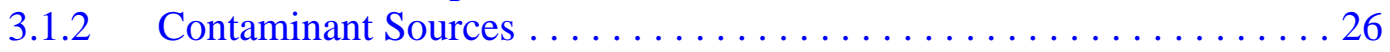

3.1.3 Release Mechanisms ........................ 26

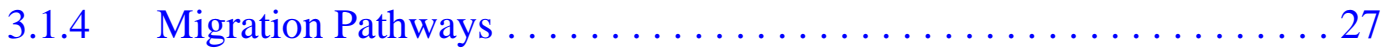

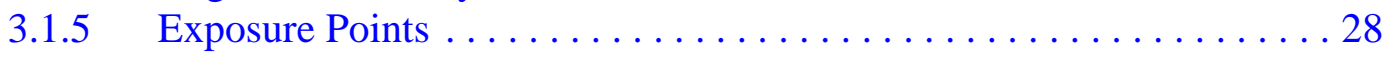




\section{Table of Contents (Continued)}

3.1.6 Exposure Routes............................ 28

3.1.7 Additional Information........................... 29

3.2 Contaminants of Potential Concern . . . . . . . . . . . . . . . . . . . . . . . . . . . 29

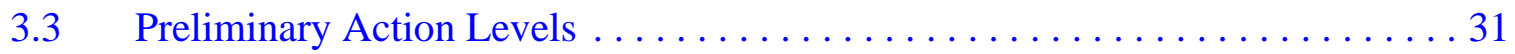

3.3.1 Chemical PALs.............................. 33

3.3.2 Total Petroleum Hydrocarbon PALs $\ldots \ldots \ldots \ldots \ldots \ldots \ldots \ldots \ldots$

3.3.3 Radionuclide PALs. .......................... 33

3.4 Data Quality Objective Process Discussion .................... 34

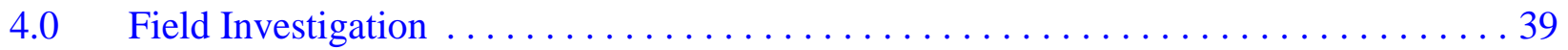

$4.1 \quad$ Technical Approach . . . . . . . . . . . . . . . . . . . . . . . . . . . . . . 39

$4.2 \quad$ Field Activities . . . . . . . . . . . . . . . . . . . . . . . . 39

4.2.1 Site Preparation Activities . . . . . . . . . . . . . . . . . . 39

4.2.2 Sample Location Selection......................... 40

4.2.2.1 Test Releases ......................... 40

4.2.2.2 Non-Test Releases $\ldots \ldots \ldots \ldots \ldots \ldots \ldots \ldots \ldots . \ldots 41$

4.2.3 Sample Collection ......................... 41

4.2.4 Sample Management $\ldots \ldots \ldots \ldots \ldots \ldots \ldots \ldots \ldots \ldots \ldots . \ldots . \ldots \ldots$

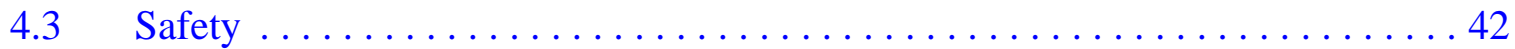

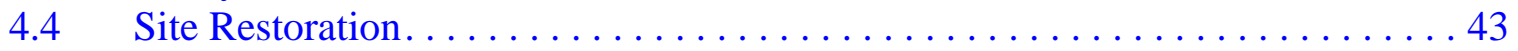

$5.0 \quad$ Waste Management.................................... 44

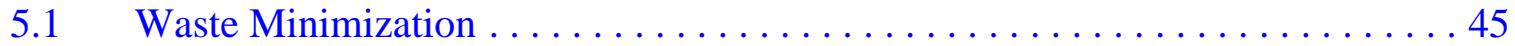

$5.2 \quad$ Potential Waste Streams . . . . . . . . . . . . . . . . . . . . . 45

$5.3 \quad$ Investigation-Derived Waste Management $\ldots \ldots \ldots \ldots \ldots \ldots \ldots \ldots \ldots$

5.3.1 Industrial and Sanitary Waste...................... 46

5.3 .2 Hydrocarbon Waste $\ldots \ldots \ldots \ldots \ldots \ldots \ldots \ldots \ldots \ldots \ldots \ldots$

5.3.3 Low-Level Waste.............................. 46

5.3.4 Hazardous Waste . . . . . . . . . . . . . . . . . . . . . . . . . . . . . . 47

5.3.5 Mixed Low-Level Waste ........................... 47

5.3.6 Polychlorinated Biphenyls .......................... 47

6.0 Quality Assurance/Quality Control $\ldots \ldots \ldots \ldots \ldots \ldots \ldots \ldots \ldots \ldots \ldots$

6.1 Quality Control Sampling Activities ....................... 48

$6.2 \quad$ Laboratory/Analytical Quality Assurance ......................... 49

6.2.1 Data Validation. ................................. 49

6.2.2 Data Quality Indicators. . . . . . . . . . . . . . . . . . . . 49

6.2.3 Precision.................................. 50

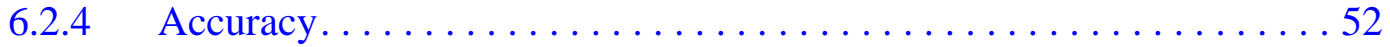

$6.2 .5 \quad$ Representativeness .......................... 53

6.2.6 Comparability................................ 53 


\section{Table of Contents (Continued)}

6.2.7 Completeness ................................ 54

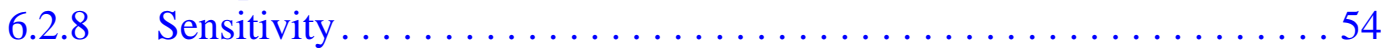

$7.0 \quad$ Duration and Records Availability . . . . . . . . . . . . . . . . . . 55

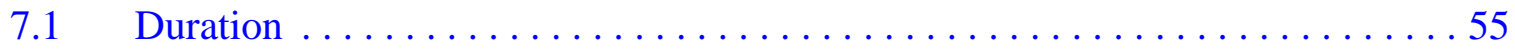

$7.2 \quad$ Records Availability.................................... 55

$8.0 \quad$ References......................................... 56

\section{Appendix A - Data Quality Objectives}

A.1.0 Introduction. ...................................... A

A.2.0 Background Information. $\ldots \ldots \ldots \ldots \ldots \ldots \ldots \ldots \ldots \ldots \ldots \ldots \ldots \ldots \ldots \ldots \ldots \ldots \ldots$

A.2.1 Corrective Action Site 18-45-02, Little Feller I Surface Crater . . . . . . . . . . A-3

A.2.2 Corrective Action Site 18-45-03, Little Feller II Surface Crater . . . . . . . . . . A-8

A.2.3 Corrective Action Site 20-23-01, U-20k Contamination Area . . . . . . . . . . . A-12

A.2.4 Corrective Action Site 20-45-01, U-20L Crater (Cabriolet). . . . . . . . . . . A-16

A.3.0 Step 1 - State the Problem................................. A-21

A.3.1 Planning Team Members ........................... A-21

A.3.2 Conceptual Site Model . . . . . . . . . . . . . . . . . . . . . A-21

A.3.2.1 Contaminant Release ........................ A-22

A.3.2.2 Potential Contaminants........................ A-25

A.3.2.3 Contaminant Characteristics..................... A-25

A.3.2.4 Site Characteristics......................... A-25

A.3.2.5 Migration Pathways and Transport Mechanisms............ A-27

A.3.2.6 Exposure Scenarios .......................... A-29

A.4.0 Step 2 - Identify the Goal of the Study ..................... A-30

A.4.1 Decision Statements . . . . . . . . . . . . . . . . . . . . . A-30

A.4.2 Alternative Actions to the Decisions $\ldots \ldots \ldots \ldots \ldots \ldots \ldots \ldots \ldots \ldots \ldots \ldots \ldots \ldots \ldots$

A.4.2.1 Alternative Actions to Decision I. . . . . . . . . . . . . . A-31

A.4.2.2 Alternative Actions to Decision II . . . . . . . . . . . . A-31

A.5.0 Step 3 - Identify Information Inputs $\ldots \ldots \ldots \ldots \ldots \ldots \ldots \ldots \ldots \ldots \ldots \ldots \ldots \ldots \ldots \ldots$

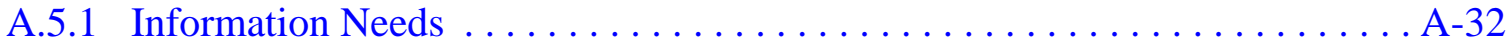

A.5.1.1 Test Releases ........................... A-32

A.5.1.2 Non-Test Releases . . . . . . . . . . . . . . . . . . . A-32

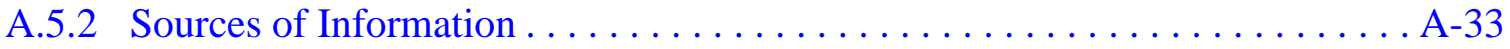

A.5.2.1 Sample Locations ............................ A-34 


\section{Table of Contents (Continued)}

A.5.2.1.1 Test Releases ......................... A-34

A.5.2.1.2 Non-Test Releases . . . . . . . . . . . . . . . . . . A-37

A.5.2.2 Analytical Methods ........................... A-38

A.6.0 Step 4 - Define the Boundaries of the Study $\ldots \ldots \ldots \ldots \ldots \ldots \ldots \ldots \ldots \ldots$ A-39

A.6.1 Target Populations of Interest. . . . . . . . . . . . . . . . . . . A-39

A.6.1.1 Test Releases ............................. A-39

A.6.2 Spatial Boundaries ............................. A-39

A.6.3 Practical Constraints . . . . . . . . . . . . . . . . . . . . . . A-39

A.6.4 Define the Sampling Units . . . . . . . . . . . . . . . . . . . . A-40

A.7.0 Step 5 - Develop the Analytic Approach ....................... A-41

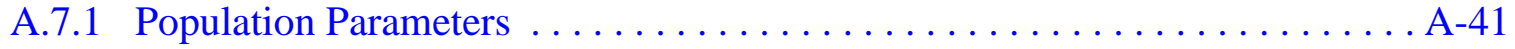

A.7.1.1 Test Releases ............................... A-41

A.7.1.2 Non-Test Releases . . . . . . . . . . . . . . . . . . . . A-42

A.7.2 Action Levels . ............................... A-42

A.7.2.1 Chemical PALs.......................... A-43

A.7.2.2 Total Petroleum Hydrocarbon PALs $\ldots \ldots \ldots \ldots \ldots \ldots \ldots \ldots$ A-43

A.7.2.3 Radionuclide PALs........................ A-43

A.7.3 Decision Rules . . . . . . . . . . . . . . . . . . . . . . . A-44

A.8.0 Step 6 - Specify Performance or Acceptance Criteria . . . . . . . . . . . . . . . . . A-45

A.8.1 Decision Hypotheses. . . . . . . . . . . . . . . . . . . . . . . . A-45

A.8.2 False Negative Decision Error . . . . . . . . . . . . . . . . . . A A-45

A.8.2.1 False Negative Decision Error for Judgmental Sampling . . . . . . . A A-46

A.8.2.2 False Negative Decision Error for Probabilistic Sampling ........ A-47

A.8.3 False Positive Decision Error . . . . . . . . . . . . . . . . . . . . . . A-48

A.9.0 Step 7 - Develop the Plan for Obtaining Data $\ldots \ldots \ldots \ldots \ldots \ldots \ldots \ldots \ldots$ A-50

A.9.1 Sampling of Test Releases .......................... A-50

A.9.1.1 Decision I Sampling ........................... A-51

A.9.1.2 Decision II Sampling ......................... A-54

A.9.2 Non-Test Releases . . . . . . . . . . . . . . . . . . . . . . . . . . . A-59

A.9.2.1 Decision I . . . . . . . . . . . . . . . . . . . . . . . . A A-59

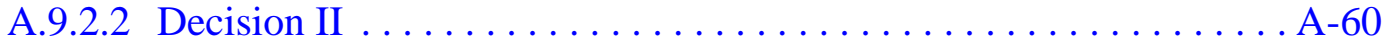

A.10.0 References.................................. A-61

\section{Appendix B - Project Organization}

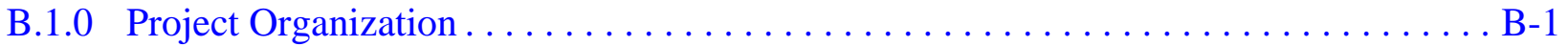




\section{Table of Contents (Continued)}

Appendix C - Determination of the Number and Location of Random Samples

C.1.0 Probabilistic Sampling Plan $\ldots \ldots \ldots \ldots \ldots \ldots \ldots \ldots \ldots \ldots \ldots \ldots \ldots \ldots \ldots \ldots \ldots \ldots \ldots$

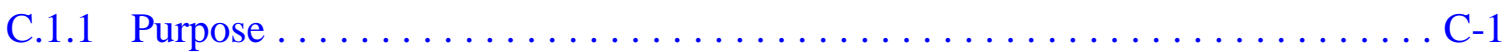

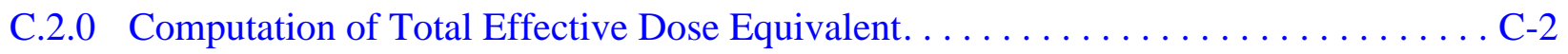

C.2.1 Computation of the Upper Confidence Limit. . . . . . . . . . . . . . C-2

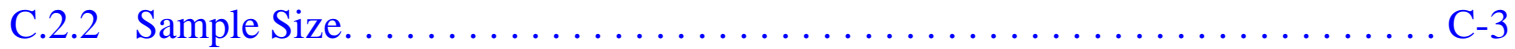

C.2.3 Sample Location Selection . . . . . . . . . . . . . . . . . . .

C.3.0 Computation of the Area Exceeding the FAL $\ldots \ldots \ldots \ldots \ldots \ldots \ldots \ldots \ldots$ C-5

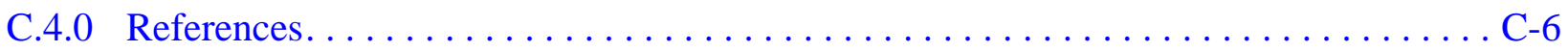

Appendix D - Nevada Division of Environmental Protection Comment Responses 


\section{List of Figures}

Number

Title

Page

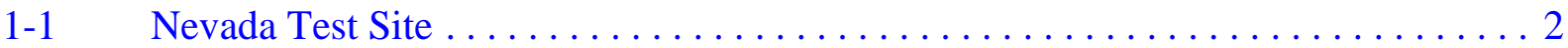

1-2 Corrective Action Unit 372 CAS Location Map...................... 3

2-1 Little Feller I Surface Crater 1994 Am-241 Flyover Survey Results . . . . . . . . . . 15

2-2 Little Feller II Surface Crater 1994 Am-241 Flyover Survey Results . . . . . . . . 17

2-3 U-20k Contamination Area (Palanquin) 1994 Am-241 Flyover

Survey Results..................................... 20

2-4 U-20L Crater (Cabriolet) 1994 Am-241 Flyover Survey Results............. 21

3-1 Conceptual Site Model Diagram............................ 24

3-2 Corrective Action Unit 372 Conceptual Site Model ...................... . 25

3-3 Risk-Based Corrective Action Decision Process ................... 32

A.2-1 Corrective Action Unit 372 CAS Location Map.................... A-4

A.2-2 Location of CAS 18-45-02, Little Feller I Surface Crater. . . . . . . . . . . . . . A-5

A.2-3 Conceptual Model of Ejected Material from a Nuclear Explosion.......... A-7

A.2-4 Location of CAS 18-45-03, Little Feller II Surface Crater . . . . . . . . . . . . . . A-9

A.2-5 Location of CAS 20-23-01, U-20k Contamination Area ............... A-13

A.2-6 Location of CAS 20-45-01, U-20L Crater (Cabriolet) . . . . . . . . . . . . A-17

A.3-1 Conceptual Site Model for CAU $372 \ldots \ldots \ldots \ldots \ldots \ldots \ldots \ldots \ldots$ A-24

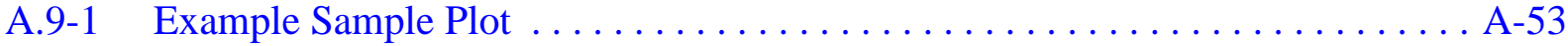

A.9-2 Proposed Sample Locations at CAS 18-45-02, Little Feller I

Surface Crater ................................... 55

A.9-3 Proposed Sample Locations at CAS 18-45-03, Little Feller II

Surface Crater . . . . . . . . . . . . . . . . . . . . . . . . . . . . 


\section{List of Figures (Continued)}

Number

Title

Page

A.9-4 Proposed Sample Locations at CAS 20-23-01, U-20k

Contamination Area. ................................. A-57

A.9-5 Proposed Sample Locations at CAS 20-45-01, U-20L

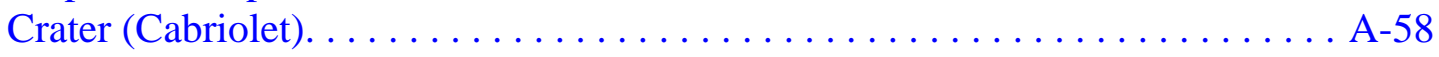

C.3-1 Correlation of TED to Distance. . . . . . . . . . . . . . . . . . . . 


\section{List of Tables}

Number

Title

Page

2-1 Summary of Precipitation Data for CAU $372 \ldots \ldots \ldots \ldots \ldots$

3-1 Constituents Reported by Analytical Methods . . . . . . . . . . . . . . . 30

3-2 Analytical Requirements for COPCs for CAU $372 \ldots \ldots \ldots \ldots \ldots \ldots \ldots$

5-1 Waste Management Regulations and Requirements . . . . . . . . . . 44

6-1 Laboratory and Analytical Performance Criteria for CAU 372

Data Quality Indicators. . . . . . . . . . . . . . . . . . . . 51

7-1 Corrective Action Investigation Activity Durations . . . . . . . . . . . . . . 55

A.3-1 Conceptual Site Model Description of Elements for Each CAS

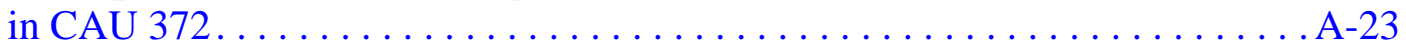

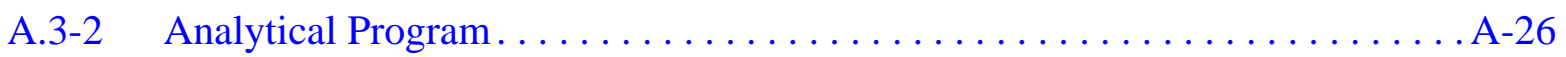

A.3-3 Land-Use and Exposure Scenarios . . . . . . . . . . . . . . . . A-29

A.5-1 Characteristics of Simple Random Sampling and Composite . . . . . . . . A-36

A.9-1 Placement of Random Composite Sample Locations. . . . . . . . . . . . . . A-54

C.2-1 VSP Placement of Random Composite Sample Locations . . . . . . . . . . . C-4 


\section{List of Acronyms and Abbreviations}

Ac

Am

ASTM

bgs

CA

CADD

CAI

CAIP

CAS

CAU

$\mathrm{Ci}$

CERCLA Comprehensive Environmental Response, Compensation, and Liability Act

CFR

$\mathrm{cm}$

Co

COC

COPC

cpm

cps

Cs

CSM Conceptual site model

DCG Derived Concentration Guideline

DoD U.S. Department of Defense

DOE U.S. Department of Energy
Actinium

Americium

American Society for Testing and Materials

Below ground surface

Contamination area

Corrective action decision document

Corrective action investigation

Corrective action investigation plan

Corrective action site

Corrective action unit

Curie

Code of Federal Regulations

Centimeter

Cobalt

Contaminant of concern

Contaminant of potential concern

Counts per minute

Counts per second

Cesium 


\section{List of Acronyms and Abbreviations (Continued)}

\begin{tabular}{ll} 
DOT & U.S. Department of Transportation \\
DQI & Data quality indicator \\
DQO & Data quality objective \\
DRI & Desert Research Institute \\
DRO & Diesel-range organics \\
EPA & U.S. Environmental Protection Agency \\
Eu & Europium \\
FAL & Final action level \\
FFACO & Federal Facility Agreement and Consent Order \\
FIDLER & Field instrument for the detection of low-energy radiation \\
FLQC & Full laboratory quality control \\
ft & Foot \\
ft & Square foot \\
GPS & Global Positioning System \\
GRO & Gasoline-range organics \\
GZ & Ground zero \\
HASL & Health and Safety Laboratory \\
HCA & High contamination area \\
I & Iodine \\
IDW & Investigation-derived waste \\
in. & Inch \\
K & Potassium \\
keV & Kiloelectron volt \\
\hline
\end{tabular}




\section{List of Acronyms and Abbreviations (Continued)}

\begin{tabular}{|c|c|}
\hline LCS & Laboratory control sample \\
\hline LLNL & Lawrence Livermore National Laboratory \\
\hline $\mathrm{m}$ & Meter \\
\hline $\mathrm{m}^{2}$ & Square meter \\
\hline $\mathrm{mCi}$ & Millicurie \\
\hline MDC & Minimum detectable concentration \\
\hline $\mathrm{mg} / \mathrm{kg}$ & Milligram per kilogram \\
\hline $\mathrm{mi}$ & Mile \\
\hline $\mathrm{mm}$ & Millimeter \\
\hline mrem/yr & Millirem per year \\
\hline $\mathrm{mR} / \mathrm{hr}$ & Milliroentgens per hour \\
\hline MS & Matrix spike \\
\hline N/A & Not applicable \\
\hline NAC & Nevada Administrative Code \\
\hline NAD & North American Datum \\
\hline NAEG & Nevada Applied Ecology Group \\
\hline $\mathrm{Nb}$ & Niobium \\
\hline $\mathrm{nCi} / \mathrm{g}$ & Nanocuries per gram \\
\hline $\mathrm{nCi} / \mathrm{m}^{2}$ & Nanocuries per square meter \\
\hline NCRP & National Council on Radiation Protection and Measurement \\
\hline ND & Normalized difference \\
\hline NDEP & Nevada Division of Environmental Protection \\
\hline NEPA & National Environmental Policy Act \\
\hline
\end{tabular}




\section{List of Acronyms and Abbreviations (Continued)}

\begin{tabular}{|c|c|}
\hline NNSA/NSO & $\begin{array}{l}\text { U.S. Department of Energy, National Nuclear Security Administration } \\
\text { Nevada Site Office }\end{array}$ \\
\hline NR & Non-test release \\
\hline NRS & Nevada Revised Statutes \\
\hline NSTec & National Security Technologies, LLC \\
\hline NTS & Nevada Test Site \\
\hline NTSWAC & Nevada Test Site Waste Acceptance Criteria \\
\hline NV/YMP & Nevada Yucca Mountain Project \\
\hline PAL & Preliminary action level \\
\hline $\mathrm{Pb}$ & Lead \\
\hline PCB & Polychlorinated biphenyl \\
\hline $\mathrm{pCi} / \mathrm{g}$ & Picocuries per gram \\
\hline PET & Potential evapotranspiration \\
\hline POC & Performance Objective for the Certification of Nonradioactive Hazardous Waste \\
\hline PPE & Personal protective equipment \\
\hline PRG & Preliminary remediation goal \\
\hline PSM & Potential source material \\
\hline $\mathrm{Pu}$ & Plutonium \\
\hline QA & Quality assurance \\
\hline QAPP & Quality Assurance Project Plan \\
\hline QC & Quality control \\
\hline RadCon & Radiological control \\
\hline $\mathrm{Rb}$ & Rubidium \\
\hline RBCA & Risk-based corrective action \\
\hline
\end{tabular}




\section{List of Acronyms and Abbreviations (Continued)}

\begin{tabular}{|c|c|}
\hline RBSL & Risk-based screening level \\
\hline RCRA & Resource Conservation and Recovery Act \\
\hline REOP & Real Estate/Operations Permit \\
\hline RESRAD & Residual Radioactive \\
\hline RIDP & Radionuclide Inventory and Distribution Program \\
\hline RL & Reporting limit \\
\hline RPD & Relative percent difference \\
\hline RRMG & Residual Radioactive Material Guidelines \\
\hline $\mathrm{Ru}$ & Ruthenium \\
\hline RWMS & Radioactive waste management site \\
\hline SNJV & Stoller-Navarro Joint Venture \\
\hline $\mathrm{Sr}$ & Strontium \\
\hline SSTL & Site-specific target level \\
\hline SVOC & Semivolatile organic compound \\
\hline Tc & Technetium \\
\hline TCLP & Toxicity Characteristic Leaching Procedure \\
\hline $\mathrm{Te}$ & Tellurium \\
\hline TED & Total effective dose \\
\hline Th & Thorium \\
\hline $\mathrm{Tl}$ & Thallium \\
\hline TLD & Thermoluminescent dosimeter \\
\hline $\mathrm{TPH}$ & Total petroleum hydrocarbons \\
\hline TR & Test release \\
\hline $\mathrm{U}$ & Uranium \\
\hline
\end{tabular}




\section{List of Acronyms and Abbreviations (Continued)}

$\begin{array}{ll}\text { UCL } & \text { Upper confidence limit } \\ \text { USGS } & \text { U.S. Geological Survey } \\ \text { UTM } & \text { Universal Transverse Mercator } \\ \text { VOC } & \text { Volatile organic compound } \\ \text { VSP } & \text { Visual Sample Plan } \\ \mathrm{Xe} & \text { Xenon } \\ \mathrm{Zr} & \text { Zirconium } \\ \mu \mathrm{R} / \mathrm{hr} & \text { Microroentgens per hour } \\ \% \mathrm{R} & \text { Percent recovery }\end{array}$




\section{Executive Summary}

Corrective Action Unit (CAU) 372 is located in Areas 18 and 20 of the Nevada Test Site, which is approximately 65 miles northwest of Las Vegas, Nevada. Corrective Action Unit 372 is comprised of the four corrective action sites (CASs) listed below:

- 18-45-02, Little Feller I Surface Crater

- 18-45-03, Little Feller II Surface Crater

- 20-23-01, U-20k Contamination Area

- 20-45-01, U-20L Crater (Cabriolet)

These sites are being investigated because existing information on the nature and extent of potential contamination is insufficient to evaluate and recommend corrective action alternatives. Additional information will be obtained by conducting a corrective action investigation (CAI) before evaluating corrective action alternatives and selecting the appropriate corrective action for each CAS. The results of the field investigation will support a defensible evaluation of viable corrective action alternatives that will be presented in the Corrective Action Decision Document.

The sites will be investigated based on the data quality objectives (DQOs) developed on February 10, 2009, by representatives of the Nevada Division of Environmental Protection; U.S. Department of Energy, National Nuclear Security Administration Nevada Site Office; Stoller-Navarro Joint Venture; Desert Research Institute, and National Security Technologies, LLC. The DQO process was used to identify and define the type, amount, and quality of data needed to develop and evaluate appropriate corrective actions for CAU 372.

Appendix A provides a detailed discussion of the DQO methodology and the DQOs specific to each CAS.

The scope of the CAI for CAU 372 includes the following activities:

- Move surface debris and/or materials, as needed, to facilitate sampling.

- Conduct radiological surveys.

- Measure in situ external dose rates using thermoluminescent dosimeters or other dose measurement devices. 
- Collect and submit environmental samples for laboratory analysis to determine internal dose rates.

- Combine internal and external dose rates to determine whether total effective dose rates exceed final action levels (FALs).

- Collect and submit environmental samples for laboratory analysis to determine whether chemical contaminants are present at concentrations exceeding FALs.

- If contamination exceeds FALs, define the extent of the contamination exceeding FALs.

- Investigate waste to determine whether potential source material is present.

This Corrective Action Investigation Plan (CAIP) has been developed in accordance with the Federal Facility Agreement and Consent Order that was agreed to by the State of Nevada; U.S. Department of Energy, Environmental Management; U.S. Department of Defense; and U.S. Department of Energy, Legacy Management (FFACO, 1996; as amended February 2008). Under the Federal Facility

Agreement and Consent Order, this CAIP will be submitted to the Nevada Division of Environmental Protection for approval. Fieldwork will be conducted following approval of the plan. 


\subsection{Introduction}

This Corrective Action Investigation Plan (CAIP) contains project-specific information including facility descriptions, environmental sample collection objectives, and criteria for conducting site investigation activities at Corrective Action Unit (CAU) 372: Area 20 Cabriolet/Palanquin Unit Craters, Nevada Test Site (NTS), Nevada.

This CAIP has been developed in accordance with the Federal Facility Agreement and Consent Order (FFACO) that was agreed to by the State of Nevada; U.S. Department of Energy (DOE); and U.S. Department of Defense (FFACO, 1996; as amended February 2008).

The corrective action sites (CAS) within CAU 372 are located in Areas 18 and 20 of the NTS, approximately 65 miles (mi) northwest of Las Vegas, Nevada (Figure 1-1). Corrective Action Unit 372 is comprised of four CASs shown on Figure 1-2 and listed below:

- 18-45-02, Little Feller I Surface Crater

- 18-45-03, Little Feller II Surface Crater

- 20-23-01, U-20k Contamination Area

- 20-45-01, U-20L Crater (Cabriolet)

The Corrective Action Investigation (CAI) will include field inspections, radiological surveys, sampling of environmental media, analysis of samples, and evaluation of investigation results. Data will be obtained to support corrective action alternative evaluations and waste management decisions.

The CAU 372 releases have been divided into test releases, which are defined as the deposition of fission products, activated products, and unburned fuel. The non-test releases are defined as all other types of releases (e.g., those resulting from spills or wastes) found at the site during the investigation.

\subsection{Purpose}

The CASs in CAU 372 are being investigated because hazardous and/or radioactive contaminants may be present in concentrations at risked-based corrective action (RBCA) levels. Existing information on the nature and extent of potential contamination is considered insufficient to evaluate and recommend corrective action alternatives for the CASs. Additional information will be generated by conducting a CAI before evaluating and selecting corrective action alternatives. 


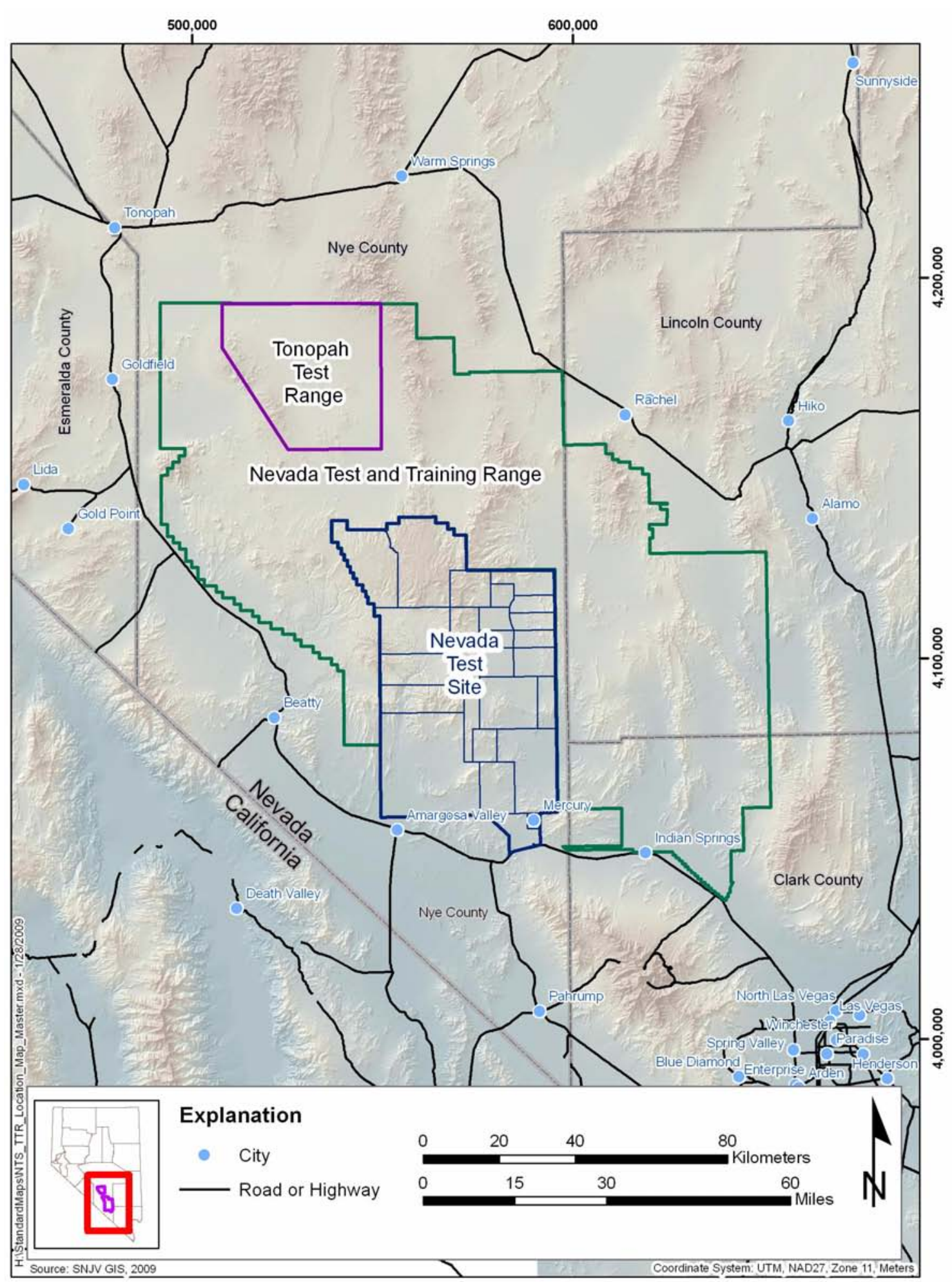

Figure 1-1

Nevada Test Site 


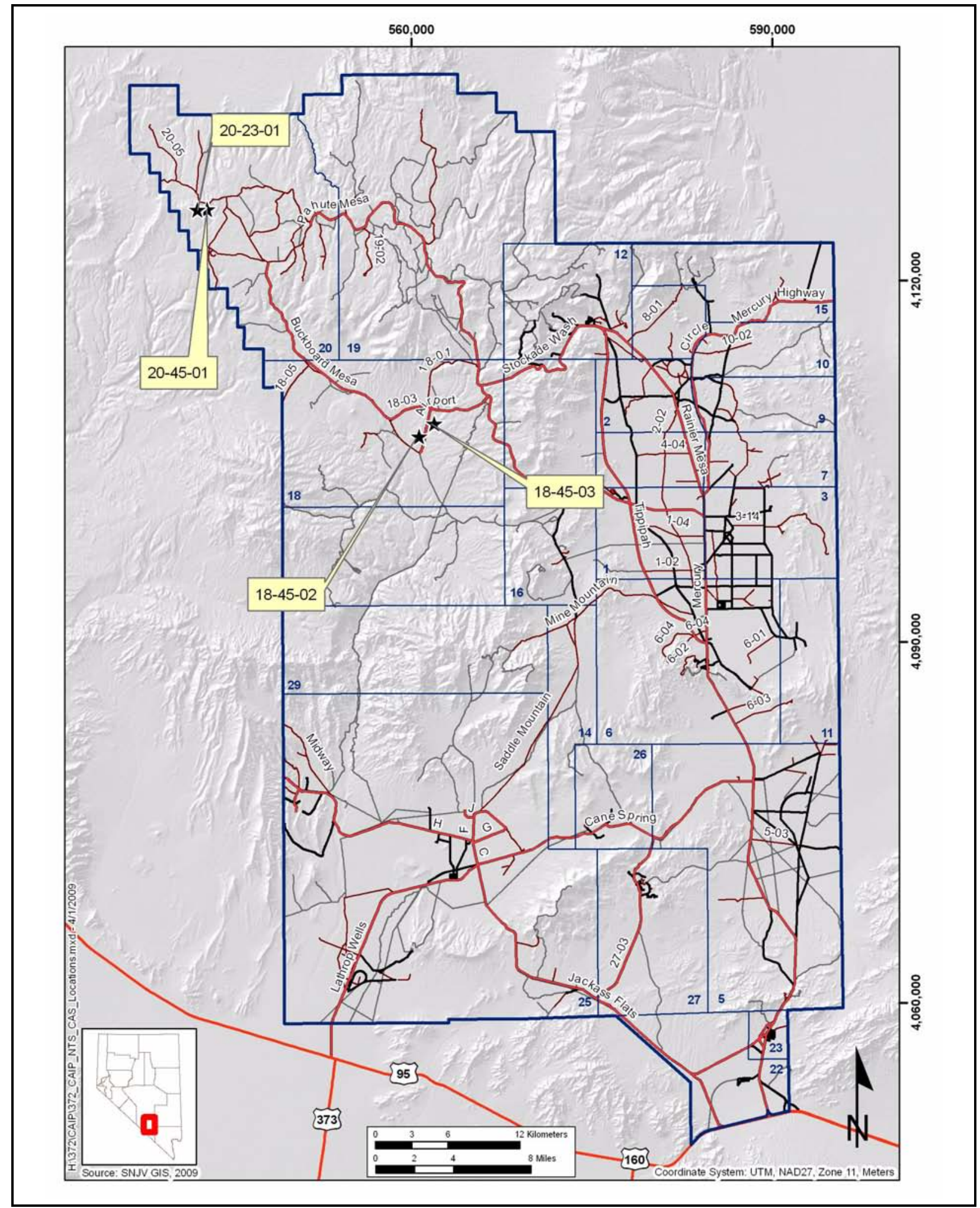

Figure 1-2

Corrective Action Unit 372 CAS Location Map 


\subsubsection{Corrective Action Unit 372 History and Description}

Corrective Action Unit 372, Area 20 Cabriolet/Palanquin Unit Craters, consists of four inactive sites located in north central Area 18 and west central Area 20. The CAU 372 sites consist of the following releases from nuclear tests:

- Corrective Action Site 18-45-02 - Radioactive material from the surface weapons-effects test, Little Feller I.

- Corrective Action Site 18-45-03 - Radioactive material from the surface weapons-effects test, Little Feller II.

- Corrective Action Site 20-23-01 - Radionuclides from the Palanquin plowshare test.

- Corrective Action Site 20-45-01 - Radionuclides from the Cabriolet plowshare test.

Operational histories for each CAU 372 CAS are detailed in Section 2.2.

\subsubsection{Data Quality Objective Summary}

The sites will be investigated based on data quality objectives (DQOs) developed by representatives of the Nevada Division of Environmental Protection (NDEP); DOE, National Nuclear Security Administration Nevada Site Office; Stoller-Navarro Joint Venture (SNJV); Desert Research Institute (DRI), and National Security Technologies, LLC (NSTec). The DQOs were used to identify and define the type, amount, and quality of data needed to develop and evaluate appropriate corrective actions for CAU 372. This CAIP describes the investigative approach developed to collect the data needs identified in the DQO process. While a detailed discussion of the DQO methodology and the DQOs specific to each CAS are presented in Appendix A, a summary of the DQO process is provided below.

The DQO problem statement for CAU 372 is: "Existing information on the nature and extent of potential contaminants is insufficient to evaluate and recommend corrective action alternatives for the CASs in CAU 372.” To address this problem, resolution of the following decision statements is required:

- Decision I: "Is any contaminant of concern (COC) associated with the CAS present in environmental media?” For judgmental sampling, any contaminant of potential 
concern (COPC) associated with a CAS activity that is present at concentrations exceeding its corresponding final action level (FAL) will be defined as a COC. For probabilistic sampling, any COPC for which the 95 percent upper confidence limit (UCL) of the mean exceeds its corresponding FAL will be defined as a COC. A COC may also be defined as a contaminant that, in combination with other like contaminants, is determined to jointly pose an unacceptable risk based on a multiple constituent analysis (NNSA/NSO, 2006). If a COC is detected, then Decision II must be resolved.

- Decision II: "Is sufficient information available to evaluate potential corrective action alternatives?” Sufficient information is defined to include the:

- Lateral and vertical extent of COC contamination.

- Information needed to determine potential remediation waste types.

- Information needed to evaluate the feasibility of remediation alternatives.

The informational inputs and data needs to resolve the problem statement and the decision statements were generated as part of the DQO process for this CAU and are documented in Appendix A. The information necessary to resolve the DQO decisions will be generated for each CAU 372 CAS by collecting and analyzing samples generated during a field investigation. The presence of contamination at each CAS will be determined by collecting and analyzing samples following these two criteria:

- For judgmental sampling, samples must be collected in areas most likely to contain a COC.

- For probabilistic sampling, samples must be collected from random locations that represent contamination within the CAS.

The DQOs for CAU 372 defined two strategies to appropriately address different types of releases that may be present at the CASs:

- A test release strategy will be used for the releases of radiological contaminants from nuclear tests. The initial test release is generally observed as an annular (ring-like) geometric pattern of contamination (i.e., soil particle activation and initial fallout), that generally decreases in intensity with distance from ground zero (GZ).

- A non-test release strategy will be used for other potential releases of contaminants (e.g., from spills and abandoned materials). 


\subsection{Scope}

To generate information needed to resolve the decision statements identified in the DQO process, the scope of the CAI for CAU 372 includes the following activities:

- Move surface debris and/or materials, as needed, to facilitate sampling.

- Conduct radiological surveys.

- Measure in situ external dose rates using thermoluminescent dosimeters (TLDs) or other dose measurement devices.

- Collect and submit environmental samples for laboratory analysis to determine internal dose rates.

- Determine whether chemical contaminants are present at concentrations exceeding FALs.

- Define the extent of the contamination exceeding FALs, if present.

- Collect and submit environmental samples for laboratory analysis of wastes present at the site to determine whether wastes exceed potential source material (PSM) criteria.

Contamination of environmental media originating from activities not identified in the conceptual site model (CSM) of any CAS will not be considered as part of this CAU unless the CSM and the DQOs are modified to include the release. If this contamination is not included in the scope of CAU 372, it will be identified as part of another CAS (either new or existing).

\subsection{Corrective Action Investigation Plan Contents}

Section 1.0 presents the purpose and scope of this CAIP, while Section 2.0 provides background information about CAU 372. Objectives of the investigation, including CSM, are presented in Section 3.0. Field investigation and sampling activities are discussed in Section 4.0, and waste management issues for this project are discussed in Section 5.0. General field and laboratory quality assurance (QA) (including collection of QA samples) are presented in Section 6.0 and in the Industrial Sites Quality Assurance Project Plan (QAPP) (NNSA/NV, 2002a). The project schedule and records availability are discussed in Section 7.0. Section 8.0 provides a list of references. 
Appendix A provides a detailed discussion of the DQO methodology and development of the DQOs specific to each CAS, while Appendix B contains information on the project organization. Appendix C provides a detailed discussion on the determination of the probabilistic sampling approach. Appendix D contains responses to NDEP comments on the draft version of this document. 


\subsection{Facility Description}

The CASs are located in Area 18 (CASs 18-45-02 and 18-45-03), and Area 20 (CASs 20-23-01 and 20-45-01) of the NTS.

\subsection{Physical Setting}

The following sections describe the general physical settings of Areas 18 and 20 of the NTS. General background information pertaining to topography, geology, hydrogeology, and climatology are provided for these specific areas of the NTS region in NTS Climatological Rain Gauge Data (ARL/SORD, 2009); Analysis of Fractures in Volcanic Cores from Pahute Mesa, Nevada Test Site (DOE/NV, 1997); Summary of Hydrogeologic Controls Ground-Water flow at the Nevada Test Site, Nye County, Nevada (Laczniak et al., 1996) Nevada Test Site 2007 Waste Management Report Area 3 and 5 Radioactive Waste Management Sites (NNSA/NSO, 2008b).

Geological and hydrological setting descriptions for the CASs are detailed in the following subsections based on the hydrogeographic area in which they are located.

\subsubsection{Area 18}

Corrective Action Sites 18-45-02 and 18-45-03 are located within the Alkali Flat Furnace Creek Ranch Subbasin. The groundwater in this area flows primarily through volcanic aquifers in a south-southwest direction towards the Death Valley and Ash Meadows discharge areas. Beneath the site lies the vitric-tuff aquifer and the welded-tuff aquifer, which are bedded tuffs and welded ash flow tuffs, respectively (DOE/NV, 1997).

Precipitation data collected from 1977 to 2008 indicates a 7.2-in. annual average rainfall at the nearest rain gauge, Little Feller II (ARL/SORD, 2009). The precipitation recharge of the Alkali Flat Furnace Creek Ranch Subbasin occurs along its northern boundary at Kawich Range and Reveille Range and along the northeastern boundary at Belted Range, Rainier Mesa, and Shoshone Mountain. Within the sub-basin, recharge occurs throughout eastern Pahute Mesa and in the southern portion of the Kawich Range. Some recharge may also occur from precipitation on Timber Mountain and the Funeral Mountains. Average annual potential evapotranspiration (PET) has been estimated as 
61.8 in. for the NTS Area 3 Radioactive Waste Management Site (RWMS) (NNSA/NSO, 2008b; Laczniak et al., 1996). Additional rainfall and PET information is presented in Table 2-1. It is expected that vertical migration of contaminants would be limited at this site due to the low annual rate of precipitation and high annual PET rate.

Table 2-1

Summary of Precipitation Data for CAU 372

\begin{tabular}{|c|c|c|c||}
\hline & $\begin{array}{c}\text { PET } \\
\text { (in.) }\end{array}$ & $\begin{array}{c}\text { Pahute Mesa 1 } \\
\text { Precipitation } \\
\text { (in.) }\end{array}$ & $\begin{array}{c}\text { Little Feller II } \\
\text { Precipitation } \\
\text { (in.) }\end{array}$ \\
\hline \hline Minimum & 59.1 & 2.6 & 1.7 \\
\hline Maximum & 63.3 & 14.5 & 13.5 \\
\hline Mean & 61.8 & 7.2 & 7.2 \\
\hline $95 \%$ UCL & 63.1 & 8.1 & 8.3 \\
\hline
\end{tabular}

Well UE-18t is located approximately $1.4 \mathrm{mi}$ northwest of CAS 18-45-02. Depth to groundwater averages approximately 912 feet (ft) below ground surface (bgs) (USGS/DOE, 2008).

Local topography within the vicinity of CASs 18-45-02 and 18-45-03 in the Buckboard Mesa area can influence the migration of potential contaminants released from the site. The direction of precipitation runoff flow is into intermittent washes that generally drain to the south.

Corrective Action Site 18-45-02 is located on top of a large ridge, and CAS 18-45-03 is located within a canyon. The CAS locations have a moderate amount of vegetation. The area around CAS 18-45-03 has been graded post-test and large mounds are present near GZ. A major wash is located east of CAS 18-45-03.

\subsubsection{Area 20}

Corrective Action Sites 20-23-01 and 20-45-01 are located within the East Thirsty Canyon and Gold Flat East drainage basin. Both CASs are on Pahute Mesa, which is a volcanic plateau underlain by tuff and lava from the Timber Mountain Oasis Valley Caldera Complex, the Silent Canyon, and the Black Mountain Calderas north of Timber Mountain. The major unit underlying Pahute Mesa is the 
Silent Canyon Caldera, which is a deep structural depression. This caldera is comprised of different types of Tertiary volcanic rocks (e.g., ash-flow tuffs). These tuffs are more than 13,000 ft thick in some places (DRI, 1988).

The average annual precipitation data calculated from 1964 to 2008 is approximately 7.2 in. for data collected from Pahute Mesa (ARL/SORD, 2009). Average annual PET for the NTS has been estimated as $61.8 \mathrm{in}$. for the Area 3 RWMS (NNSA/NSO, 2008b; Laczniak et al., 1996). Additional rainfall and PET information is presented in Table 2-1. It is expected that vertical migration of contaminants would be very limited at this site due to the low annual rate of precipitation and high annual PET rate.

The closest well to these CASs, ER-20-1, indicates an average groundwater depth of 1,988 ft bgs (606 meters $[\mathrm{m}])$.

The Area 20 sites are moderately vegetated. Corrective Action Site 20-23-01 has scattered boulders. Corrective Action Site 20-45-01 has a large crater lip present at GZ and a wash flowing through it that drains to the south.

\subsection{Operational History}

The following subsections provide a description of the use and history of each CAS in CAU 372 that may have resulted in potential releases to the environment. The CAS-specific summaries are designed to describe the current definition of each CAS and illustrate significant, known activities.

\subsubsection{Corrective Action Site 18-45-02, Little Feller I Surface Crater}

This CAS consists of a release of radionuclides to the surrounding soil from the Little Feller I surface test, an atmospheric weapons-effects test with a low yield detonated approximately $3.3 \mathrm{ft}$ (1 m) above the ground on July 17, 1962 (DOE/NV, 1996b and 2000). Little Feller I was the last atmospheric test conducted at the NTS, and was a warhead fired from the Davy Crockett weapons system (DOE/NV, 1996b) (see Figure A.2-2). The warhead was launched to simulate an operational firing and detonated close to the earth's surface. Military maneuvers (i.e., Ivy Flats) were performed in the vicinity to provide soldiers with experience in tactical nuclear weapon operations (DNA, 1993). 


\subsubsection{Corrective Action Site 18-45-03, Little Feller II Surface Crater}

This CAS consists of a release of radionuclides to the surrounding soil from the Little Feller II surface test, an atmospheric weapons-effects test with a low yield detonated on July 7, 1962 (DOE/NV, 1996b and 2000). Little Feller II was a test of the Davy Crockett weapons system. Part of Operation Sunbeam, this low-yield test was conducted to evaluate the effects of a nuclear detonation on various targets (DOE/NV, 1996b and 2000) (see Figure A.2-3). The device was suspended from a cable between posts approximately $3.3 \mathrm{ft}(1 \mathrm{~m})$ above ground (DNA, 1993; DOE/NV, 2000). A radiological controlled area is associated with this release but does not identify the boundary of the CAS. Figure A.2-4 is a depiction of the CAS area. Presently, multiple vehicles, large wooden posts, large metal items, mounds, and scattered testing artifacts remain at the site.

\subsubsection{Corrective Action Site 20-23-01, U-20k Contamination Area}

This CAS consists of a release of radionuclides to the surrounding soil from the Palanquin plowshare test. This 4.3 kilotons (kt) plowshare test was conducted on April 14, 1965, as part of Operation Whetstone and was designed for debris entrapment. Depth of burial of the device was approximately $279 \mathrm{ft}$ (DOE/NV, 1996b and 2000) (see Figure A.2-5). Presently, metal towers, cables and wood debris remain at the site. The crater area is not visible from outside the CA fence line. The resulting crater is approximately $24 \mathrm{~m}$ in depth and $36 \mathrm{~m}$ in radius (LLNL, 1965).

\subsubsection{Corrective Action Site 20-45-01, U-20L Crater (Cabriolet)}

This CAS is located in the Pahute Mesa area in the East Thirsty Canyon and Gold Flat East drainage basins at an elevation of approximately 6,109 ft (USGS, 2007) (Figure A.2-6). The area was the site of the Cabriolet plowshare test conducted on January 26, 1968. This 2.3 kt test was part of Operation Crosstie and was designed as a cratering experiment. Depth of burial of the device was approximately $171 \mathrm{ft}$ (DOE/NV, 1996b and 2000). Presently, debris in the area consists of metal, cable, wood and concrete. The area contains a large crater located in the center of the Cabriolet fence line. 


\subsection{Waste Inventory}

Available documentation, interviews with former site employees, process knowledge, and general historical NTS practices were used to identify wastes that may be present.

\subsubsection{Corrective Action Site 18-45-02, Little Feller I Surface Crater}

Debris identified at CAS 18-45-02 include a large military tank, metal, wood, cables, and piping (SNJV, 2008). Potential waste types include sanitary and radioactive waste. Both waste types may be comprised of debris, investigation-derived waste (IDW), decontamination liquids, and contaminated soils.

\subsubsection{Corrective Action Site 18-45-03, Little Feller II Surface Crater}

Debris identified at CAS 18-45-03 include four wooden posts, multiple vehicles (a tank, trucks, and Jeeps), large metal items, metal doors, pipes, cables, wood and other historical testing artifacts (SNJV, 2008). Potential waste types include sanitary and radioactive waste. Both waste types may be comprised of debris, IDW, decontamination liquids and contaminated soils.

\subsubsection{Corrective Action Site 20-23-01, U-20k Contamination Area}

Debris identified at CAS 20-23-01 include metal towers, cable, and wood. The crater was not visible during site reconnaissance. The potential exists for additional debris within the crater or along the crater lip (SNJV, 2008). Potential waste types include sanitary and radioactive waste. Both waste types may be comprised of debris, IDW, decontamination liquids, and solids.

\subsubsection{Corrective Action Site 20-45-01, U-20L Crater (Cabriolet)}

Debris identified at CAS 20-45-01 include some metal, cable, wood and concrete. It was not possible to view the crater during site reconnaissance. The potential exists for additional debris within the crater or along the crater lip (SNJV, 2008). Potential waste types include sanitary and radioactive waste. Both waste types may be comprised of debris, IDW, decontamination liquids, and soils. 


\subsection{Release Information}

Known or suspected releases, including potential release mechanisms, and migration routes, and exposure pathways associated with each CAS are described in this section.

Exposure routes to site workers include ingestion, inhalation, and/or dermal contact (absorption) from disturbance of contaminated soils and/or debris. Site workers may also be exposed to direct ionizing radiation by performing activities in proximity to radioactive materials.

The release of radioactive contamination to soil surface from nuclear weapons testing at the CAS locations include the fallout of fuel and fission fragments from the blast and the neutron activation of soils and any debris or structures in the immediate area of GZ. Radioactive contamination for CASs 20-23-01 and 20-45-01 include prompt injection of material into the crater as well as fallout to the surrounding soils. Non-test release sources (e.g., batteries or lead bricks), if present, may also have released contamination to soils at the CASs.

Migration pathways include the lateral migration of potential contaminants across soil/sediments and vertical migration of potential contaminants into subsurface soils. Erosion of material contaminated by fallout and prompt injection are all subject to this migration pathway. At the CAU 372 CASs, migration pathways include the surface runoff as sheet flow downslope from the source of the radioactivity and the intermittent flow in the various drainages within the area of deposition.

\subsection{Investigative Background}

The following subsections summarize previous investigations conducted at the CAU 372 sites. More detailed discussions of these investigations are in Appendix A.

\subsubsection{Corrective Action Site 18-45-02, Little Feller I Surface Crater}

Isotopes identified immediately following the detonation were iodine (I)-131, ruthenium (Ru)-103, and zirconium (Zr)-95/niobium (Nb)-95 (DOE/NV, 1996b). Short-lived radionuclides are not expected to be encountered at the CAS location; however, the daughter products with much longer half-lives could be present. 
An aerial radiological survey (flyover survey) was conducted at the NTS in 1994. The man-made exposure rate from radionuclides at Little Feller I ranged from 30 to 39 microroentgens per hour $(\mu \mathrm{R} / \mathrm{hr}$ ), with identified americium (Am)-241 at readings of greater than 5,000 counts per second (cps) (BN, 1999). Figure 2-1 shows the isopleth plots for the Am-241 results from the 1994 flyover survey.

The Radionuclide Inventory and Distribution Program (RIDP) investigation was conducted from 1981 through 1986, which estimated the inventory of man-made radionuclides at the NTS through in situ soil measurements, and some (limited) soil sampling. Both in situ gamma spectroscopy and limited confirmatory soil sampling were implemented at the study areas. Alpha-emitting radionuclides (primarily plutonium [Pu] isotopes) as well as gamma-emitting radionuclides (e.g., Am-241, targeted contaminants cobalt [Co]-60, cesium [Cs]-137, and several europium [Eu] isotopes) were identified at CAS 18-45-02 (see Figure 2-1) (DRI, 1985 and 2007).

\subsubsection{Corrective Action Site 18-45-03, Little Feller II Surface Crater}

In 1972, the Nevada Applied Ecology Group (NAEG) began investigating the Little Feller II site by sampling surface soils. Samples were taken along a 1,500-ft transect starting at GZ and following the long axis of the approximate center of the plume (Gilbert et al., 1977). Later, 315 locations were sampled at the surface based on a grid using 200-ft spacings. Activities of Pu-239/240 and Am-241 were found at significantly higher levels than other radionuclides, with the highest value for Am-241 at 8.38 nancocuries per gram $(\mathrm{nCi} / \mathrm{g})$ at approximately $280 \mathrm{ft}$ northwest of $\mathrm{GZ}$. The results for the $\mathrm{Pu}-239 / 240$ activities were given in multiples of Am-241, and ranged from 8 to 24 times that of Am-241 activities. A gross gamma radiological survey determined that the highest reading was 0.3 milliroentgens per hour ( $\mathrm{mR} / \mathrm{hr}$ ), coinciding with the location of the highest Am-241 result. Portable alpha instrument measurements indicated a range of 200 to 50,000 counts per minute (cpm) (300 ft northwest of GZ) along the 1,500-ft transect. Additionally, a large, man-made mound was noted to be present near GZ.

Subsequently, the NAEG surmised that the large mound of soil and rock debris (measuring $10 \mathrm{~m}$ wide, $28 \mathrm{~m}$ long, and $3 \mathrm{~m}$ high) appears have been used to store contaminated material that was removed (scrapped or dug) from the GZ area (Essington, 1981). Fourteen locations on the mound were sampled for the purpose of estimating the radionuclide inventory of the mound. Only surface 


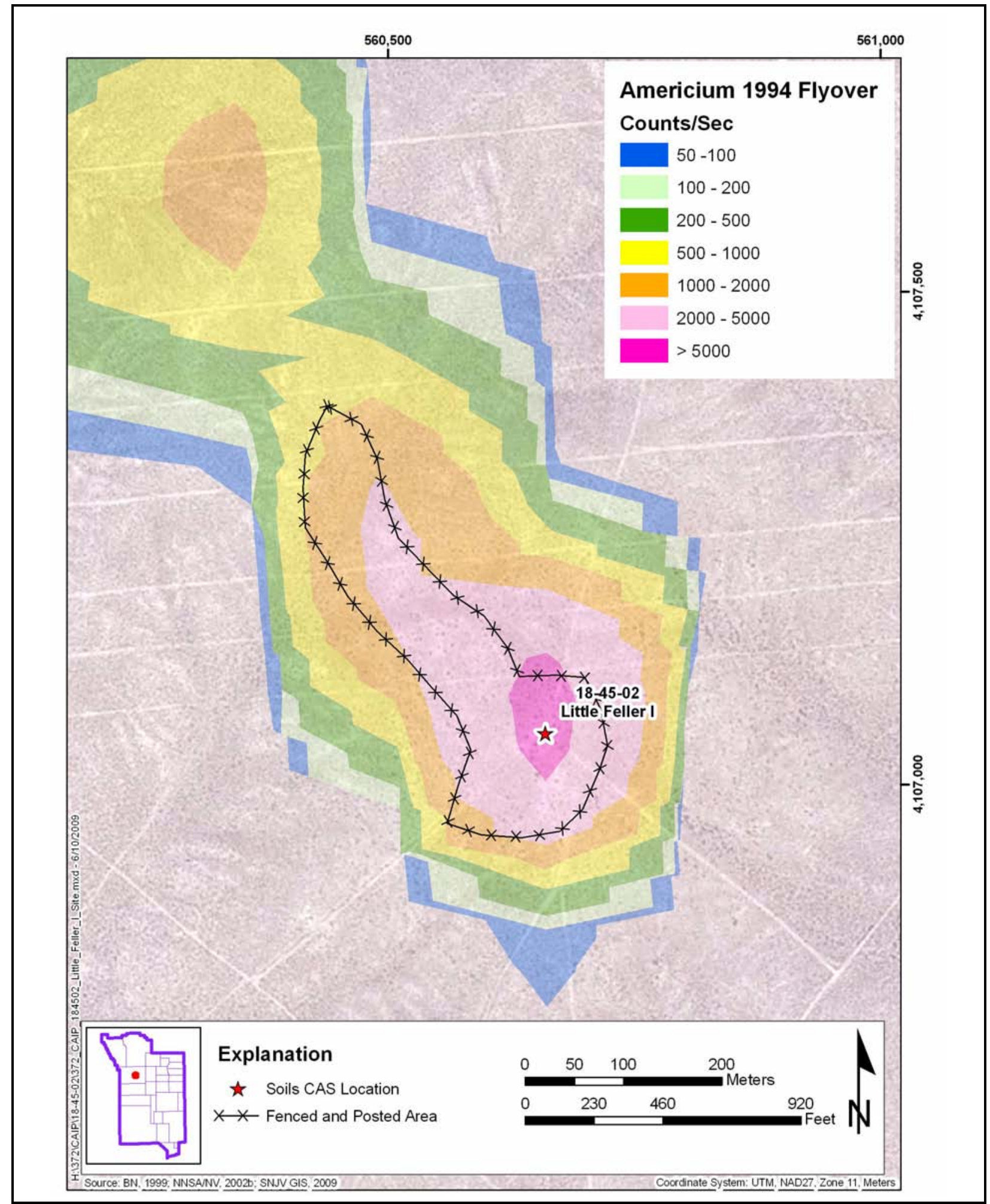

Figure 2-1

Little Feller I Surface Crater 1994 Am-241 Flyover Survey Results 
samples were collected; the presence of large rock and the tendency of the mound to cave in during attempts to sample at depth prevented sampling of the mound interior. From analytical results, the inventory of radionuclides in the mound was estimated to be 7.7 Curies (Ci) for Pu-239/240, and 0.84 Ci for Am-241, with lesser amounts for Cs-137, Eu-152, and Co-60.

In follow-up work published for the NAEG, most of the U-239/240, Am-241, and Cs-137 activity was found to be in the top $5 \mathrm{~cm}$ of soil at most locations, with exceptions being at locations in sediment accumulations in a drainage area east and south of GZ (Essington, 1982), and in several areas of sandier soil texture to the north of GZ (Essington, 1985). Most of the total radioactivity of the soils was found to be in the 0.25 - to 2-millimeter $(\mathrm{mm})$ size soil fraction, with the radioactive particles occurring as either spherical glass particles or as glass coatings on sand particles (Lee et al., 1985). Contamination from Am-241, defined as values more than 10 picocuries per gram (pCi/g), extended to approximately $800 \mathrm{~m}$ north and $120 \mathrm{~m}$ south of GZ, with widths of $100 \mathrm{~m}$ in the south up to $400 \mathrm{~m}$ in the north (Essington, 1985). The radionuclide inventory for the site (surface soil) was estimated to be approximately $35 \mathrm{Ci}$ for Pu-239/240 and Am-241, 130 to 160 millicuries (mCi) for Cs-137, and $300 \mathrm{mCi}$ for strontium (Sr)-90, with calculated distributions (Block Medians, Block Means,

Confidence Band on Block Medians, and Kriging Standard Deviations) of Pu-239/240 and Am-241 presented in several figures (Gilbert et al., 1985).

The flyover survey conducted at the NTS in 1994 measured the man-made exposure rate at Little Feller II of 24 to $30 \mu \mathrm{R} / \mathrm{hr}$, with Am-241 identified at 2,000 to 5,000 cps (BN, 1999). Figure 2-2 shows the Am-241 flyover survey results for this CAS.

The RIDP investigation identified alpha-emitting radionuclides (primarily plutonium isotopes) as well as gamma-emitting radionuclides (e.g., Am-241, Co-60, Cs-137, and several europium isotopes) at the site (DRI, 1985 and 2007).

\subsubsection{Corrective Action Site 20-23-01, U-20k Contamination Area}

Isotopes identified immediately after detonation included: barium/lanthanum-140; I -131, -133, -135; molybdenum-99m; Sr-91; technetium (Tc)-99; xenon (Xe)-135; yttrium-91m; and Zr/Nb-95 and -97, (DOE/NV, 1996b). 


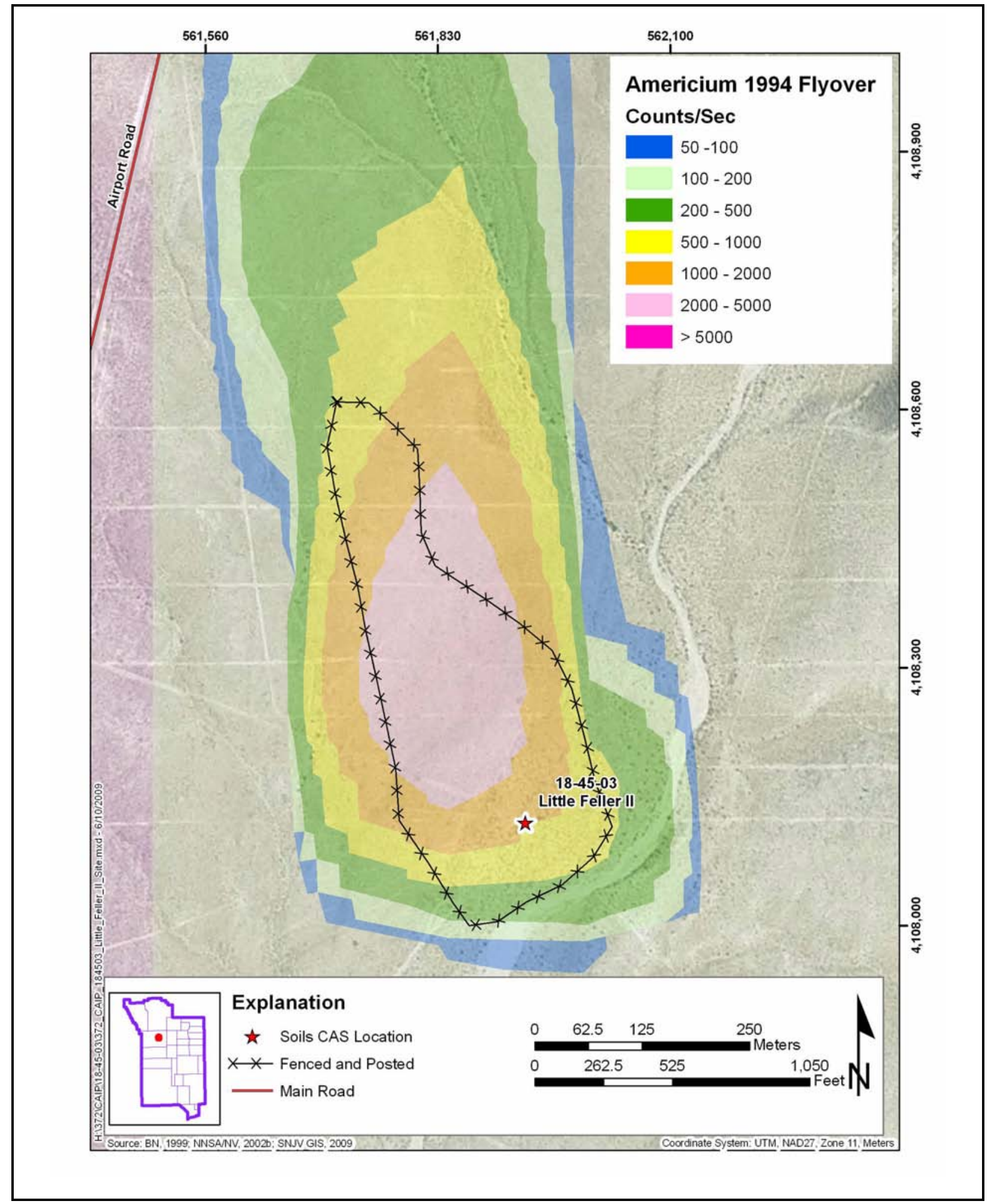

Figure 2-2

Little Feller II Surface Crater 1994 Am-241 Flyover Survey Results 
In the mid-1970s, the NAEG began investigating the Palanquin site by sampling surface soils. Samples were taken along a transect starting at approximately $600 \mathrm{ft}$ north of GZ extending to $10,000 \mathrm{ft}$ at Palanquin and following the long axis of the approximate center of the plume (Gilbert et al., 1977). Activities of Am-241 at Palanquin ranged from approximately $60 \mathrm{nCi} / \mathrm{g}$ at approximately $600 \mathrm{ft}$ north/northwest of GZ to less than $0.003 \mathrm{nCi} / \mathrm{g}$ at approximately 10,000 ft north.

During work conducted from 1977 to early 1978, the NAEG collected a suite of samples in local washes to aid in identifying subsequent erosion of radioactive material from a recent burn across the area (Essington, 1978). However, the results were not published. Readings from an alpha radiation survey at Palanquin were the highest outside a 300-ft GZ zone at approximately $430 \mathrm{ft}$ north of GZ; the beta/gamma survey readings were highest at approximately $570 \mathrm{ft}$ north of GZ. The field instrument for the detection of low-energy radiation (FIDLER) readings were the highest at approximately $500 \mathrm{ft}$ north of GZ.

In 1981, the NAEG noted that the Palanquin and Cabriolet sites appeared to be quite different in radionuclide composition from safety experiment sites and Little Feller II (Essington, 1981). The $\mathrm{Pu}-238$ to $\mathrm{Pu}-239 / 240$ ratios were considerably higher than at the other sites, and the presence of considerable amounts of U-233/234 was noted.

Follow-up work published for the NAEG in 1985 presented contour graphs of the gross-beta and gross-gamma surveys at both sites, suggesting that the contributing radionuclides are distributed on the soil surface differently (Essington, 1985). The ratio of Pu-238 to $\mathrm{Pu}-239 / 240$ was determined to range up to three, and considerable concentrations of U-233/234 were found in soil samples. The authors suggested that Pu-242 and U-232 were also likely present, though samples were not analyzed for these two isotopes. Separately, the radionuclide inventory for the combined sites (surface soil) was estimated to be approximately $13 \mathrm{Ci}$ for plutonium and americium, $1.5 \mathrm{Ci}$ for $\mathrm{Cs}-137$, and $1.4 \mathrm{Ci}$ for Sr-90, with calculated distributions (Block Medians, Block Means, Confidence Band on Block Medians, and Kriging Standard Deviations) of Pu-239/240 and Am-241, and Sr-90, presented in several figures (Gilbert et al., 1985).

The flyover survey conducted at the NTS in 1994 measured the exposure rate from man-made radionuclides at Palanquin ranging from 270 to $900 \mu \mathrm{R} / \mathrm{hr}$, with identified isotopes of Am-241, 
Co-60, and Cs-137. The Am-241 flyover survey data showed levels of more than 5,000 cps (BN, 1999). Figure 2-3 shows the Am-241 isopleths for the Palanquin area.

The RIDP investigation identified alpha-emitting radionuclides (primarily plutonium isotopes) as well as gamma-emitting radionuclides (e.g., Am-241, Co-60, Cs-137, and several europium isotopes) at the site (DRI, 1985 and 2007). Figure 2-4 shows the Am-241 isopleths for the 1994 flyover survey.

\subsubsection{Corrective Action Site 20-45-01, U-20L Crater (Cabriolet)}

Isotopes identified immediately following the detonation included: I-131, -133, -134 and -135; krypton-87 and -88; rubidium (Ru)-88; Sr-91; tellurium (Te)-132; tungsten-187; and Xe-133 and -135 (DOE/NV, 1996).

In the mid-1970s, the NAEG began investigating the Cabriolet site by sampling surface soils along a transect starting approximately $150 \mathrm{ft}$ north of GZ extending to $500 \mathrm{ft}$ at Cabriolet, following the long axis of the approximate center of the plume (Gilbert et al., 1977). Activities of Am-241 and $\mathrm{Pu}-239 / 240$ at Cabriolet ranged between approximately 0.2 and $0.9 \mathrm{nCi} / \mathrm{g}$ at the three locations sampled (Gilbert et al., 1977). Gamma readings at Cabriolet ranged from $0.7 \mathrm{mR} / \mathrm{hr}$ at $150 \mathrm{ft}$ from $\mathrm{GZ}$ to $1.5 \mathrm{mR} / \mathrm{hr}$ at $184 \mathrm{ft}$ north, then gradually declined to $0.2 \mathrm{mR} / \mathrm{hr}$ at approximately $400 \mathrm{ft}$ north.

During work conducted from 1977 to early 1978, the NAEG collected a suite of samples in local washes to aid in identifying subsequent erosion of radioactive material from a recent burn area across the area (Essington, 1978). However, results were not published. At Cabriolet, the highest readings from an alpha radiation survey were at the south perimeter of the 300-ft GZ zone, with the highest beta/gamma and FIDLER readings identified at several areas north, west, and south of GZ.

In 1981, the NAEG noted that the Palanquin and Cabriolet sites appeared to be relatively different in radionuclide composition than safety experiment sites and Little Feller II (Essington, 1981). The $\mathrm{Pu}-238$ to $\mathrm{Pu}-238 / 239$ ratios were considerably higher at the other sites, and the presence of considerable amounts of U-233/234 was noted.

Follow-up work published for the NAEG in 1985 presented contour graphs of the gross-beta and gross-gamma surveys at both sites, showing different distributions, which suggested that the contributing radionuclides are distributed on the soil surface differently (Essington, 1985). The ratio 


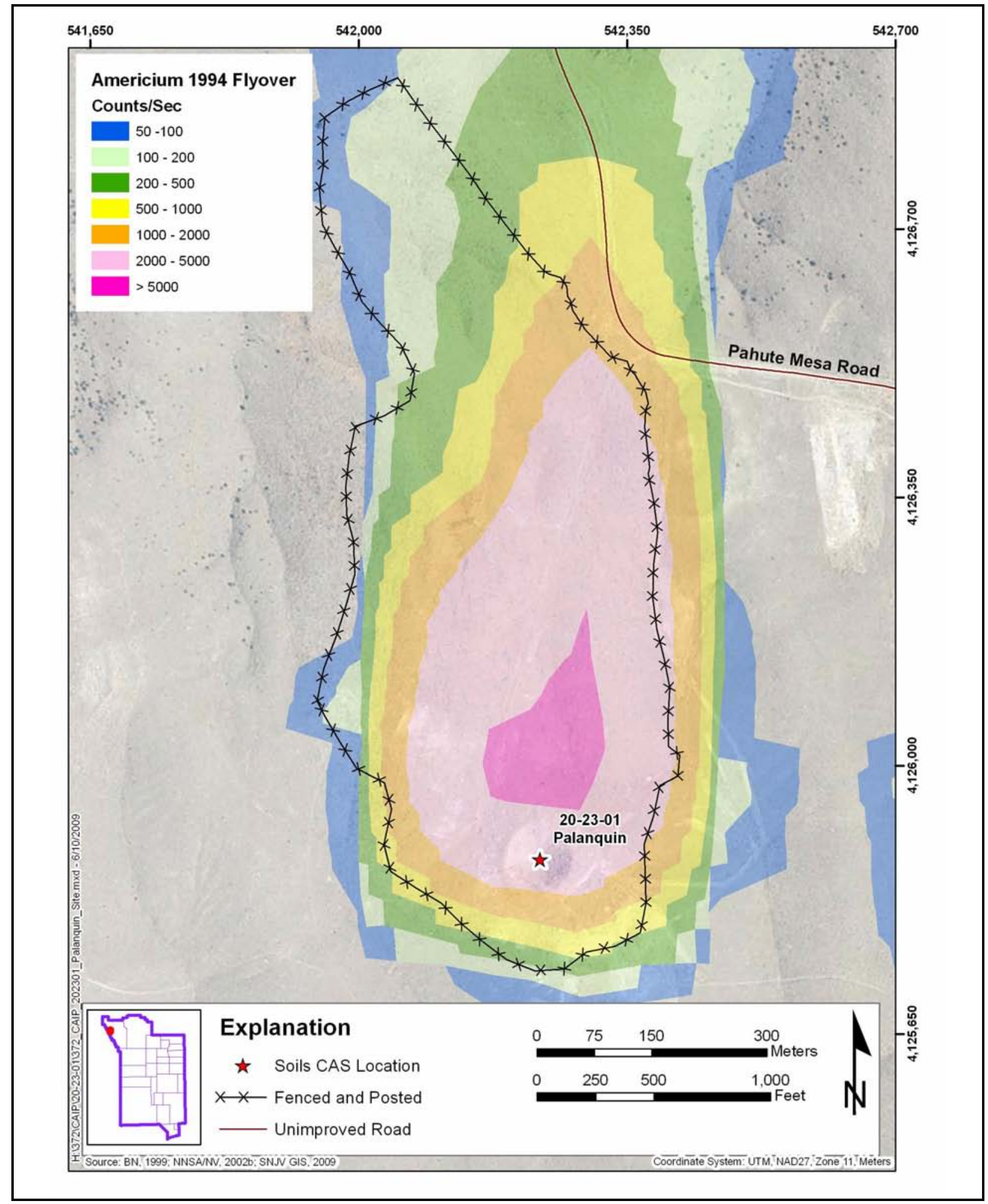

Figure 2-3

U-20k Contamination Area (Palanquin) 1994 Am-241 Flyover Survey Results 


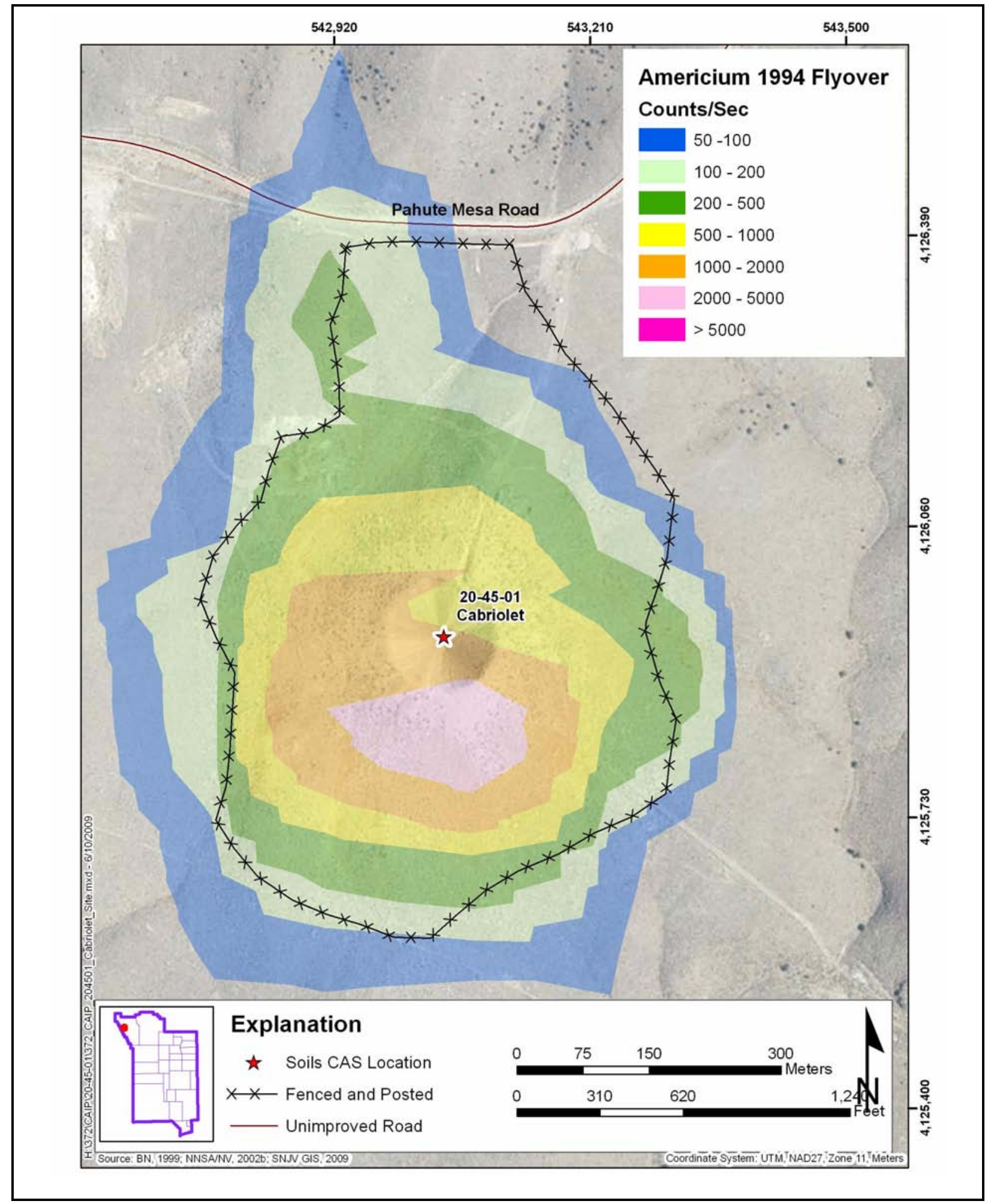

Figure 2-4

U-20L Crater (Cabriolet) 1994 Am-241 Flyover Survey Results 
of $\mathrm{Pu}-238$ to $\mathrm{Pu}-239 / 240$ was determined to range up to three, and considerable concentrations of U-233/234 were found in soil samples. The authors suggested that Pu-242 and U-232 were also likely present, though samples were not analyzed for these two isotopes. Separately, the radionuclide inventory for the combined sites (surface soil) was estimated to be approximately $13 \mathrm{Ci}$ for plutonium and americium, 1.5 Ci for Cs-137, and 1.4 Ci for Sr-90, with calculated distributions (Block Medians, Block Means, Confidence Band on Block Medians, and Kriging Standard Deviations) of Pu-239/240 and Am-241, and Sr-90, presented in several figures (Gilbert et al., 1985).

The flyover survey conducted at the NTS in 1994 measured the exposure rate from man-made radionuclides at Cabriolet from 75 to $120 \mu \mathrm{R} / \mathrm{hr}$, with identified Am-241, Co-60, and Cs-137. The Am-241 flyover survey data shows levels of 2,000 to 5,000 cps (BN, 1999).

The RIDP investigation indicated alpha-emitting radionuclides (primarily plutonium isotopes) as well as gamma-emitting radionuclides (e.g., Am-241, Co-60, Cs-137, and several europium isotopes) at the site (DRI, 1985 and 2007).

\subsubsection{National Environmental Policy Act}

The Final Environmental Impact Statement for the Nevada Test Site and Off-Site Locations in the State of Nevada (DOE/NV, 1996a) includes site investigation activities such as those proposed for CAU 372.

In accordance with the NNSA/NSO National Environmental Policy Act (NEPA) Compliance Program, a NEPA checklist will be completed before beginning site investigation activities at CAU 372. This checklist requires NNSA/NSO project personnel to evaluate their proposed project activities against a list of potential impacts that include, but are not limited to: air quality, chemical use, waste generation, noise level, and land use. Completion of the checklist results in a determination of the appropriate level of NEPA documentation by the NNSA/NSO NEPA Compliance Officer. This will be accomplished before mobilization for the field investigation. 


\subsection{Objectives}

This section presents an overview of the DQOs for CAU 372 and formulation of the CSM. Also presented is a summary listing of the COPCs, the preliminary action levels (PALs) for the investigation, and the process used to establish FALs. Additional details and figures depicting the CSM are located in Appendix A.

\subsection{Conceptual Site Model}

The CSM describes the most probable scenario for current conditions at the site and defines the assumptions that are the basis for identifying appropriate sampling strategy and data collection methods. An accurate CSM is important because it serves as the basis for all subsequent inputs and decisions throughout the DQO process.

The CSM was developed for CAU 372 using information on the physical setting, potential contaminant sources, releases, historical background, knowledge from similar sites, and physical and chemical properties of the potentially affected media and COPCs. Figure 3-1 depicts the conceptual pathway to receptors from CAU 372 sources. Figure 3-2 is a graphical depiction of the CSM.

If evidence of contamination associated with these CASs is identified that is not consistent with the presented CSM, the situation will be reviewed, the CSM revised, the DQOs reassessed, and a recommendation made as to how to proceed. In such cases, decision-makers listed in Section A.3.1 will be notified and given the opportunity to comment on and/or concur with the recommendation.

The following sections discuss future land use and the identification of exposure pathways (combination of source, release mechanisms, migration pathways, exposure points, and receptor exposure route) for CAU 372.

\subsubsection{Land-Use and Exposure Scenarios}

Land-use zones where the CAU 372 CASs are located dictate future land use and restrict current and future land use to nonresidential (i.e., industrial) activities. 


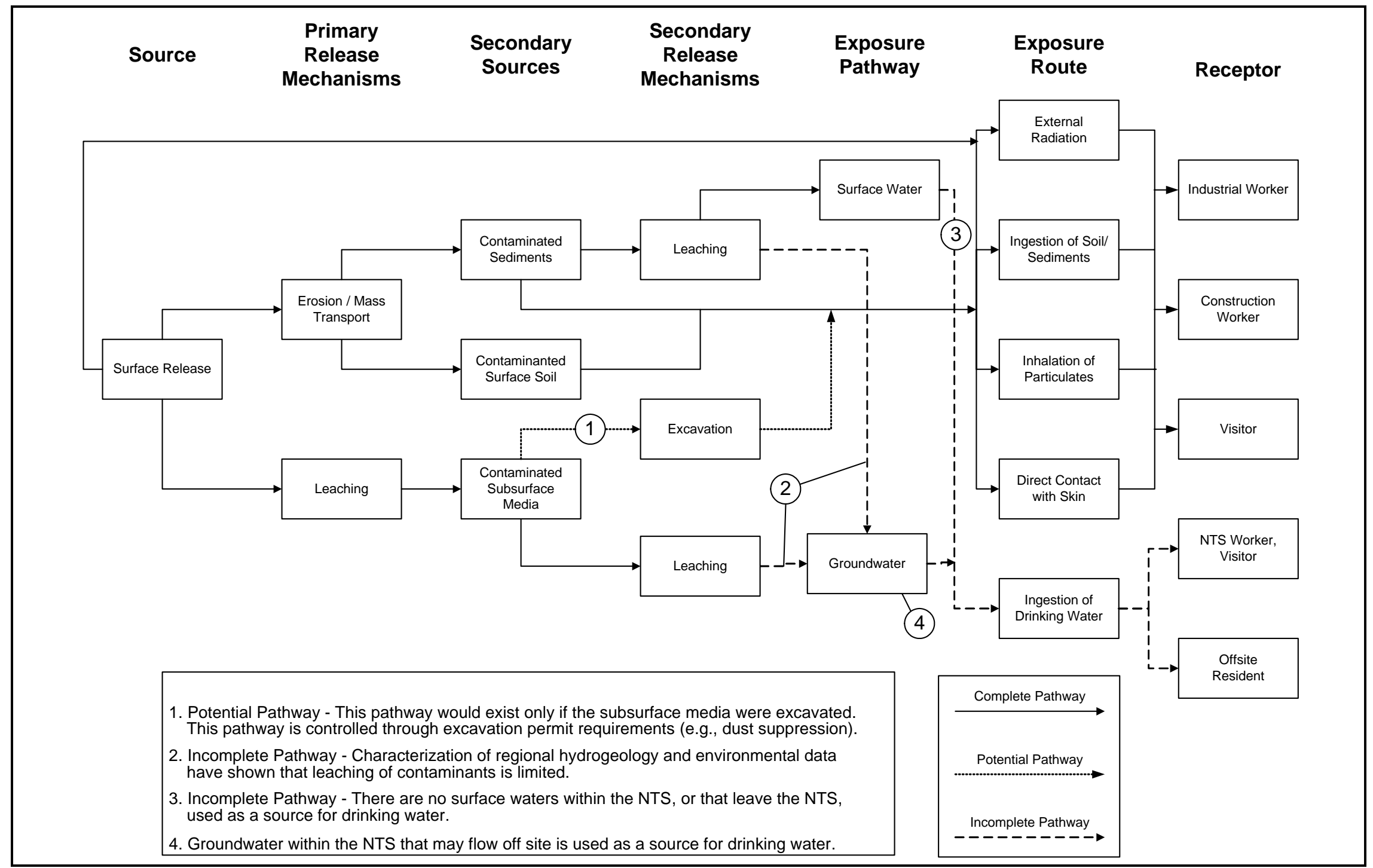

Figure 3-1

Conceptual Site Model Diagram

\section{UNCONTROLLED When Printed}




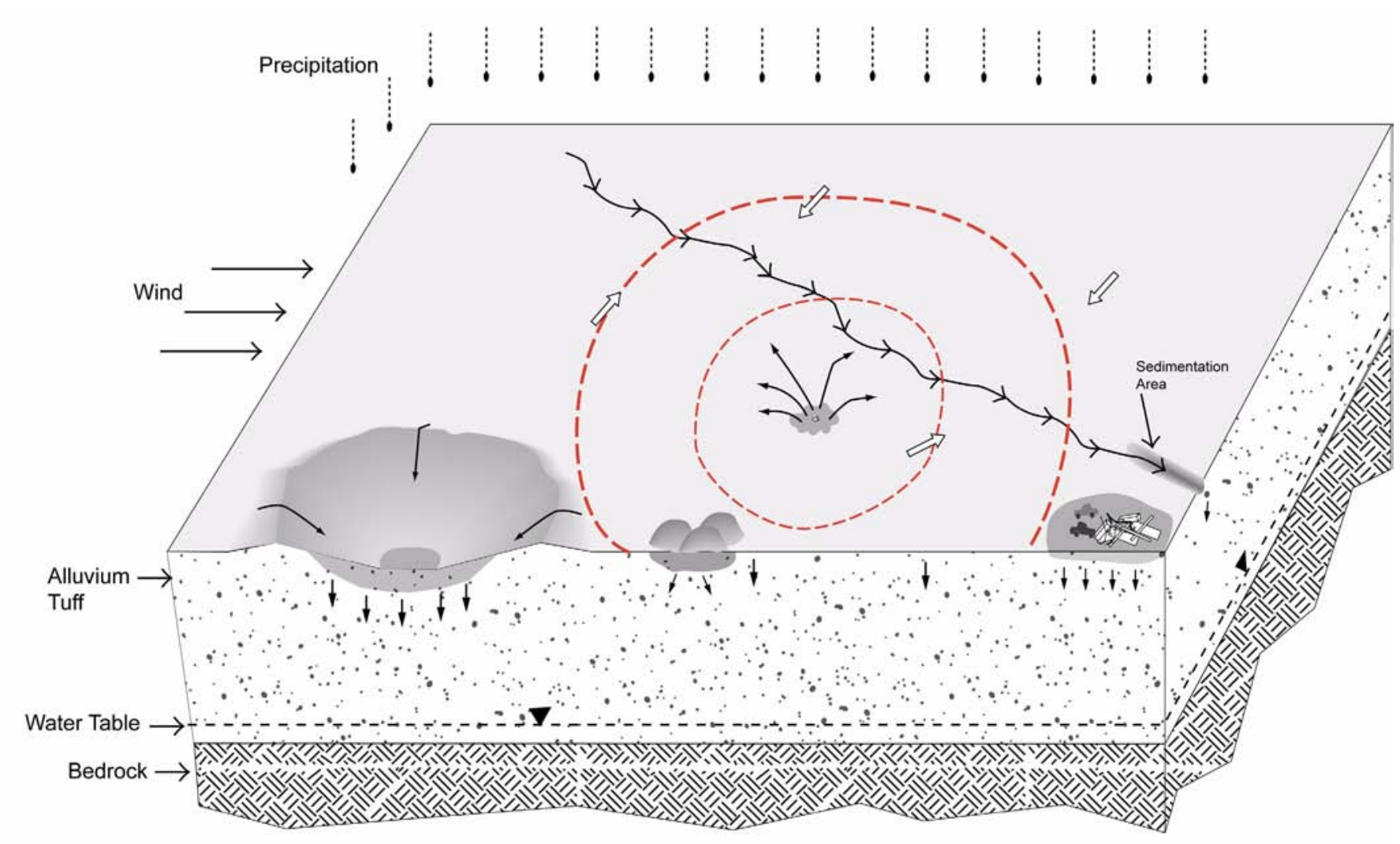

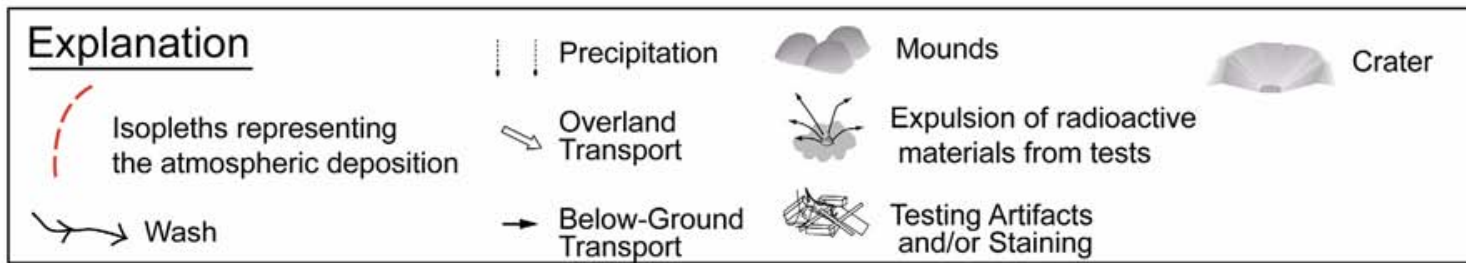

Figure 3-2

Corrective Action Unit 372 Conceptual Site Model 
Corrective Action Sites 18-45-02 and 18-45-03 are located in the land-use zone described as a

"Reserved Zone” within the NTS. This area includes land and facilities that provide widespread flexible support for diverse short-term testing and experimentation. The reserved zone is also used for short-duration exercises and training such as nuclear emergency response, Federal Radiological Monitoring and Assessment Center training, and U.S. Department of Defense (DoD) exercises and training (DOE/NV, 1998).

Corrective Action Sites 20-23-01 and 20-45-01 are located in the land-use zone described as "Nuclear Test Zone” within the NTS. This area is reserved for dynamic experiments, hydrodynamic tests, and underground nuclear weapons and weapons effects tests. This zone includes compatible defense and nondefense research, development, and testing activities (DOE/NV, 1998).

The exposure scenario for the CAU 372 is Occasional Use Area. This exposure scenario assumes exposure to industrial workers who are not assigned to the area as a regular work site but may occasionally use the site for intermittent or short-term activities. Site workers under this scenario are assumed to be on the site for an equivalent of 10 hours per day, 10 days per year, for 5 years.

\subsubsection{Contaminant Sources}

The identified contamination sources for the CASs are releases of radiological contamination to the atmosphere and soil surface as a result of weapons related (CASs 18-45-02 and 18-45-03) and plowshare (CASs 20-23-01 and 20-45-01) nuclear tests. Expected COPCs include: Am-241; Co-60; Cs-137; Eu-152, -154, -155; Pu-238, -239/240; Sr-90; and uranium (U)-233, -234, -235, -238.

Non-test sources may include batteries, lead bricks, and other wastes that may be present at the CASs in CAU 372. Other wastes (e.g., batteries, lead bricks) may have been used during the testing or left at the sites during or after activities related to the tests conducted.

\subsubsection{Release Mechanisms}

Release mechanisms for the CASs in CAU 372 include neutron activation of soil and structural components, release of fission products, and release of unfissioned nuclear fuel from the detonation of nuclear devices. The atmospheric detonations irradiated the surrounding soil with neutrons, causing the activation of some elements in the soil (primarily Eu-152 and -154). Fission fragments 
were released in an annular pattern around GZ with a bias toward the prevailing wind direction at the time of detonation (to the north). Radionuclides with a low melting point (e.g., iodine) traveled significant distances before condensing and falling out of the plume, while those with higher melting points (e.g., cesium) condensed earlier and were deposited closer to GZ. The nuclear fuel that did not fission (e.g., U-235) has a very high melting point and is generally found near GZ. For the plowshare tests (CASs 20-23-01 and 20-45-01), release mechanisms for radioactive contamination include the prompt injection of material into the crater that occurred from the detonation, as well as the fallout found around GZ.

\subsubsection{Migration Pathways}

Potential migration pathways include the lateral migration of contaminants across soil surface, and accumulation in drainages and craters, and vertical migration of potential contaminants into the subsurface soils.

The surface migration pathways for CAU 372 include lateral movement of potential contaminants into washes transecting the site since the original deposition. Contaminants released into unnamed intermittent washes within the site are potentially subject to higher transport rates than contaminants released to areas outside the natural or man-made drainages. The washes entering and leaving these areas are generally dry but are subject to infrequent, potentially intense, stormwater flows. These stormwater flow events provide an intermittent mechanism for both vertical (infiltration) and horizontal transport of contaminants. Contaminated sediments entrained by these stormwater events would be carried by the streamflow to locations where the flowing water loses energy and the sediments drop out. These locations are readily identified as sedimentation areas. The washes located near the CASs in Area 18 drain into Fortymile Wash, off site, and ultimately to Death Valley. The washes around the Area 20 CASs flow into Thirsty Canyon and ultimately to Death Valley. Other migration pathways of contamination from the site includes wind-borne material and material pushed along dirt roads within the depositional areas in the vicinity (e.g., moved during road maintenance).

Migration pathways at the CASs are expected to be predominately vertical although potential spills or leaks at the ground surface may also have limited lateral migration. The depth of infiltration (shape of the subsurface contaminant plume) will be dependent upon the type, volume, and duration of the 
discharge, as well as the presence of relatively impermeable layers that could modify vertical or horizontal transport pathways, both on the ground surface (e.g., concrete) and in the subsurface (e.g., caliche layers).

Migration is influenced by physical and chemical characteristics of the contaminants and media. Contaminant characteristics include, but are not limited to: solubility, density, and absorption potential. Media characteristics include permeability, porosity, water holding capacity, sorting, chemical composition, and organic content. In general, contaminants with low solubility, high affinity for media, and high density (e.g., actinides found at the CAS locations) can be expected to be found relatively close to release points. Contaminants with high solubility, low affinity for media, and low density can be expected to be found further from release points. These factors affect the migration pathways and potential exposure points for the contaminants in the various media under consideration.

Infiltration and percolation of precipitation serves as a driving force for downward migration of contaminants. However, due to high PET (annual PET at the Area 3 RWMS is estimated at 61.8 in. (157 centimeters [cm]) and limited precipitation for this region is $7.2 \mathrm{in.} \mathrm{(18.29} \mathrm{cm}$ [Area 18]) and

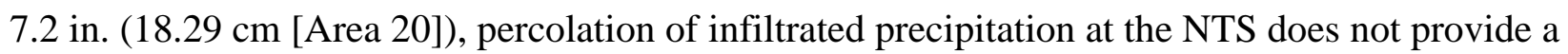
significant mechanism for vertical migration of contaminants to groundwater (ARL/SORD, 2009; DOE/NV, 1992; Laczniak et al., 1996; NNSA/NSO, 2008b; Winograd and Thordarson, 1975).

\subsubsection{Exposure Points}

Exposure points for the CSM are expected to be areas of surface contamination where visitors and site workers may come in contact with contaminated soil. Subsurface exposure points may also exist if construction workers come in contact with contaminated media during excavation activities.

\subsubsection{Exposure Routes}

Exposure routes to site workers include ingestion, inhalation, and/or dermal contact (absorption) from disturbance of, or direct contact with, contaminated media. Site workers may also be exposed to direct ionizing radiation by performing activities in proximity to radioactive materials. 


\subsubsection{Additional Information}

Information concerning topography, geology, climatic conditions, hydrogeology, floodplains, and infrastructure at the CAU 372 CASs is presented in Section 2.1 as it pertains to the investigation. This information has been addressed in the CSM and will be considered during the evaluation of corrective action alternatives, as applicable. Climatic and site conditions (e.g., surface and subsurface soil descriptions) as well as specific structure descriptions will be recorded during the CAI. Areas of erosion and deposition within the washes will be qualitatively evaluated to provide additional information on potential off site migration of contamination. Movement of the ephemeral stream channels may be identified based on a comparison of historical photographs and visual observations where erosion and deposition have occurred within the washes.

\subsection{Contaminants of Potential Concern}

Based on the identified releases at the CAU 372 CASs (see Section 3.1.2), the COPCs for CAU 372 that are applicable to Decision I environmental samples are defined as the contaminants reported from the following analyses:

- Gamma spectroscopy

- Isotopic uranium

- Isotopic plutonium

- Isotopic americium

- Strontium-90

If a biasing factor is encountered that indicates possible presence of chemical contamination, samples will be submitted for analysis based on the nature of the biasing factor (e.g, lead bricks, stains). These may include the analyte(s) reported from the following analyses:

- Total petroleum hydrocarbons (TPH)-diesel-range organics (DRO)

- Total petroleum hydrocarbons-gasoline-range organics (GRO)

- Polychlorinated biphenyls (PCBs)

- Semivolatile organic compounds (SVOCs)

- Volatile organic compounds (VOCs)

- Resource Conservation and Recovery Act (RCRA) metals

The analytes reported for each analytical method are listed in Table 3-1. The list of COPCs is intended to encompass all of the contaminants that could potentially be present at each CAS. These COPCs were identified during the planning process through the review of site history, process 
Table 3-1

Constituents Reported by Analytical Methods

\begin{tabular}{|c|c|c|c|c|c|c|c|}
\hline \multicolumn{2}{|c|}{ VOCs } & \multicolumn{2}{|c|}{ SVOCs } & \begin{tabular}{|l} 
TPH \\
DRO \\
GRO
\end{tabular} & \begin{tabular}{|c|} 
PCBS \\
Aroclor 1016 \\
Aroclor 1221 \\
Aroclor 1232 \\
Aroclor 1242 \\
Aroclor 1248 \\
Aroclor 1254 \\
Aroclor 1260 \\
Aroclor 1268
\end{tabular} & \begin{tabular}{l}
\multicolumn{1}{c}{ Metals } \\
Arsenic \\
Barium \\
Beryllium \\
Cadmium \\
Chromium \\
Lead \\
Mercury \\
Selenium \\
Silver
\end{tabular} & \begin{tabular}{|c|} 
Radionuclides \\
Gross Alpha/Beta
\end{tabular} \\
\hline $\begin{array}{l}\text { 1,1,1,2-Tetrachloroethane } \\
\text { 1,1,1-Trichloroethane } \\
\text { 1,1,2,2-Tetrachloroethane } \\
\text { 1,1,2-Trichloroethane } \\
\text { 1,1-Dichloroethane } \\
\text { 1,1-Dichloroethene } \\
\text { 1,2,4-Trichlorobenzene } \\
\text { 1,2,4-Trimethylbenzene } \\
\text { 1,2-Dibromo-3-chloropropane } \\
\text { 1,2-Dichlorobenzene } \\
\text { 1,2-Dichloroethane } \\
\text { 1,2-Dichloropropane } \\
\text { 1,3,5-Trimethylbenzene } \\
\text { 1,3-Dichlorobenzene } \\
\text { 1,4-Dichlorobenzene } \\
\text { 1,4-Dioxane } \\
\text { 2-Butanone } \\
\text { 2-Chlorotoluene } \\
\text { 2-Hexanone } \\
\text { 4-isopropyltoluene } \\
\text { 4-Methyl-2-pentanone } \\
\text { Acetone } \\
\text { Acetonitrile } \\
\text { Allyl chloride } \\
\text { Benzene } \\
\text { Bromodichloromethane } \\
\text { Bromoform } \\
\text { Bromomethane } \\
\text { Carbon disulfide }\end{array}$ & $\begin{array}{l}\text { Carbon tetrachloride } \\
\text { Chlorobenzene } \\
\text { Chloroethane } \\
\text { Chloroform } \\
\text { Chloromethane } \\
\text { Chloroprene } \\
\text { cis-1,2-Dichloroethene } \\
\text { Dibromochloromethane } \\
\text { Dichlorodifluoromethane } \\
\text { Ethyl methacrylate } \\
\text { Ethylbenzene } \\
\text { Isobutyl alcohol } \\
\text { Isopropylbenzene } \\
\text { Methacrylonitrile } \\
\text { Methyl methacrylate } \\
\text { Methylene chloride } \\
\text { n-Butylbenzene } \\
\text { n-Propylbenzene } \\
\text { sec-Butylbenzene } \\
\text { Styrene } \\
\text { tert-Butylbenzene } \\
\text { Tetrachloroethene } \\
\text { Toluene } \\
\text { Total Xylenes } \\
\text { Trichloroethene } \\
\text { Trichlorofluoromethane } \\
\text { Vinyl acetate } \\
\text { Vinyl chloride }\end{array}$ & $\begin{array}{l}\text { 2,3,4,6-Tetrachlorophenol } \\
\text { 2,4,5-Trichlorophenol } \\
\text { 2,4,6-Trichlorophenol } \\
\text { 2,4-Dimethylphenol } \\
\text { 2,4-Dinitrotoluene } \\
\text { 2-Chlorophenol } \\
\text { 2-Methylnaphthalene } \\
\text { 2-Methylphenol } \\
\text { 2-Nitrophenol } \\
\text { 3-Methylphenol }{ }^{\text {a }} \text { (m-cresol) } \\
\text { 4-Methylphenol }{ }^{\text {a }} \text { (p-cresol) } \\
\text { 4-Chloroaniline } \\
\text { 4-Nitrophenol } \\
\text { Acenaphthene } \\
\text { Acenaphthylene } \\
\text { Aniline } \\
\text { Anthracene } \\
\text { Benzo(a)anthracene } \\
\text { Benzo(a)pyrene } \\
\text { Benzo(b)fluoranthene } \\
\text { Benzo(g,h,i)perylene } \\
\text { Benzo(k)fluoranthene } \\
\text { Benzoic Acid } \\
\text { Benzyl Alcohol } \\
\text { Bis(2-ethylhexyl) phthalate } \\
\text { Butyl benzyl phthalate } \\
\text { Carbazole } \\
\text { Chrysene } \\
\text { Di-n-butyl Phthalate }\end{array}$ & $\begin{array}{l}\text { Di-n-octyl Phthalate } \\
\text { Dibenzo(a,h)anthracene } \\
\text { Dibenzofuran } \\
\text { Diethyl Phthalate } \\
\text { Dimethyl Phthalate } \\
\text { Fluoranthene } \\
\text { Fluorene } \\
\text { Hexachlorobenzene } \\
\text { Hexachlorobutadiene } \\
\text { Hexachloroethane } \\
\text { Indeno(1,2,3-cd)pyrene } \\
\text { n-Nitroso-di-n-propylamine } \\
\text { Naphthalene } \\
\text { Nitrobenzene } \\
\text { Pentachlorophenol } \\
\text { Phenanthrene } \\
\text { Phenol } \\
\text { Pyrene } \\
\text { Pyridine }\end{array}$ & $\begin{array}{l}\text { DRO } \\
\text { GRO }\end{array}$ & \begin{tabular}{|l} 
Aroclor 1016 \\
Aroclor 1221 \\
Aroclor 1232 \\
Aroclor 1242 \\
Aroclor 1248 \\
Aroclor 1254 \\
Aroclor 1260 \\
Aroclor 1268
\end{tabular} & $\begin{array}{l}\text { Arsenic } \\
\text { Barium } \\
\text { Beryllium } \\
\text { Cadmium } \\
\text { Chromium } \\
\text { Lead } \\
\text { Mercury } \\
\text { Selenium } \\
\text { Silver }\end{array}$ & $\begin{array}{l}\text { Gross Alpha/Beta } \\
\text { Am-241 } \\
\text { Pu-238 } \\
\text { Pu-239/240 } \\
\text { Sr-90 } \\
\text { U-234 } \\
\text { U-235 } \\
\text { U-238 } \\
\text { Tritium } \\
\\
\text { Gamma-Emitting } \\
\text { Ac-228 } \\
\text { Am-241 } \\
\text { Co-60 } \\
\text { Cs-137 } \\
\text { Eu-152 } \\
\text { Eu-154 } \\
\text { Eu-155 } \\
\text { K-40 } \\
\text { Nb-94 } \\
\text { Pb-212 } \\
\text { Pb-214 } \\
\text { Tl-208 } \\
\text { Th-234 } \\
\text { U-235 }\end{array}$ \\
\hline
\end{tabular}

aMay be reported as 3,4-Methylphenol or m,p-cresol.

\footnotetext{
Ac $=$ Actinium

$\mathrm{K}=$ Potassiu

$\mathrm{Pb}=$ Lead
}

$\mathrm{TI}=$ Thallium 
knowledge, past investigation efforts (where available), and inferred activities associated with the CASs.

\subsection{Preliminary Action Levels}

The PALs presented in this section are to be used for site screening purposes. They are not necessarily intended to be used as cleanup action levels or FALs. However, they are useful in screening out contaminants that are not present in sufficient concentrations to warrant further evaluation, therefore streamlining the consideration of remedial alternatives. The RBCA process used to establish FALs is described in the Industrial Sites Project Establishment of Final Action Levels (NNSA/NSO, 2006). This process conforms with Nevada Administrative Code (NAC) Section 445A.227, which lists the requirements for sites with soil contamination (NAC, 2006b). For the evaluation of corrective actions, NAC Section 445A.22705 (NAC, 2006c) requires the use of American Society for Testing and Materials (ASTM) Method E 1739-95 (ASTM, 1995) to "conduct an evaluation of the site, based on the risk it poses to public health and the environment, to determine the necessary remediation standards (i.e., FALs) or to establish that corrective action is not necessary."

This RBCA process, summarized in Figure 3-3, defines three tiers (or levels) of evaluation involving increasingly sophisticated analyses:

- Tier 1 evaluation - Sample results from source areas (highest concentrations) are compared to action levels based on generic (non-site-specific) conditions (i.e., the PALs established in the CAIP). The FALs may then be established as the Tier 1 action levels, or the FALs may be calculated using a Tier 2 evaluation.

- $\quad$ Tier 2 evaluation - Conducted by calculating Tier 2 site-specific target levels (SSTLs) using site-specific information as inputs to the same or similar methodology used to calculate Tier 1 action levels. The Tier 2 SSTLs are then compared to individual sample results from reasonable points of exposure (as opposed to the source areas as is done in Tier 1) on a point-by-point basis. The TPH concentrations will not be used for risk-based decisions under Tier 2 or Tier 3. Rather, the individual constituents of the TPH will be compared to the SSTLS.

- $\quad$ Tier 3 evaluation - Conducted by calculating Tier 3 SSTLs on the basis of more sophisticated risk analyses using methodologies described in ASTM Method E 1739-95 that consider site-, pathway-, and receptor-specific parameters. 


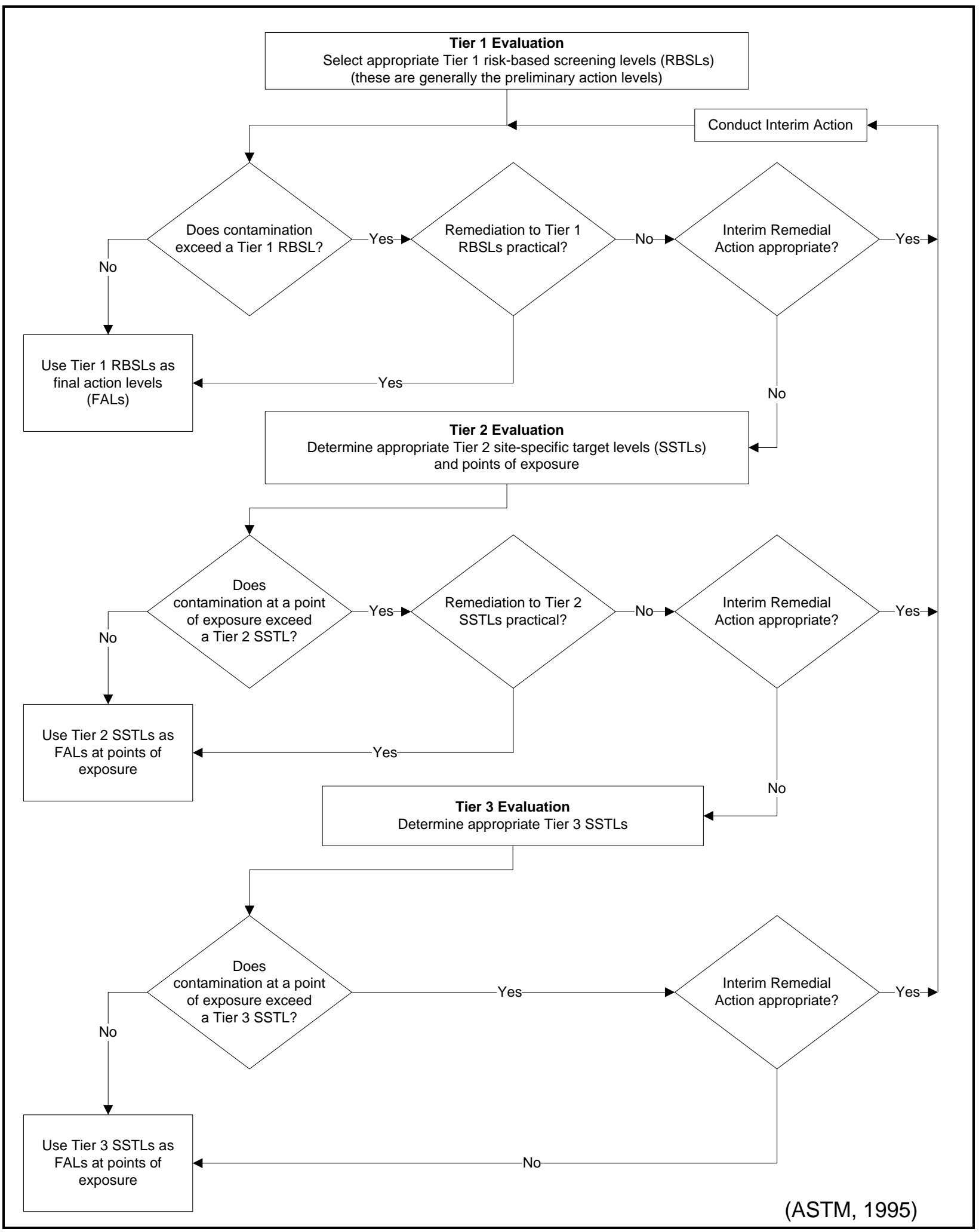

Figure 3-3

Risk-Based Corrective Action Decision Process 
The RBCA process includes a provision for conducting an interim remedial action if necessary and appropriate. The decision to conduct an interim action may be made at any time during the investigation and at any level (tier) of analysis. Concurrence of the decision-makers listed in Section A.3.1 will be obtained before any interim action is implemented. Evaluation of DQO decisions will be based on conditions at the site following completion of any interim actions. Interim actions conducted will be reported in the Corrective Action Decision Document (CADD).

The FALs (along with the basis for their selection) will be proposed in the CADD, and compared to laboratory results in the evaluation of potential corrective actions.

\subsubsection{Chemical PALs}

Except as noted herein, the chemical PALs are defined as the U.S. Environmental Protection Agency (EPA) Region 9 Preliminary Remediation Goals (PRGs) for contaminants in industrial soils (EPA, 2008a). Background concentrations for RCRA metals will be used instead of PRGs when natural background concentrations exceed the PRG, as is often the case with arsenic on the NTS. Background is considered the mean plus two standard deviations for sediment samples collected by the Nevada Bureau of Mines and Geology throughout the Nevada Test and Training Range (formerly the Nellis Air Force Range) (NBMG, 1998; Moore, 1999). For detected chemical COPCs without established PRGs, the protocol used by the EPA Region 9 in establishing PRGs (or similar) will be used to establish PALs. If used, this process will be documented in the CADD.

\subsubsection{Total Petroleum Hydrocarbon PALs}

The PAL for TPH is 100 milligrams per kilogram $(\mathrm{mg} / \mathrm{kg})$ as listed in NAC 445A.2272 (NAC, 2006d).

\subsubsection{Radionuclide PALs}

For test releases of radioactive contaminants, the PAL is 25-millirem-per-year (mrem/yr) total effective dose (TED), based upon a modified Industrial Area exposure scenario (1,076 square feet $\left[\mathrm{ft}^{2}\right]$ (100-square meter $\left.\left[\mathrm{m}^{2}\right]\right)$ and 2-in. [5 cm] depth). 
The Industrial Area exposure scenario is described in Industrial Sites Project Establishment of Final Action Levels (NNSA/NSO, 2006). That document establishes the default exposure conditions and Residual Radioactive (RESRAD) computer code input parameters to be used to calculate the potential radiation dose over a land area. Several input parameters are not specified so that site-specific information can be inputted.

The Industrial Area scenario has been modified by prespecifying values for several input parameters (e.g., an area of contamination of 1,076 $\mathrm{ft}^{2}\left[100 \mathrm{~m}^{2}\right]$ and a 2-in. [5 $\mathrm{cm}$ ] depth of contamination).

These values match the CSM. In addition, Derived Concentration Guideline (DCG) values for each individual radionuclide potential contaminant of concern were calculated. The DCG is the value, in $\mathrm{pCi} / \mathrm{g}$ for surface soil, for a particular radionuclide, that would result in a dose of $25 \mathrm{mrem} / \mathrm{yr}$. Use of DCGs in site evaluation facilitates the determination of a radiation dose estimate for each soil sample.

For non-test releases, the PALs for radiological contaminants (other than tritium) are based on the National Council on Radiation Protection and Measurement (NCRP) Report No. 129 recommended screening limits for construction, commercial, and industrial land-use scenarios (NCRP, 1999) using a 25-mrem/yr-dose constraint (Murphy, 2004) and the generic guidelines for residual concentration of radionuclides in DOE Order 5400.5 (DOE, 1993). The NCRP-based PALs are based on the construction, commercial, and industrial land-use scenario provided in the guidance and are appropriate for the NTS based on future land-use scenarios as presented in Section 3.1.1.

\subsection{Data Quality Objective Process Discussion}

This section contains a summary of the DQO process that is presented in Appendix A. The DQO process is a strategic planning approach based on the scientific method that is designed to ensure that the data collected will provide sufficient and reliable information to identify, evaluate, and technically defend the recommendation of viable corrective actions (e.g., no further action, clean closure, or closure in place).

As presented in Section 1.1.2, the DQOs address two types of potential contaminant releases:

- Test releases of contaminants are defined as releases of radionuclides from the nuclear test detonations. 
- Non-test releases of contamination include potential releases (e.g., spills, PSM) that are associated with pre-and post-test activities.

The test releases will be investigated through a combination of probabilistic and judgmental sampling, and the non-test releases through judgmental sampling only. Therefore, discussions related to these two investigation strategies are presented separately.

The DQO strategy for CAU 372 was developed at a meeting on February 10, 2009. The DQOs were developed to identify data needs, clearly define the intended use of the environmental data, and to design a data collection program that will satisfy these purposes. During the DQO discussions for this CAU, the informational inputs or data needs to resolve problem statements and decision statements were documented.

The problem statement for CAU 372 is: "Existing information on the nature and extent of potential contamination is insufficient to evaluate and recommend corrective action alternatives for the CASs in CAU 372." To address this problem statement, resolution of the following decision statements is required:

- Decision I: "Is any COC associated with the CAS present in environmental media?" If a COC is identified, then Decision II must be resolved. Resolution of this decision statement is discussed in Section A.4.1.

- Decision II: "If a COC is present, is sufficient information available to evaluate potential corrective action alternatives?” Sufficient information is defined to include:

- The lateral and vertical extent of COC contamination.

- The information needed to determine potential remediation waste types.

- The information needed to evaluate the feasibility of remediation alternatives.

The presence of a COC would require a corrective action. A corrective action may also be necessary if there is a potential for wastes that are present at a site to result in the introduction of COCs into site environmental media. To evaluate the potential for wastes to result in the introduction of a COC to the surrounding environmental media, the following conservative assumptions were made:

- That any containment of wastes would fail at some point, and the waste would be released to the surrounding soil. 
- For non-liquid wastes, the resulting concentration of contaminants in the surrounding soil would be equal to the concentration of contaminants in the wastes.

- For liquid wastes, the resulting concentration of contaminants in the surrounding soil would be calculated based on the concentration of contaminants in the wastes and the liquid holding capacity of the soil.

Decision I samples will be submitted to analytical laboratories for the analyses listed in Section 3.2. Decision II samples will be submitted for the analysis of all unbounded COCs. In addition, samples will be submitted for analyses as needed to support waste management or health and safety decisions.

The data quality indicators (DQIs) of precision, accuracy, representativeness, completeness, comparability, and sensitivity needed to satisfy DQO requirements are discussed in Section 6.2. Laboratory data will be assessed in the CADD to confirm or refute the CSM and determine whether the DQO data needs were met.

To satisfy the DQI of sensitivity (presented in Section 6.2.8), the analytical methods must be sufficient to detect contamination that is present in the samples at concentrations less than or equal to the corresponding FALs. Analytical methods and target minimum detectable concentrations (MDCs) for each CAU 372 COPC are provided in Table 3-2. The MDC is the lowest concentration of a chemical or radionuclide parameter that can be detected in a sample within an acceptable level of error. Due to changes in analytical methodology and analytical laboratory contracts, the criteria for precision and accuracy in Table 3-2 may vary from corresponding information in the QAPP (NNSA/NV, 2002a). 
Table 3-2

Analytical Requirements for COPCs for CAU 372

(Page 1 of 2)

\begin{tabular}{|c|c|c|c|c|c|}
\hline Analysis $^{a}$ & $\begin{array}{l}\text { Medium or } \\
\text { Matrix }\end{array}$ & $\begin{array}{c}\text { Analytical } \\
\text { Method }\end{array}$ & $\mathrm{MDC}^{\mathrm{b}}$ & $\begin{array}{l}\text { Laboratory } \\
\text { Precision }\end{array}$ & $\begin{array}{l}\text { Laboratory } \\
\text { Accuracy }\end{array}$ \\
\hline \multicolumn{6}{|c|}{ Environmental Samples } \\
\hline \multicolumn{6}{|c|}{ Organics } \\
\hline VOCs & All & $8260^{c}$ & $<$ PALS & Lab-specific $^{d}$ & Lab-specific $^{d}$ \\
\hline SVOCs & All & $8270^{c}$ & $<$ PALs & Lab-specific $^{d}$ & Lab-specific $^{d}$ \\
\hline PCBs & All & $8082^{c}$ & \multirow{3}{*}{$<$ PALs } & Lab-specific $^{d}$ & Lab-specific $^{d}$ \\
\hline TPH-DRO & All & 8015 Modified $^{c}$ & & Lab-specific $^{d}$ & Lab-specific $^{d}$ \\
\hline Pesticides & All & $8081^{c}$ & & Lab-specific $^{d}$ & Lab-specific $^{d}$ \\
\hline \multicolumn{6}{|c|}{ Inorganics } \\
\hline Metals & All & $6010 / 6020^{c}$ & $<$ PALs & 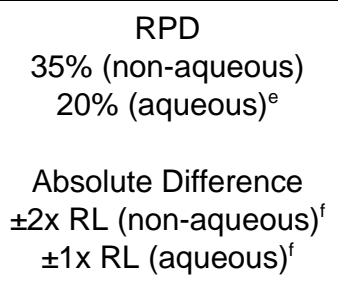 & $\begin{array}{c}\text { MS Recovery } \\
(\% \mathrm{R}) \\
75-125^{\mathrm{c}} \\
\\
\text { LCS Recovery } \\
(\% \mathrm{R}) \\
80-120^{\mathrm{c}}\end{array}$ \\
\hline \multicolumn{6}{|c|}{ Radionuclide Samples } \\
\hline \multirow[t]{2}{*}{$\begin{array}{c}\text { Gamma } \\
\text { Spectroscopy }\end{array}$} & Aqueous & EPA $901.1^{\mathrm{g}}$ & \multirow[t]{2}{*}{$\begin{array}{l}<\text { PALs } \\
\text { (non-test } \\
\text { releases) }\end{array}$} & $\begin{array}{c}\text { RPD } \\
35 \% \text { (non-aqueous) }^{\mathrm{e}} \\
20 \% \text { (aqueous) }^{\mathrm{e}}\end{array}$ & \multirow[t]{2}{*}{$\begin{array}{c}\text { LCS Recovery } \\
(\% \mathrm{R}) \\
80-120^{\mathrm{c}}\end{array}$} \\
\hline & Non-aqueous & GA-01-R ${ }^{h}$ & & $\begin{array}{c}N D \\
-2<N D<2^{e}\end{array}$ & \\
\hline Isotopic U & All & $U-02-R C^{h}$ & \multirow{7}{*}{$\begin{array}{l}<\text { PALs } \\
\text { (non-test } \\
\text { releases) }\end{array}$} & \multirow{7}{*}{$\begin{array}{c}\text { RPD } \\
35 \% \text { (non-aqueous) }^{\mathrm{e}} \\
20 \% \text { (aqueous) }^{\mathrm{e}}\end{array}$} & \multirow{7}{*}{$\begin{array}{c}\text { Chemical Yield } \\
\text { Recovery (\%R) } \\
30-105^{\mathrm{j}} \\
\\
\text { LCS Recovery } \\
(\% \mathrm{R}) \\
80-120^{\mathrm{j}}\end{array}$} \\
\hline \multirow{2}{*}{ Isotopic $\mathrm{Pu}$} & Aqueous & Pu-10-RC ${ }^{h}$ & & & \\
\hline & Non-aqueous & Pu-02-RC & & & \\
\hline \multirow{2}{*}{ Isotopic Am } & Aqueous & Am-03-RC & & & \\
\hline & Non-aqueous & Am-01-RC & & & \\
\hline \multirow{2}{*}{ Sr-90 } & Aqueous & EPA $905.0^{g}$ & & & \\
\hline & Non-aqueous & Sr-02-RCh & & & \\
\hline
\end{tabular}


Table 3-2

Analytical Requirements for COPCs for CAU 372

(Page 2 of 2)

\begin{tabular}{|c|c|c|c|c|c|}
\hline Analysis $^{a}$ & $\begin{array}{l}\text { Medium or } \\
\text { Matrix }\end{array}$ & $\begin{array}{c}\text { Analytical } \\
\text { Method }\end{array}$ & $M^{\prime b}$ & $\begin{array}{l}\text { Laboratory } \\
\text { Precision }\end{array}$ & $\begin{array}{l}\text { Laboratory } \\
\text { Accuracy }\end{array}$ \\
\hline \multicolumn{6}{|c|}{ Waste Samples } \\
\hline \multirow{2}{*}{$\begin{array}{c}\text { Gross } \\
\text { Alpha/Beta }\end{array}$} & Aqueous & EPA $900.0^{c}$ & \multirow{4}{*}{$\begin{array}{l}<\text { PALs } \\
\text { (non-test } \\
\text { releases) }\end{array}$} & \multirow{3}{*}{$\begin{array}{c}\text { RPD } \\
35 \% \text { (non-aqueous) }^{\mathrm{e}} \\
20 \% \text { (aqueous) }^{\mathrm{e}}\end{array}$} & \multirow{5}{*}{$\begin{array}{l}\text { MS Recovery } \\
(\% \mathrm{R}) \\
\text { Lab-specific }^{k}\end{array}$} \\
\hline & Non-aqueous & SM $7110 B^{i}$ & & & \\
\hline \multirow{2}{*}{ Tritium } & Aqueous & EPA $906.0^{c}$ & & & \\
\hline & Non-aqueous & $\begin{array}{l}\text { Laboratory } \\
\text { Procedure }^{k}\end{array}$ & & $-2<N D<2^{i}$ & \\
\hline TCLP Metals & Leachate & $1311 / 6010 / 7470^{c}$ & $\begin{array}{c}<\text { Regulatory } \\
\text { Levels }\end{array}$ & $\begin{array}{l}\text { Absolute Difference } \\
\pm 2 \times \text { RL (non-aqueous) } \\
\text { 土1x RL (aqueous) }\end{array}$ & \\
\hline TCLP VOCs & Leachate & $1311 / 8260^{c}$ & $\begin{array}{c}<\text { Regulatory } \\
\text { Levels }\end{array}$ & Lab-specific $^{d}$ & Lab-specific $^{d}$ \\
\hline TCLP SVOCS & Leachate & $1311 / 8270^{c}$ & $\begin{array}{c}<\text { Regulatory } \\
\text { Levels }\end{array}$ & Lab-specific $^{d}$ & Lab-specific $^{d}$ \\
\hline TCLP Pesticides & Leachate & $1311 / 8081^{c}$ & $\begin{array}{c}<\text { Regulatory } \\
\text { Levels }\end{array}$ & Lab-specific $^{d}$ & Lab-specific $^{d}$ \\
\hline
\end{tabular}

${ }^{\mathrm{a}} \mathrm{A}$ list of analytes reported for each method is provided in Table 3-1.

${ }^{\mathrm{b}}$ The MDC is the minimum concentration of a constituent that can be measured and reported with $99 \%$ confidence (SW-846).

${ }^{\mathrm{c}}$ Test Methods for Evaluating Solid Waste, Physical/Chemical Methods (EPA, 2008b).

${ }^{d}$ Precision and accuracy criteria are developed in-house using approved laboratory standard operating procedures in accordance with industry standards and the SNJV Statement of Work requirements (SNJV, 2006).

eSampling and Analysis Plan Guidance and Template (EPA, 2000).

${ }^{\dagger}$ Contract Laboratory Program National Functional Guidelines for Inorganic Data Review (EPA, 2004).

gPrescribed Procedures for Measurement of Radioactivity in Drinking Water (EPA, 1980).

${ }^{\mathrm{h}}$ The Procedures Manual of the Environmental Measurements Laboratory (DOE, 1997).

'Evaluation of Radiochemical Data Usability (Paar and Porterfield, 1997).

'Professional judgment and other industry acceptance criteria are used.

kLaboratory standard operating procedures in accordance with industry standards and the SNJV Statement of Work requirements (SNJV, 2006).

LCS = Laboratory control sample

MS = Matrix spike

ND = Normalized difference

$\mathrm{RL}=$ Reporting limit
RPD = Relative percent difference

TCLP $=$ Toxicity Characteristic Leaching Procedure

$\% \mathrm{R}=$ Percent recovery 


\subsection{Field Investigation}

This section contains a description of the activities to be conducted to gather and document information from the CAU 372 field investigation.

\subsection{Technical Approach}

The information necessary to satisfy the DQO data needs will be generated for each CAU 372 CAS by collecting and analyzing samples generated during a field investigation. The presence and nature of contamination associated with test releases will be evaluated using a combination of judgmental and probabilistic sampling approaches. The presence and nature of contamination that is associated with non-test releases (e.g., spills, PSM) will be evaluated using a judgmental approach. The detailed sampling strategy is presented in Appendix A.

If it is determined that a COC is present at any CAS, that CAS will be further addressed by determining the extent of contamination before evaluating corrective action alternatives. The number, location, and spacing of step-out sampling may be modified by the Task Manager or Site Supervisor, as warranted by site conditions, to achieve DQO criteria stipulated in Appendix A. Where sampling locations are modified by the Task Manager or Site Supervisor, justification for these modifications will be documented in the field logbook and the CADD. Significant modifications shall be agreed to by NDEP before implementation. If an unexpected condition is significantly different than the CSM, the activity will be rescoped and the identified decision-makers notified for concurrence.

\subsection{Field Activities}

Field activities at CAU 372 include site preparation, sample location selection, and sample collection activities.

\subsubsection{Site Preparation Activities}

Site preparation activities to be conducted before environmental sampling include: relocation or removal of surface debris or instrument support structures; provision of sanitary facilities; performing 
radiological surveys; and performing visual surveys at the CASs within CAU 372 to identify staining, discoloration, disturbance of native soils, or other indication of potential contamination.

\subsubsection{Sample Location Selection}

\subsubsection{Test Releases}

For the test releases at the CAU 372 CASs, the Decision I sample plot locations will be determined judgmentally based on the results of the radiological survey and applicable historical sampling results. One sample plot will be established at each CAS in a location likely to exceed a dose rate of 25 mrem/yr. Four composite samples will be collected from each plot. Data collected will be used to estimate the total TED for each sample. The TED will be determined for each sample by summing the internal and external dose components. Sample results for individual radionuclides will be used to calculate internal dose using RESRAD computer code. External dose will be determined by collecting in situ measurements using a dose measurement device (e.g., TLDs). These dose measurements will be taken at the approximate center of the sample plot at a height of $1 \mathrm{~m}$. Decision criteria is based on the 95 percent UCL of the average TED estimates from the four samples for each plot.

A probabilistic sampling approach will be implemented for the selection of sample locations within each sample plot at the CASs. At each plot, each composite sample will consist of soil collected from nine random sample locations within the plot. For each composite sample, the first location will be selected randomly, and the remaining eight sample locations will be established on a systematic triangular grid (Section A.9.0). Selection of probabilistic sample locations at these CASs, including an example of the predetermined sample locations at one plot (Figure A.9-1), are presented in Sections A.5.2.1.1 and A.9.1. Section A.5.2.1.1 briefly reviews the methodology and computation approach for the probabilistic sampling, while Section A.9.1 describes the sample location selection process.

In addition to the probabilistic sampling, biased samples will be collected from the drainages that transect the sites. These samples will be located based on radiological walkover data and visual evidence of sediment accumulation. 


\subsubsection{Non-Test Releases}

For non-test releases at the CAU 372 CASs, a judgmental sampling approach will be used to investigate the likelihood of the soil containing a COC if biasing factors are present. Biasing factors (e.g., stains, radiological survey results, and wastes suspected of containing hazardous or radiological components) are defined in Section A.5.2.1.2 and will be the basis of sample location selection. As biasing factors are identified and used for selection of sampling locations, they will be recorded in the appropriate field documents.

Decision II sampling will consist of further defining the extent of contamination where COCs have been confirmed. For investigations of non-test releases at all CASs, step-out (Decision II) sample locations will be arranged in a triangular pattern around areas containing a COC at distances based on site conditions, COC concentrations, process knowledge, and biasing factors. If COCs extend beyond step-out locations, additional Decision II samples will be collected from locations further from the source. If a spatial boundary is reached, the CSM is shown to be inadequate, or the Site Supervisor determines that extent sampling needs to be re-evaluated; work will be temporarily suspended, NDEP notified, and the investigation strategy will be re-evaluated. A minimum of one analytical result less than the action level from each lateral and vertical direction will be required to define the extent of COC contamination.

For the test release in CASs in CAU 372, if the results from the Decision I sample plot yield a 95 percent UCL of the TED above 25-mrem/yr dose, additional sample plots will be required for Decision II. For Decision II, an additional nine sample plot locations will be determined along three sampling vectors, outward from GZ, based upon the 1994 flyover survey and applicable historical sampling results, and refined by a radiological survey (BN, 1999). The outermost sample plot on each vector will be placed beyond the anticipated 25-mrem/yr-dose boundary. If the initial nine sample plots do not define the 25-mrem/yr-dose boundary, sample plots will be established outward from GZ until a sample plot is located beyond the 25-mrem/yr-dose boundary on each vector.

\subsubsection{Sample Collection}

The CAU 372 sampling program will consist of the following activities:

- Collect and analyze samples from locations as described in Section 4.2.2. 
- Collect required QC samples.

- Collect waste management samples (if required).

- Collect external dose measurements by hanging TLDs at the sample plots or collect instrument dose readings at extent locations.

- Record Global Positioning System (GPS) coordinates for each environmental sample location.

Decision I surface soil samples 0 to 2 in. bgs $(5 \mathrm{~cm})$ for test releases and 0 to 6 in. bgs $(15.24 \mathrm{~cm})$ for non-test releases) will be collected. If biasing factors are present in the soils below locations where Decision I samples were collected, Decision II sampling will include collecting subsurface soil samples by hand augering or other techniques as appropriate. Subsurface soil samples will be collected at depth intervals selected by the Site Supervisor or Task Manager. Samples will be based on biasing factors to a depth where the biasing factors are no longer obvious.

\subsubsection{Sample Management}

The laboratory requirements (i.e., MDCs, precision, and accuracy) to be used when analyzing the COPCs are presented in Table 3-2. The analytical program for each CAS is presented in Section 3.2. All sampling activities and QC requirements for field and laboratory environmental sampling will be conducted in compliance with the QAPP (NNSA/NV, 2002a) and other applicable, approved procedures.

\subsection{Safety}

A site-specific health and safety document will be prepared and approved before the field effort. This document presents the requirements for protecting the health and safety of the workers. The following safety issues will be taken into consideration when evaluating the hazards and associated control procedures for field activities:

- Potential hazards to site personnel and the public include, but are not limited to: radionuclides, chemicals (e.g., heavy metals, VOCs, SVOCs, and petroleum hydrocarbons), adverse and rapidly changing weather, remote location, motor vehicle and heavy equipment operations, and work conducted around craters which have not been approved for entry.

- Proper training of all site personnel to recognize and mitigate the anticipated hazards. 
- Work controls to reduce or eliminate the hazards including engineering controls, substitution of less hazardous materials, and use of appropriate personal protective equipment (PPE).

- Occupational exposure monitoring to prevent overexposures to hazards such as radionuclides, chemicals, and physical agents (e.g., heat, cold, and high wind).

- Radiological surveying for alpha/beta and gamma emitters to minimize and/or control personnel exposures; use of the "as-low-as-reasonably-achievable" principle when addressing radiological hazards.

- Emergency and contingency planning to include medical care and evacuation, decontamination, spill control measures, and appropriate notification of project management. The same principles apply to emergency communications.

\subsection{Site Restoration}

Upon completion of CAI and waste management activities, the following actions will be implemented before closure of the site Real Estate/Operations Permit (REOP):

- All equipment, wastes, debris, and materials associated with the CAI will be removed from the site.

- All signage and fencing (unless part of a corrective action) will be removed from the site.

- Site will be inspected and certified that restoration activities have been completed. 


\subsection{Waste Management}

Management of the waste generated during the CAU 372 field investigation will be managed in accordance with all applicable DOE orders, U.S. Department of Transportation (DOT) regulations, state and federal waste regulations, and agreements and permits between DOE and NDEP. Applicable waste management regulations and requirements are listed in Table 5-1. Wastes will be characterized based on these regulations using process knowledge, field screening results, and analytical results from investigation and waste samples. Waste types that may be generated during the CAI include sanitary, industrial, low-level radioactive, hazardous, hydrocarbon, or mixed wastes.

Table 5-1

Waste Management Regulations and Requirements

\begin{tabular}{|c|c|c|}
\hline Waste Type & Federal Regulation & Additional Requirements \\
\hline Solid (nonhazardous) & N/A & $\begin{array}{c}\text { NRS }^{\mathrm{a}} 444.440-444.620 \\
\text { NAC }^{\mathrm{b}} 444.570-444.7499 \\
\text { NTS Landfill Permit SW13-097-04 }{ }^{\text {c }} \text {, Rev. } 5 \\
\text { NTS Landfill Permit SW13-097-03 }{ }^{\text {, }} \text {, Rev. } 7\end{array}$ \\
\hline Liquid/Rinsate (nonhazardous) & N/A & $\begin{array}{l}\text { Water Pollution Control General Permit, } \\
\text { GNEV93001, Rev. iv }{ }^{\mathrm{e}}\end{array}$ \\
\hline Hazardous & $\begin{array}{c}\mathrm{RCRA}^{\mathrm{f}} \\
40 \text { CFR 260-282 }\end{array}$ & $\begin{array}{c}\text { NRS }^{a} 459.400-459.600 \\
\text { NAC }^{b} 444.850-444.8746 \\
P^{\prime} C^{g}\end{array}$ \\
\hline Low-Level Radioactive & N/A & DOE Orders and NTSWAC ${ }^{h}$ \\
\hline Mixed & $\begin{array}{c}\text { RCRA }^{f} \\
40 \text { CFR 260-282 }\end{array}$ & $\begin{array}{l}\text { NTSWAC } \\
\text { POC }^{\mathrm{h}}\end{array}$ \\
\hline Hydrocarbon & N/A & $\begin{array}{c}\text { NTS Landfill Permit SW13-097-02', Rev. } 7 \\
\text { NAC }^{\text {b } 445 A .2272}\end{array}$ \\
\hline
\end{tabular}

${ }^{a}$ Nevada Revised Statutes (NRS, 2007a, b, c)

${ }^{\mathrm{b}}$ Nevada Administrative Code (NAC, 2006a and d)

'Area 23 Class II Solid Waste Disposal Site (NDEP, 2006a)

${ }^{\mathrm{d} A r e a} 9$ Class III Solid Waste Disposal Site (NDEP, 2006c)

eNevada Test Site Sewage Lagoons (NDEP, 2005)

${ }^{\mathrm{f}}$ Resource Conservation and Recovery Act (CFR, 2007a)

${ }^{9}$ Nevada Test Site Performance Objective for the Certification of Nonradioactive Hazardous Waste (BN, 1995)

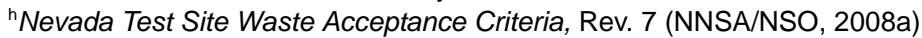

'Area 6 Class III Solid Waste Disposal Site for hydrocarbon waste (NDEP, 2006b)

${ }^{\mathrm{i}}$ Toxic Substances Control Act (CFR, 2007b and c)

CFR $=$ Code of Federal Regulations

$\mathrm{N} / \mathrm{A}=$ Not applicable
NRS $=$ Nevada Revised Statutes

$\mathrm{POC}=$ Performance Objective for the Certification of Nonradioactive Hazardous Waste 
Disposable sampling equipment, PPE, and rinsate are considered potentially contaminated waste only by virtue of contact with potentially contaminated media (e.g., soil) or potentially contaminated debris (e.g., metal and concrete). Therefore, these wastes may be characterized based on CAI sample results. Conservative estimates of total waste contaminant concentrations may be made based on the mass of the waste, the amount of contaminated media contained in the waste, and the maximum concentration of contamination found in the media.

The following sections discuss how the field investigation will be conducted to minimize the generation of waste, the waste streams that are expected to be generated, and the management of IDW.

\subsection{Waste Minimization}

The CAI will be conducted in a manner that will minimize the generation of wastes by using process knowledge, visual examination, and/or radiological survey and swipe results to avoid the collection of uncontaminated media or the characterization of uncontaminated IDW as other than industrial or sanitary waste. As appropriate, media and debris will be returned to its original location. To limit unnecessary generation of hazardous or mixed waste, hazardous materials will not be used during the CAI unless required. Other waste minimization practices will include, as appropriate, avoidance of contact with contaminated materials, dry decontamination, wet decontamination over source locations, and careful segregation of waste streams.

\subsection{Potential Waste Streams}

The expected waste streams to be generated during the CAU 372 field investigation include sanitary and low-level radioactive wastes from the sampling activities. However, because of the uncertainty in what actually is present within the CAS boundaries (e.g., lead debris, batteries, historic spills) the following waste streams are included as potential waste streams that may require management and disposal:

- $\quad$ Field-screening waste (e.g., disposable sampling equipment [e.g., plastic, paper, sample containers, aluminum foil, spoons, bowls], and/or PPE contaminated by field-screening activities)

- Environmental media (e.g., soil) 
- Surface debris in investigation area (e.g., metal, concrete, batteries)

- Decontamination rinsate

\subsection{Investigation-Derived Waste Management}

The onsite management of IDW will be determined based on regulations associated with the particular waste type (e.g., sanitary, low-level, hazardous, hydrocarbon, mixed), or the combination of waste types. The following subsections describe how specific waste types will be managed.

\subsubsection{Industrial and Sanitary Waste}

Sanitary IDW, if generated, will be collected, managed, and disposed of in accordance with the sanitary waste management regulations and the permits for operation of the NTS A23 Waste Landfills. Industrial IDW, if generated, will be placed in a roll-off box located in Mercury, or other approved roll-off box, for ultimate disposal in the U10c Industrial Waste Landfill.

\subsubsection{Hydrocarbon Waste}

Hydrocarbon soil wastes (containing more than $100 \mathrm{mg} / \mathrm{kg}$ of TPH), if generated, will be managed on site in a drum or other appropriate container until fully characterized. Hydrocarbon waste may be disposed of at a designated hydrocarbon landfill, an appropriate hydrocarbon waste management facility (e.g., recycling facility), or by other method in accordance with the State of Nevada regulations (NDEP, 2006b).

\subsubsection{Low-Level Waste}

Low-level radioactive wastes, if generated, will be managed in accordance with the contractor-specific waste certification program plan, DOE orders, and the requirements of the current version of the Nevada Test Site Waste Acceptance Criteria (NNSA/NSO, 2008a). Potential radioactive waste drums containing soil, PPE, disposable sampling equipment, and/or rinsate, and/or bulk debris may be staged and managed at a designated radioactive material area. 


\subsubsection{Hazardous Waste}

Suspected hazardous wastes, if generated, will be placed in DOT-compliant containers. All containerized hazardous waste will be handled, inspected, and managed in accordance with Title 40 CFR 265 Subpart I (CFR, 2007a).

\subsubsection{Mixed Low-Level Waste}

Mixed wastes, if generated, shall be managed according to the requirements for hazardous wastes and the requirements for low-level waste.

\subsubsection{Polychlorinated Biphenyls}

Polychlorinated biphenyl wastes, if generated, will be managed according to 40 CFR 761 (CFR, 2007b), State of Nevada requirements (NAC, 2006a), and DOE guidance. 


\subsection{Quality Assurance/Quality Control}

The overall objective of the characterization activities described in this CAIP is to collect accurate and defensible data to support the selection and implementation of a closure alternative for each CAS in CAU 372. Sections 6.1 and 6.2 discuss the collection of required QC samples in the field and QA requirements for laboratory/analytical data to achieve closure. Unless otherwise stated in this CAIP or required by the results of the DQO process (see Appendix A), this investigation will adhere to the QAPP (NNSA/NV, 2002a).

\subsection{Quality Control Sampling Activities}

Field QC samples will be collected in accordance with established procedures. Field QC samples are collected and analyzed to aid in determining the validity of environmental sample results. The number of required QC samples depends on the types and number of environmental samples collected. The minimum frequency of collecting and analyzing QC samples for this investigation, as determined in the DQO process, include:

For radiological samples:

- Field duplicates (1 per 20 environmental samples or 1 per CAS per matrix, if less than 20 collected)

- Laboratory QC samples (1 per 20 environmental samples or 1 per CAS per matrix, if less than 20 collected)

For chemical samples (if collected):

- $\quad$ Trip blanks (1 per cooler containing samples for VOC analysis)

- Equipment rinsate blanks (1 per sampling event for each type of decontamination procedure)

- Source blanks (1 per lot of uncharacterized source water that contacts sampled media)

- Field duplicates (1 per 20 environmental samples or 1 per CAS per matrix, if less than 20 collected) 
- $\quad$ Field blanks (1 per CAS depending on site conditions).

- Laboratory QC samples (1 per 20 environmental samples or 1 per CAS per matrix, if less than 20 collected).

Additional QC samples may be submitted based on site conditions at the discretion of the Task Manager or Site Supervisor. Field QC samples shall be analyzed using the same analytical procedures implemented for associated environmental samples. Additional details regarding field QC samples are available in the QAPP (NNSA/NV, 2002a).

\subsection{Laboratory/Analytical Quality Assurance}

Criteria for the investigation, as stated in the DQOs (Appendix A) and except where noted, require laboratory analytical quality data be used for making critical decisions. Rigorous QA/QC will be implemented for all laboratory samples including documentation, data verification and validation of analytical results, and an assessment of DQIs as they relate to laboratory analysis.

\subsubsection{Data Validation}

Data verification and validation will be performed in accordance with the QAPP (NNSA/NV, 2002a), except where otherwise stipulated in this CAIP. Chemical and radiological laboratory data from samples that are collected and analyzed will be evaluated for data quality according to company-specific procedures. The data will be reviewed to ensure that all required samples were appropriately collected, analyzed, and the results met data validation criteria. Validated data, including estimated data (i.e., J-qualified), will be assessed to determine whether they meet the DQO requirements of the investigation and the performance criteria for the DQIs. The results of this assessment will be documented in the CADD. If the DQOs were not met, corrective actions will be evaluated, selected, and implemented (e.g., refine CSM or resample to fill data gaps).

\subsubsection{Data Quality Indicators}

The DQIs are qualitative and quantitative descriptors used in interpreting the degree of acceptability or utility of data. Data quality indicators are used to evaluate the entire measurement system and laboratory measurement processes (i.e., analytical method performance) as well as to evaluate 
individual analytical results (i.e., parameter performance). The quality and usability of data used to make DQO decisions will be assessed based on the following DQIs:

- Precision

- Accuracy/bias

- Representativeness

- Comparability

- Completeness

- Sensitivity

Table 6-1 provides the established analytical method/measurement system performance criteria for each of the DQIs and the potential impacts to the decision if the criteria are not met. The following subsections discuss each of the DQIs that will be used to assess the quality of laboratory data. Due to changes in analytical methodology and analytical laboratory contracts, criteria for precision and accuracy in Table 3-1 may vary from corresponding information in the QAPP (NNSA/NV, 2002a).

\subsubsection{Precision}

Precision is a measure of the repeatability of the analysis process from sample collection through analysis results and is used to assess the variability between two equal samples.

Determinations of precision will be made for field duplicate samples and laboratory duplicate samples. Field duplicate samples will be collected simultaneously with samples from the same source under similar conditions in separate containers. The duplicate sample will be treated independently of the original sample in order to assess field impacts and laboratory performance on precision through a comparison of results. Laboratory precision is evaluated as part of the required laboratory internal QC program to assess performance of analytical procedures. The laboratory sample duplicates are an aliquot, or subset, of a field sample generated in the laboratory. They are not a separate sample but a split, or portion, of an existing sample. Typically, laboratory duplicate QC samples include matrix spike duplicate and LCS duplicate samples for organic, inorganic, and radiological analyses.

Precision is a quantitative measure used to assess overall analytical method and field-sampling performance as well as to assess the need to "flag” (qualify) individual parameter results when corresponding QC sample results are not within established control limits. 
Table 6-1

Laboratory and Analytical Performance Criteria for CAU 372 Data Quality Indicators

\begin{tabular}{|c|c|c|}
\hline $\begin{array}{l}\text { Data Quality } \\
\text { Indicator }\end{array}$ & Performance Metric & $\begin{array}{l}\text { Potential Impact on Decision } \\
\text { If Performance Metric Not Met }\end{array}$ \\
\hline Precision & $\begin{array}{l}\text { At least } 80 \% \text { of the sample results for each } \\
\text { measured contaminant are not qualified for } \\
\text { precision based on the criteria for each } \\
\text { analytical method-specific and } \\
\text { laboratory-specific criteria presented in } \\
\text { Section } 6.2 .3 \text {. }\end{array}$ & $\begin{array}{l}\text { If the performance metric is not met, the } \\
\text { affected analytical results from each } \\
\text { affected CAS will be assessed to } \\
\text { determine whether there is sufficient } \\
\text { confidence in analytical results to use the } \\
\text { data in making DQO decisions. }\end{array}$ \\
\hline Accuracy & $\begin{array}{l}\text { At least } 80 \% \text { of the sample results for each } \\
\text { measured contaminant are not qualified for } \\
\text { accuracy based on the method-specific and } \\
\text { laboratory-specific criteria presented in } \\
\text { Section } 6.2 .4 \text {. }\end{array}$ & $\begin{array}{l}\text { If the performance metric is not met, the } \\
\text { affected analytical results from each } \\
\text { affected CAS will be assessed to } \\
\text { determine whether there is sufficient } \\
\text { confidence in analytical results to use the } \\
\text { data in making DQO decisions. }\end{array}$ \\
\hline Representativeness & $\begin{array}{l}\text { Samples contain contaminants at } \\
\text { concentrations present in the environmental } \\
\text { media from which they were collected. }\end{array}$ & $\begin{array}{l}\text { Analytical results will not represent true } \\
\text { site conditions. Inability to make } \\
\text { appropriate DQO decisions. }\end{array}$ \\
\hline Comparability & $\begin{array}{l}\text { Sampling, handling, preparation, analysis, } \\
\text { reporting, and data validation are performed } \\
\text { using standard methods and procedures. }\end{array}$ & $\begin{array}{l}\text { Inability to combine data with data } \\
\text { obtained from other sources and/or } \\
\text { inability to compare data to regulatory } \\
\text { action levels. }\end{array}$ \\
\hline $\begin{array}{l}\text { Completeness } \\
\text { (judgmental) }\end{array}$ & $\begin{array}{l}80 \% \text { of the CAS-specific COPCs } \\
\text { have valid results. }\end{array}$ & $\begin{array}{l}\text { Cannot support/defend decision on } \\
\text { whether COCs are present. }\end{array}$ \\
\hline $\begin{array}{l}\text { Completeness } \\
\text { (probabilistic) }\end{array}$ & $\begin{array}{l}\text { Calculated minimum sample size required to } \\
\text { produce a valid statistical comparison of the } \\
\text { sample mean to the FAL as presented in } \\
\text { Section A.9.1.1. }\end{array}$ & $\begin{array}{l}\text { Cannot support/defend decision on } \\
\text { whether COCs are present }\end{array}$ \\
\hline Sensitivity & $\begin{array}{l}\text { Minimum detectable concentrations are less } \\
\text { than or equal to respective FALs. }\end{array}$ & $\begin{array}{l}\text { Cannot determine whether COCs are } \\
\text { present or migrating at levels of concern. }\end{array}$ \\
\hline
\end{tabular}

The criteria used for the assessment of inorganic chemical precision when both results are greater than or equal to $5 x$ reporting limit (RL) is 20 percent and 35 percent for aqueous and soil samples, respectively. When either result is less than $5 x \mathrm{RL}$, a control limit of $\pm 1 \mathrm{x} R \mathrm{R}$ and $\pm 2 \mathrm{x}$ RL for aqueous and soil samples, respectively, is applied to the absolute difference.

The criteria used for the assessment of organic chemical precision is based on professional judgment using laboratory defined control limits. 
The criteria used for the assessment of radiological precision when both results are greater than or equal to 5x MDC is 20 percent and 35 percent for aqueous and soil samples, respectively. When either result is less than 5x MDC, the ND should be between -2 and +2 for aqueous and soil samples. The parameters to be used for assessment of precision for duplicates are listed in Table 3-2.

Values that are outside the specified criteria do not necessarily result in the qualification of analytical data. It is only one factor in making an overall judgment about the quality of the reported analytical results. The performance metric for assessing the DQI of precision on DQO decisions (see Table 6-1) is that at least 80 percent of sample results for each measured contaminant are not qualified due to duplicates exceeding the criteria. If this performance is not met, an assessment will be conducted in the CADD on the impacts to DQO decisions specific to affected contaminants.

\subsubsection{Accuracy}

Accuracy is a measure of the closeness of an individual measurement to the true value. It is used to assess the performance of laboratory measurement processes.

Accuracy is determined by analyzing a reference material of known parameter concentration or by reanalyzing a sample to which a material of known concentration or amount of parameter has been added (spiked). Accuracy will be evaluated based on results from three types of spiked samples: full laboratory quality control (FLQC), LCS, and surrogates (organics). The LCS sample is analyzed with the field samples using the same sample preparation, reagents, and analytical methods employed for the samples. One LCS will be prepared with each batch of samples for analysis by a specific measurement.

The criteria used for the assessment of inorganic chemical accuracy are 75 to 125 percent for FLQC recoveries and 80 to 120 percent for LCS recoveries. For organic chemical accuracy, FLQC and LCS laboratory-specific percent recovery criteria developed and generated in-house by the laboratory according to approved laboratory procedures are applied. The criteria used for the assessment of radiochemical accuracy are 80 to 120 percent for LCS and FLQC recoveries.

Values that are outside the criteria specified do not necessarily result in the qualification of analytical data. It is only one factor in making an overall judgment about the quality of the reported analytical 
results. Factors beyond laboratory control, such as sample matrix effects, can cause the measured values to be outside of the established criteria. Therefore, the entire sampling and analytical process may be evaluated when determining the usability of the affected data.

The performance metric for assessing the DQI of accuracy on DQO decisions (see Table 6-1) is that at least 80 percent of the sample results for each measured contaminant are not qualified for accuracy. If this performance is not met, an assessment will be conducted in the CADD on the impacts to DQO decisions specific to affected contaminants and CASs.

\subsubsection{Representativeness}

Representativeness is the degree to which sample characteristics accurately and precisely represent characteristics of a population or an environmental condition (EPA, 2002). Representativeness is assured by carefully developing the sampling strategy during the DQO process such that false negative and false positive decision errors are minimized. The criteria listed in DQO Step 6 - Specify the Tolerable Limits on Decision Errors are:

- For Decision I judgmental sampling, having a high degree of confidence that the sample locations selected will identify COCs if present anywhere within the CAS.

- For Decision I probabilistic sampling, having a high degree of confidence that the sample locations selected will represent contamination of the CAS.

- Having a high degree of confidence that analyses conducted will be sufficient to detect any COCs if present in the samples.

- For Decision II, having a high degree of confidence that the sample locations selected will identify the extent of COCs.

These are qualitative measures that will be used to assess measurement system performance for representativeness. The assessment of this qualitative criterion will be presented in the CADD.

\subsubsection{Comparability}

Comparability is a qualitative parameter expressing the confidence with which one dataset can be compared to another (EPA, 2002). The criteria for the evaluation of comparability will be that all sampling, handling, preparation, analysis, reporting, and data validation were performed and 
documented in accordance with approved procedures that are in conformance with standard industry practices. Analytical methods and procedures approved by DOE will be used to analyze, report, and validate the data. These methods and procedures are in conformance with applicable methods used in industry and government practices. An evaluation of comparability will be presented in the CADD.

\subsubsection{Completeness}

Completeness is defined as generating sufficient data of the appropriate quality to satisfy the data needs identified in the DQOs. For judgmental sampling, completeness will be evaluated using both a quantitative measure and a qualitative assessment. The quantitative measurement to be used to evaluate completeness is presented in Table 6-1 and is based on the percentage of measurements that are judged to be valid.

For the judgmental sampling approach, the completeness goal is 80 percent for CAS-specific COPC, and 100 percent for target contaminants. If this goal is not achieved, the dataset will be assessed for potential impacts on making DQO decisions. For the probabilistic sampling approach, the completeness goal is a calculated minimum sample size required to produce a valid statistical comparison of the sample mean to the FAL. The methodology for determining minimum required sample size is described in Section A.9.1.1.

The qualitative assessment of completeness is an evaluation of the sufficiency of information available to make DQO decisions. This assessment will be based on meeting the data needs identified in the DQOs and will be presented in the CADD. Additional samples will be collected if it is determined that the number of samples do not meet completeness criteria.

\subsubsection{Sensitivity}

Sensitivity is the capability of a method or instrument to discriminate between measurement responses representing different levels of the variable of interest (EPA, 2002). The evaluation criteria for this parameter will be that measurement sensitivity (i.e., MDCs) will be less than or equal to the corresponding FALs. If this criterion is not achieved, the affected data will be assessed for usability and potential impacts on meeting site characterization objectives. This assessment will be presented in the CADD. 


\subsection{Duration and Records Availability}

\subsection{Duration}

Table 7-1 is a tentative duration of activities (in calendar days) for CAI activities.

Table 7-1

Corrective Action Investigation Activity Durations

\begin{tabular}{|c|c|}
\hline Duration (days) & Activity \\
\hline \hline 10 & Site Preparation \\
\hline 76 & Fieldwork Preparation and Mobilization \\
\hline 55 & Sampling \\
\hline 160 & Data Assessment \\
\hline 180 & Waste Management \\
\hline
\end{tabular}

\subsection{Records Availability}

Historical information and documents referenced in this plan are retained in the NNSA/NSO project files in Las Vegas, Nevada, and can be obtained through written request to the DOE Federal Sub-Project Director. This document is available in the DOE public reading rooms located in Las Vegas and Carson City, Nevada, or by contacting the DOE Federal Sub-Project Director. The NDEP maintains the official Administrative Record for all activities conducted under the auspices of the FFACO. 


\subsection{References}

ARL/SORD, see Air Resources Laboratory/Special Operations and Research Division.

ASTM, see American Society for Testing and Materials.

Air Resources Laboratory/Special Operations and Research Division. 2009. NTS Climatological Rain Gauge Data. As accessed at http://www.sord.nv.doe/home_climate_rain.htm on May 15.

American Society for Testing and Materials. 1995. Standard Guide for Risk-Based Corrective Action Applied at Petroleum Release Sites, ASTM E 1739-95 (Reapproved 2002). Philadelphia, PA.

BN, see Bechtel Nevada.

Bechtel Nevada. 1995. Nevada Test Site Performance Objective for Certification of Nonradioactive Hazardous Waste, Rev. 0, G-E11/96.01. Las Vegas, NV.

Bechtel Nevada. 1999. An Aerial Radiological Survey of the Nevada Test Site, DOE/NV/11718--324. Prepared for the U.S. Department of Energy, Nevada Operations Office. Las Vegas, NV: Remote Sensing Laboratory.

CFR, see Code of Federal Regulations.

Code of Federal Regulations. 2007a. Title 40 CFR, Parts 260-282, "Hazardous Waste Management System: General.” Washington, DC: U.S. Government Printing Office.

Code of Federal Regulations. 2007b. Title 40 CFR, Part 761, "Polychlorinated Biphenyls (PCBs) Manufacturing, Processing, Distribution in Commerce, and Use Prohibitions.” Washington, DC: U.S. Government Printing Office.

Code of Federal Regulations. 2007c. Title 40 CFR, Part 763, “Asbestos.” Washington, DC:

U.S. Government Printing Office.

DNA, see Defense Nuclear Agency.

Defense Nuclear Agency. 1993. Guide to U.S. Atmospheric Nuclear Weapon Effects Data, DASIAC SR-92-007. December. Alexandria, VA.

DOE, see U.S. Department of Energy.

DOE/NV, see U.S. Department of Energy, Nevada Operations Office.

DRI, see Desert Research Institute. 
Desert Research Institute. 1985. Nevada Test Site Radionuclide Inventory and Distribution Program: Report \#2, Areas 2 and 4, DOE/NV/10162-20. Prepared by R.D. McArthur and J.F. Kordas. Las Vegas, NV.

Desert Research Institute. 1988. CERCLA Preliminary Assessment of DOE's Nevada Operations Office Nuclear Weapons Testing Areas. April. Las Vegas, NV.

Desert Research Institute. 2007. Radionuclide Inventory and Distribution Program (RIDP) Database, Rev. 2. April. Prepared by K. Gray, D.S. Shafer, K. Self, C. Martin, and R. McArthur. Las Vegas, NV.

EPA, see U.S. Environmental Protection Agency.

Essington, E.H. 1978. "Soil Radioactivity Distribution Studies for the Nevada Applied Ecology Group.” In: Selected Environmental Plutonium Research Reports of the NAEG, NVO-192. pp. 177-243. June. M.G. White, P.B. Dunaway, and D.L. Wireman, eds. Las Vegas, NV: U.S. Department of Energy, Nevada Operations Office.

Essington, E.H. 1981. Progress of Soil Radionuclide Distribution Studies for Nevada Applied Ecology Group - 1981, LA-UR-81-1585. Los Alamos, NM: Los Alamos Scientific Laboratory.

Essington, E.H. 1982. "Progress of Soil Radionuclide Distribution Studies for the Nevada Applied Ecology Group.” In: The Radioecology of Transuranics and Other Radionuclides in Desert Ecosystems, NVO-224. pp. 145-184. December. W.A. Howard, P.B. Dunaway, and R.G. Fuller, eds. Las Vegas, NV: U.S. Department of Energy, Nevada Operations Office.

Essington, E.H. 1985. "Soil Radionuclide Distribution Studies for the Nevada Applied Ecology Group-1981.” In: The Dynamics of Transuranics and Other Radionuclides in Natural Environments, NVO-272. Nevada Applied Ecology Group. pp. 123-195. December. W.A. Howard and R.G. Fuller, eds. Las Vegas, NV: U.S. Department of Energy, Nevada Operations Office.

Gilbert, R.O., E.H. Essington, D.N. Brady, P.G. Doctor, and L.L Eberhardt. 1977. "Statistical Activities During 1976 and the Design and Initial Analysis of Nuclear Site Studies.” In: Transuranics in Desert Ecosystems, NVO-181. pp. 331-366. November. Las Vegas, NV: U.S. Department of Energy, Nevada Operations Office.

Gilbert, R.O., J.C. Simpson, E.W. Engel, and R.R. Kinnison. 1985. "Estimating Isotopic Ratios, Spatial Distribution, and Inventory of Radionuclides at Nuclear Sites.” In: The Dynamics of Transuranics and Other Radionuclides in Natural Environments, NVO-272. pp. 381-429 December. W.A. Howard and R.G. Fuller, eds. Las Vegas, NV: U.S. Department of Energy, Nevada Operations Office. 
FFACO, see Federal Facility Agreement and Consent Order.

Federal Facility Agreement and Consent Order. 1996 (as amended February 2008). Agreed to by the State of Nevada; U.S. Department of Energy, Environmental Management; U.S. Department of Defense; and U.S. Department of Energy, Legacy Management.

LLNL, see Lawrence Livermore National Laboratory.

Laczniak, R.J., J.C. Cole, D.A. Sawyer, and D.A. Trudeau. 1996. Summary of Hydrogeologic Controls Ground-Water flow at the Nevada Test Site, Nye County, Nevada. As accessed at http://water.usgs.geo/pubs/wri/wri964109/report.htm on 30 October 2008.

Lawrence Livermore National Laboratory. 1965. Gamma Fallout Fields, Project Palanquin. April. Livermore, CA.

Lee, S.Y., T. Tamura, and I.L. Larsen. 1985. "Characterization of Nuclear Site 201 Soils from the Nevada Test Site.” In: The Dynamics of Transuranics and Other Radionuclides in Natural Environments, NVO-272. pp. 99-113. December. W.A. Howard and R.G. Fuller, eds. Las Vegas, NV: U.S. Department of Energy, Nevada Operations Office.

Moore, J., Science Applications International Corporation. 1999. Memorandum to M. Todd (SAIC) entitled, “Background Concentrations for NTS and TTR Soil Samples,” 3 February. Las Vegas, NV: IT Corporation.

Murphy, T., Bureau of Federal Facilities. 2004. Letter to R. Bangerter (NNSA/NSO) entitled, "Review of Industrial Sites Project Document Guidance for Calculating Industrial Sites Project Remediation Goals for Radionuclides in Soil Using the Residual Radiation (RESRAD) Computer Code," 19 November. Las Vegas, NV.

NAC, see Nevada Administrative Code.

NBMG, see Nevada Bureau of Mines and Geology.

NCRP, see National Council on Radiation Protection and Measurements.

NDEP, see Nevada Division of Environmental Protection.

NNSA/NSO, see U.S. Department of Energy, National Nuclear Security Administration Nevada Site Office.

NNSA/NV, see U.S. Department of Energy, National Nuclear Security Administration Nevada Operations Office.

NRS, see Nevada Revised Statutes. 
National Council on Radiation Protection and Measurements. 1999. Recommended Screening Limits for Contaminated Surface Soil and Review of Factors Relevant to Site-Specific Studies, NCRP Report No. 129. Bethesda, MD.

Nevada Administrative Code. 2006a. NAC 444, "Sanitation.” Carson City, NV. As accessed at http://www.leg.state.nv.us/nac on 9 October 2008.

Nevada Administrative Code. 2006b. NAC 445A.227, “Contamination of Soil: Order by Director for Corrective Action; Factors To Be Considered in Determining Whether Corrective Action Required.” Carson City, NV. As accessed at http://www.leg.state.nv.us/nac on 9 October 2008.

Nevada Administrative Code. 2006c. NAC 445A.22705, "Contamination of Soil: Evaluation of Site by Owner or Operator; Review of Evaluation by Division.” Carson City, NV. As accessed at http://www.leg.state.nv.us/nac on 9 October 2008.

Nevada Administrative Code. 2006d. NAC 445A.2272, "Contamination of Soil: Establishment of Action Levels.” Carson City, NV. As accessed at http://www.leg.state.nv.us/nac on 9 October 2008.

Nevada Bureau of Mines and Geology. 1998. Mineral and Energy Resource Assessment of the Nellis Air Force Range, Open-File Report 98-1. Reno, NV.

Nevada Division of Environmental Protection. 2005. Water Pollution Control General Permit, No. GNEV93001, Rev. iv. Carson City, NV.

Nevada Division of Environmental Protection. 2006a. Class II Solid Waste Disposal Site for Municipal and Solid Waste, Area 23 of the NTS, Permit SW 13-097-04, Rev. 5. Carson City, NV.

Nevada Division of Environmental Protection. 2006b (as amended in August 2000). Class III Solid Waste Disposal Site for Hydrocarbon Burdened Soils, Area 6 of the NTS, Permit SW 13-097-02, Rev. 7. Carson City, NV.

Nevada Division of Environmental Protection. 2006c (as amended in August 2000). Class III Solid Waste Disposal Site; UIOc, Area 9 of the NTS, Permit SW 13-097-03. Carson City, NV.

Nevada Revised Statutes. 2007a. NRS 444.440 - 444.620, “Collection and Disposal of Solid Waste.” Carson City, NV.

Nevada Revised Statutes. 2007b. NRS 459.400 - 459.600, “Disposal of Hazardous Waste.” Carson City, NV.

Nevada Revised Statutes. 2007c. NRS 618.750 - 618.840, “Control of Asbestos.” Carson City, NV.

Paar, J.G., and D.R. Porterfield. 1997. Evaluation of Radiochemical Data Usability, ES/ER/MS-5. April. Oak Ridge, TN: U.S. Department of Energy. 
SNJV, see Stoller-Navarro Joint Venture

SNJV GIS, see Stoller-Navarro Joint Venture Geographic Information Systems.

Stoller-Navarro Joint Venture. 2006. Model Statement of Work for Analytical Laboratories, Rev. 0. February. Las Vegas, NV.

Stoller-Navarro Joint Venture. 2008. Written communication. Subject: "Nevada Test Site Soils Project Corrective Action Sites.” September. Las Vegas, NV.

Stoller-Navarro Joint Venture Geographic Information Systems. 2009. ESRI ArcGIS Software.

USGS, see U.S. Geological Survey.

USGS/DOE, see U.S. Geological Survey and U.S. Department of Energy.

U.S. Department of Energy. 1993. Radiation Protection of the Public and the Environment, DOE Order 5400.5, Change 2. Washington, DC: U.S. Government Printing Office.

U.S. Department of Energy. 1997a. Evaluation of Radiochemical Data Usability, ES/ER/MS-5. April. Prepared by J.G. Paar and D.R. Porterfield. Oak Ridge, TN: U.S. Department of Energy.

U.S. Department of Energy. 1997b. The Procedures Manual of the Environmental Measurements Laboratory, HASL-300, 28th Ed., Vol. I. February. New York, NY.

U.S. Department of Energy, National Nuclear Security Administration Nevada Operations Office. 2002a. Industrial Sites Quality Assurance Project Plan, Nevada Test Site, Nevada, Rev. 3, DOE/NV--372. Las Vegas, NV.

U.S. Department of Energy, National Nuclear Security Administration Nevada Operations Office. 2002b. Nevada Test Site Orthophoto Site Atlas, DOE/NV/11718--604. Prepared by Bechtel Nevada. Las Vegas, NV.

U.S. Department of Energy, National Nuclear Security Administration Nevada Site Office. 2006. Industrial Sites Project Establishment of Final Action Levels, Rev. 0, DOE/NV--1107. Las Vegas, NV.

U.S. Department of Energy, National Nuclear Security Administration Nevada Site Office. 2008a. Nevada Test Site Waste Acceptance Criteria, DOE/NV-325-Rev. 7. Las Vegas, NV.

U.S. Department of Energy, National Nuclear Security Administration Nevada Site Office. 2008b. Nevada Test Site 2007 Waste Management Report Area 3 and Area 5 Radioactive Waste Management Sites, DOE/NV/25946-490. June. Las Vegas, NV. 
U.S. Department of Energy, Nevada Operations Office. 1992. Remedial Investigation and Feasibility Study for the Plutonium Contaminated Soils at Nevada Test Site, Nellis Air Force Range and Tonopah Test Range. April. Las Vegas, NV.

U.S. Department of Energy, Nevada Operations Office. 1996a. Final Environmental Impact Statement for the Nevada Test Site and Off-Site Locations in the State of Nevada, DOE/EIS 0243. Las Vegas, NV.

U.S. Department of Energy, Nevada Operations Office. 1996b. Radiological Effluents Released From U.S. Continental Tests 1961 Through 1992, DOE/NV-317 (Rev 1) UC-702. August. Las Vegas, NV.

U.S. Department of Energy, Nevada Operations Office. 1997. Analysis of Fractures in Volcanic Cores from Pahute Mesa, Nevada Test Site, DOE/NV/11718-160. September. Las Vegas, NV.

U.S. Department of Energy, Nevada Operations Office. 1998. Nevada Test Site Resource Management Plan, DOE/NV--518. Las Vegas, NV.

U.S. Department of Energy, Nevada Operations Office. 2000. United States Nuclear Tests, July 1945 through September 1992, DOE/NV-209-Rev 15. Las Vegas, NV.

U.S. Environmental Protection Agency. 1980. Prescribed Procedures for Measurement of Radioactivity in Drinking Water, EPA 600/4-80-032. Cincinnati, OH: Environmental Monitoring and Support Laboratory Office of Research and Development.

U.S. Environmental Protection Agency. 2000. Sampling and Analysis Plan (Field Sampling Plan and Quality Assurance Project Plan) with Guidance. San Francisco, CA.

U.S. Environmental Protection Agency. 2002. Guidance for Quality Assurance Project Plans, EPA QA/G5. Washington, DC.

U.S. Environmental Protection Agency. 2004. USEPA Contract Laboratory Program National Functional Guidelines for Inorganic Data Review, OSWER 9240.1-45/EPA 540-R-04-004. October. Washington, DC: Office of Solid Waste and Emergency Response.

U.S. Environmental Protection Agency. 2008a. Region 9: Superfund, Preliminary Remediation Goals, Screening Levels for Chemical Contaminants. As accessed at http://www.epa.gov/region09/waste/sfund/prg/index.html on 5 November. Prepared by EPA Office of Superfund and Oak Ridge National Laboratory.

U.S. Environmental Protection Agency. 2008b. SW-846 On-Line, Test Methods for Evaluating Solid Physical/Chemical Methods. As accessed at http://www.epa.gov/epaoswer/hazwaste/test/main.htm on 20 November. 
U.S. Geological Survey. 1990. Geologic Map of the Nevada Test Site, Southern Nevada, USGS Map I-2046. Denver, CO.

U.S. Geological Survey. 2007. "Rock-Property Information from the Core Library and Data Center at Mercury and Nevada Water Science Center Office in Henderson, Nevada; Rock-Property Database.” As accessed at http://nevada.usgs.gov/mercury/rock.html on 9 October 2008. Mercury, NV.

U.S. Geological Survey. 2008. “Ground-Water Levels for Nevada.” As accessed at http://nwis.waterdata.usgs.gov/nv/nwis/gwlevels on October 9.

U.S. Geological Survey and U.S. Department of Energy. 2008. "USGS/USDOE Cooperative Studies in Nevada; Water-Level Wells, Nevada Test Site.” As accessed at http://nevada.usgs.gov/doe_nv/ntsmap.htm on 4 October.

Winograd, I.J., and W. Thordarson. 1975. Hydrology and Hydrochemical Framework, South-Central Great Basin, Nevada-California, with Special Reference to the Nevada Test Site, USGS Professional Paper 712-C. Denver, CO. 


\section{Appendix A}

\section{Data Quality Objectives}




\section{A.1.0 Introduction}

The DQO process described in this appendix is a seven-step strategic systematic planning method used to plan data collection activities and define performance criteria for the CAU 372, Area 20 Cabriolet/Palanquin Unit Craters field investigation. The DQOs are designed to ensure that the data collected will provide sufficient and reliable information to identify, evaluate, and technically defend recommended corrective actions (i.e., no further action, closure in place, or clean closure). Existing information about the nature and extent of contamination at the CASs in CAU 372 is insufficient to evaluate and select preferred corrective actions; therefore, a CAI will be conducted.

The CAU 372 investigation will be based on the DQOs presented in this appendix as developed by representatives of the NDEP and the NNSA/NSO. The seven steps of the DQO process presented in Sections A.3.0 through A.9.0 were developed in accordance with Guidance on Systematic Planning Using the Data Quality Objectives Process (EPA, 2006b).

The DQO process presents a combination of probabilistic and judgmental sampling approaches. In general, the procedures used in the DQO process provide:

- A method to establish performance or acceptance criteria, which serve as the basis for designing a plan for collecting data of sufficient quality and quantity to support the goals of a study.

- Criteria that will be used to establish the final data collection design such as:

- The nature of the problem that has initiated the study and a conceptual model of the environmental hazard to be investigated.

- The decisions or estimates that need to be made and the order of priority for resolving them.

- $\quad$ The type of data needed.

- An analytic approach or decision rule that defines the logic for how the data will be used to draw conclusions from the study findings. 
- Acceptable quantitative criteria on the quality and quantity of the data to be collected, relative to the ultimate use of the data.

- A data collection design that will generate data meeting the quantitative and qualitative criteria specified. A data collection design specifies the type, number, location, and physical quantity of samples and data, as well as the QA and QC activities that will ensure that sampling design and measurement errors are managed sufficiently to meet the performance or acceptance criteria specified in the DQOs. 


\section{A.2.0 Background Information}

The following four CASs comprise CAU 372 and are located in Areas 18 and 20 of the NTS, as shown in Figure A.2-1:

- 18-45-02, Little Feller I Surface Crater

- 18-45-03, Little Feller II Surface Crater

- 20-23-01, U-20k Contamination Area

- 20-45-01, U-20L Crater (Cabriolet)

Sections A.2.1 through A.2.4 provide a description, physical setting and operational history, release information, and previous investigation results for each CAS in CAU 372.

\section{A.2.1 Corrective Action Site 18-45-02, Little Feller I Surface Crater}

Corrective Action Site 18-45-02 consists of a release of radionuclides to the surrounding soil from the Little Feller I surface test. Two radiological controlled areas are associated with this release. The larger area is fenced and posted as a Contamination Area (CA), while an area limited to the immediate GZ is posted as a High Contamination Area (HCA). Figure A.2-2 is a depiction of the CAS area. Presently, a large military tank and scattered testing artifacts remain at the site.

Physical Setting and Operational History - Corrective Action Site 18-45-02 is located west of Airport Road in Area 18. The area was the site of the Little Feller I weapons effects test conducted on July 17, 1962. Part of Operation Sunbeam, this low-yield test was conducted to evaluate the effects of a nuclear weapon on various targets (DOE/NV, 1996b and 2000). The site does not appear to have been used for other purposes.

The Litter Feller I test location is located east of Buckboard Mesa in the Alkali Flat-Furnace Creek Ranch Subbasin of the Fortymile Wash drainage basin. The site is within a large fenced area of gently sloping to nearly flat topographic relief atop a mountain with moderate vegetation. In the general area, there are a few drainage systems that flow in a southern direction that provide intermittent drainage out of the fenced area into Fortymile Wash.

Corrective Action Site 18-45-02 is geologically situated within the caldera moat-filling, tertiary-aged sediments. There are no known faults present within a 0.62-mi radius (USGS, 2007). Monitoring 


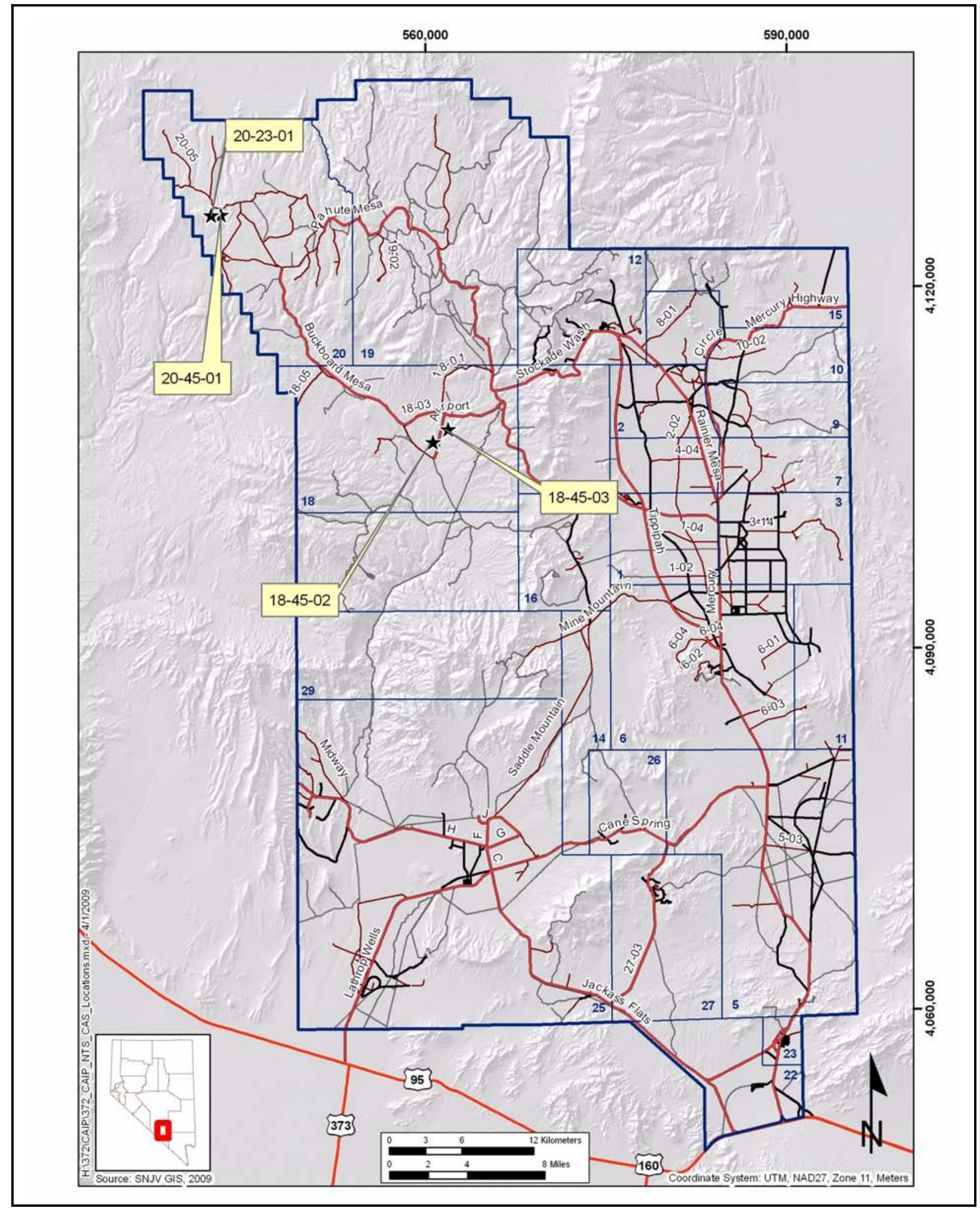

Figure A.2-1

Corrective Action Unit 372 CAS Location Map 


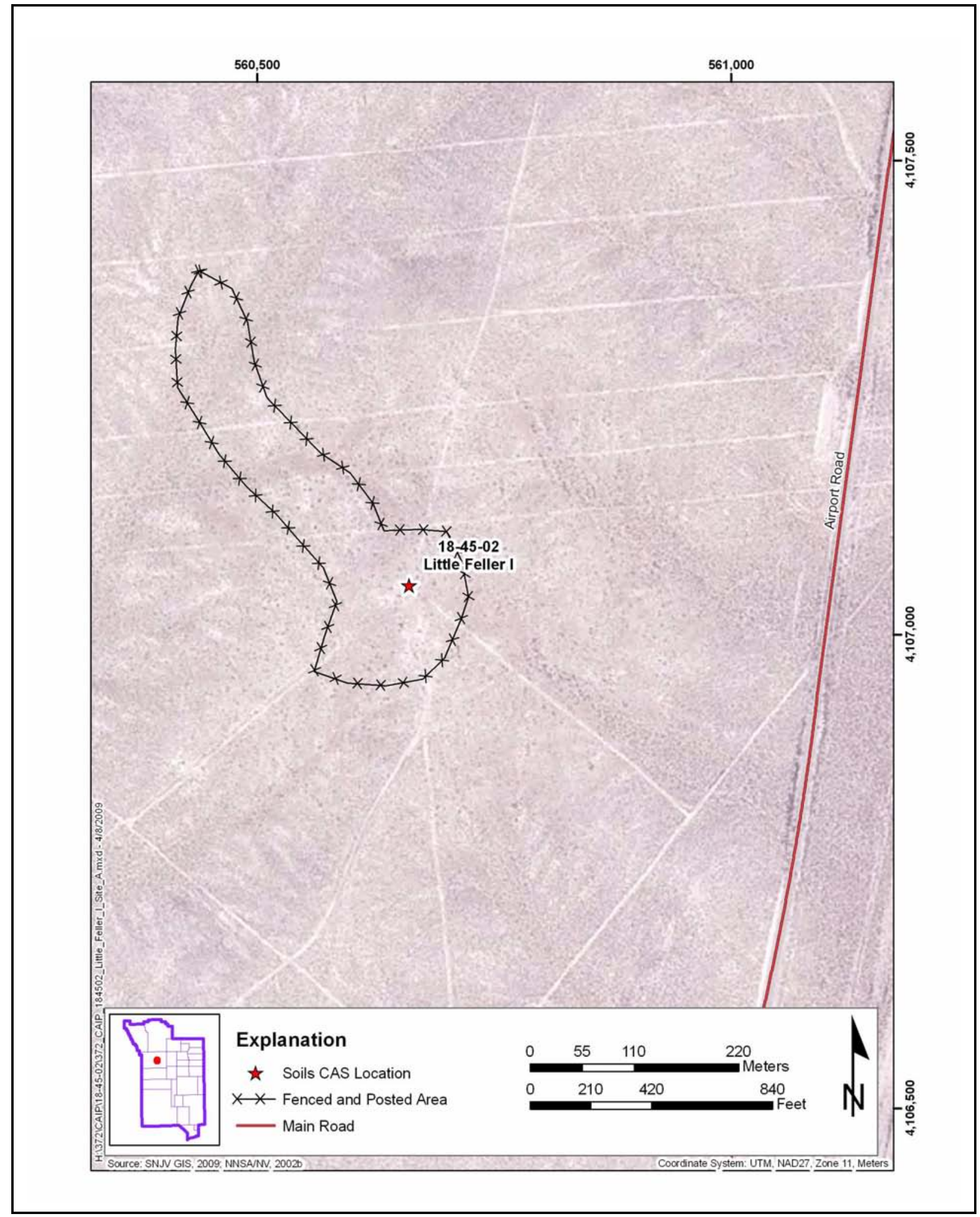

Figure A.2-2

Location of CAS 18-45-02, Little Feller I Surface Crater 
Well ER-30-1 is located approximately $4.04 \mathrm{mi}$ south of this CAS and penetrated approximately $381.9 \mathrm{ft}$ of the quaternary alluvium and tertiary-age post-caldera, moat-filling sediments. The well head for Well ER-30-1 is approximately $541 \mathrm{ft}$ lower than CAS 18-45-02 in elevation, which suggests that the sediments could be much thicker at the CAS. Well UE-18t is located approximately $1.4 \mathrm{mi}$ northwest of CAS 18-45-02. This well is approximately 2,600 ft deep and depth to groundwater averages are approximately $912 \mathrm{ft}$ bgs (USGS/DOE, 2008).

The average annual precipitation is 7.2 in. at the nearest rain gauge, Little Feller II (ARL/SORD, 2009). Annual PET has been estimated as 61.8 in. for the Area 3 RWMS (NNSA/NSO, 2008b).

Release Information - The release of radioactive contamination to soil surface from nuclear weapons testing at the site includes the fallout of fuel particles, fission products and the neutron activation of soils and debris in the immediate area of GZ. Isotopes identified following detonation include the short-lived isotopes: I-131, Ru-103, and Zr-95/Nb-95. Because the short-lived isotopes identified following detonation have decayed, the expected COPCs include the long-lived isotopes: Am-241; Co-60; Cs-137; Eu-152, -154, -155; Pu-238, 239/240; Sr-90; Th-232; and U-234, -235, -238. Figure A.2-3 shows a conceptual model of the ejection and the material from the crater of a nuclear explosion.

Previous Investigation Results - Previous investigations for CAS 18-45-02 included flyover surveys in 1980, 1994, and 1999 (e.g., aircraft using radiological detection systems to identify gamma radiation). The flyover surveys conducted at CAS 18-45-02 identified radiological contamination based upon gamma emissions at the site. The 1980 flyover survey only searched for Cs-137 and did not perform other isotopic analyses. The results show low levels of Cs-137 over the Little Feller I area. The 1994 flyover survey detected Am-241 in the 30- to 39- $\mu \mathrm{R} / \mathrm{hr}$ range. An extensive Am-241 plume that was elongated to the north was found in and around GZ (BN, 1999).

Other investigations include the RIDP investigation conducted throughout the NTS from 1981 through 1986, which estimated the inventory of man-made radionuclides through in situ soil measurements and limited soil sampling (DRI, 1985 and 2007). Both in situ gamma spectroscopy and limited confirmatory soil sampling were implemented at the study areas. Alpha-emitting radionuclides, primarily plutonium isotopes, as well as gamma-emitting radionuclides (e.g., Am-241, Co-60, Cs-137, and several europium isotopes) were identified at CAS 18-45-02. 


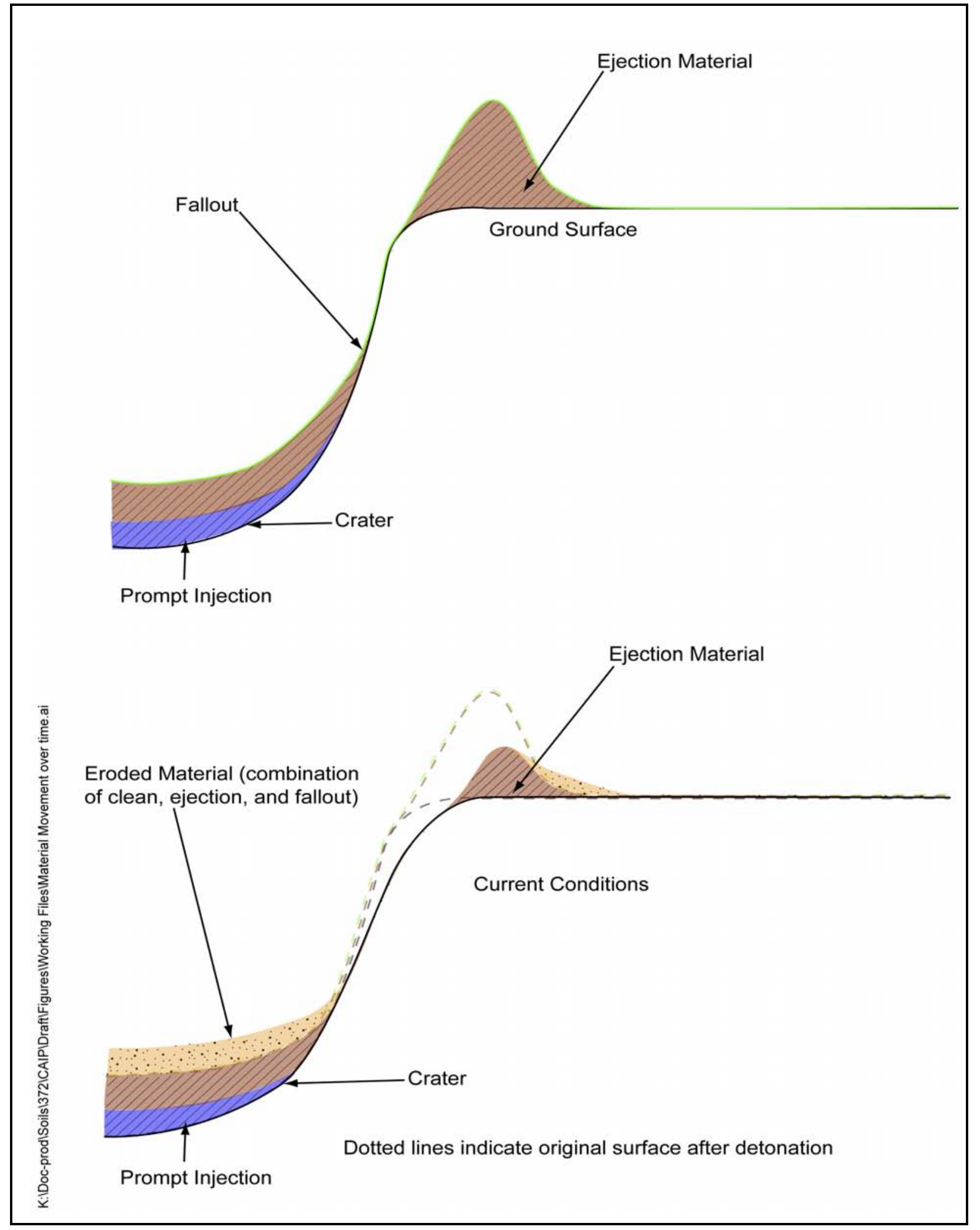

Figure A.2-3

Conceptual Model of Ejected Material from a Nuclear Explosion 
Other CASs in the area of CAS 18-45-02 include CAS 18-99-01, a military tank associated with the Little Feller II test, but located within the plume for Little Feller I, and determined by DRI archaeologists to have historical significance. This military tank was left in place and the CAS was transferred to CAU 4000, No Further Action Sites. Corrective Action Site 18-24-03, in the area of Little Feller I, consisted of a battery. However, during the initial evaluation, no battery or soil staining was observed at the CAS location, and the site was closed without further investigation.

\section{A.2.2 Corrective Action Site 18-45-03, Little Feller II Surface Crater}

Corrective Action Site 18-45-03 consists of a release of radionuclides to the surrounding soil from the Little Feller II surface test. A radiological controlled area is associated with this release but does not identify the boundary of the CAS. Figure A.2-4 is a depiction of the CAS area. Presently, multiple vehicles, large wooden posts, large metal items, mounds, and scattered testing artifacts remain at the site.

Physical Setting and Operational History - Corrective Action Site 18-45-03 is located east of Airport Road in Area 18. The area was the site of the Little Feller II weapons effects test conducted on July 7, 1962. Part of Operation Sunbeam, this low-yield test was conducted to evaluate the effects of a nuclear detonation on various targets (DOE/NV, 1996b and 2000). There is no documentation indicating that this site was used for other purposes.

This CAS is located east of Buckboard Mesa in the Fortymile Wash drainage basin (USGS, 2007). The site is within a fenced area of gently sloping to nearly flat topographic relief with moderate vegetation. There are multiple intermittent streams or drainages present near Little Feller II GZ as well as the northern and eastern sections of the associated Am-241 plume. These streams flow in a southerly direction and provide intermittent drainage to Fortymile Wash drainage basin.

Corrective Action Site 18-45-03 is geologically situated within young and intermediate aged alluvial and colluvial geologic units. There are no known faults present within a 1,640 ft radius (USGS, 2007). Monitoring Well ER-30-1 located approximately $4.8 \mathrm{mi}$ south of this CAS and penetrates approximately $381.89 \mathrm{ft}$ of the quaternary alluvium and tertiary-age post caldera, moat-filling sediments. Well UE-18t is located approximately $1.5 \mathrm{mi}$ northwest of CAS 18-45-03, and depth to groundwater averages approximately $912.1 \mathrm{ft}$ bgs (USGS/DOE, 2008). 


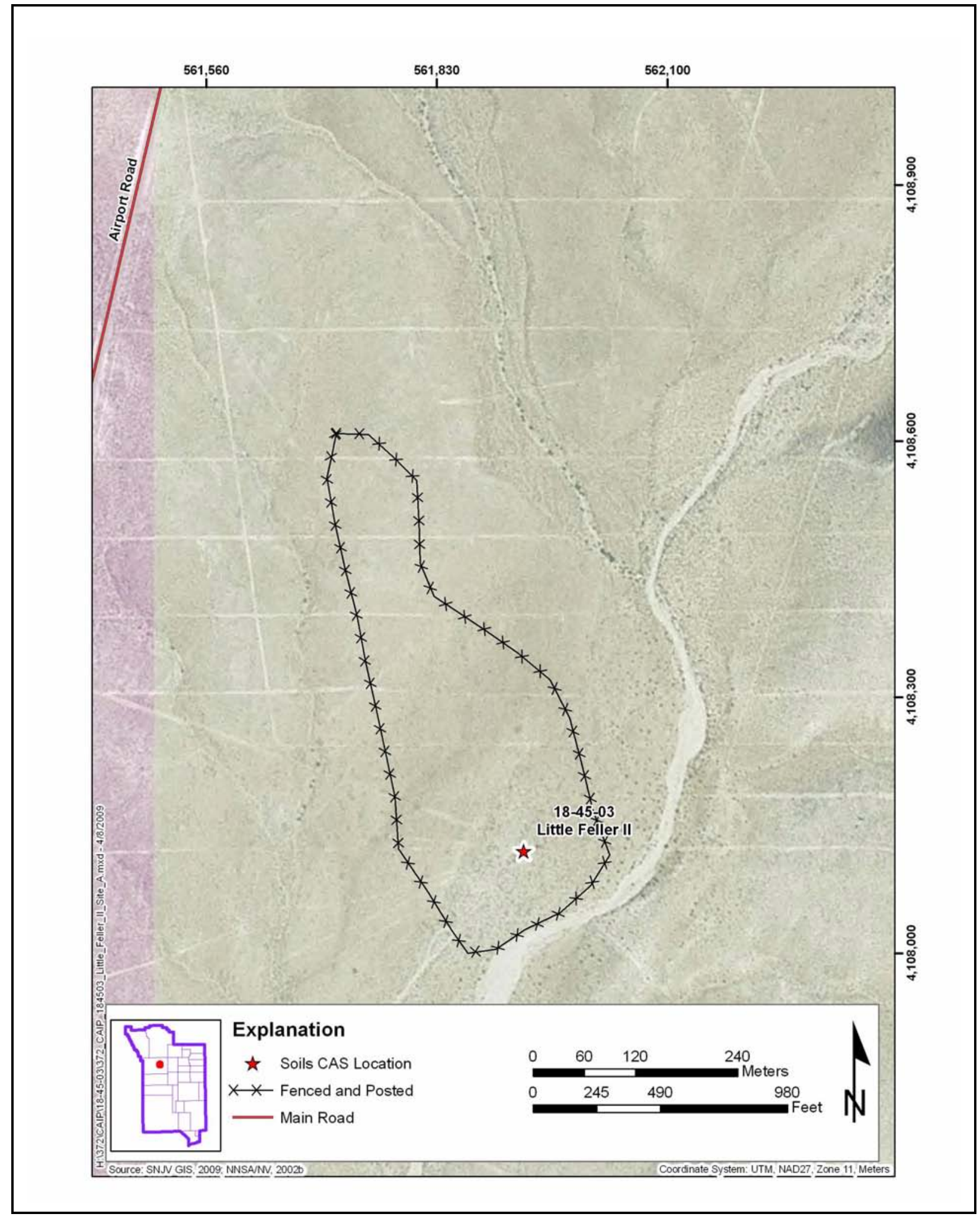

Figure A.2-4

Location of CAS 18-45-03, Little Feller II Surface Crater 
The average annual precipitation is 7.2 in. at the nearest station, Little Feller II (ARL/SORD, 2009). Annual PET has been estimated as 61.8 in. for the Area 3 RWMS (NNSA/NSO, 2008b).

Release Information - The release of radioactive contamination to soil surface from nuclear weapons testing at the site includes the fallout of fuel particles, fission products and the neutron activation of soils and debris in the immediate area of GZ. Expected COPCs include: Am-241; Co-60; Cs-137; Eu-152, -154, -155; Pu-238, -239/240; Sr-90; Th-232; and U-234, -235, -238. Figure A.2-3 shows the conceptual models of the ejection after a nuclear test.

Previous Investigation Results - Previous investigations for CAS 18-45-03 include flyover surveys in 1980 and 1994 (e.g., aircraft using radiological detection systems to identify gamma radiation). The flyover surveys conducted at CAS 18-45-03 identified radiological contamination based upon gamma emissions at the site. The 1980 flyover survey only searched for Cs-137 and did not perform other isotopic analyses. The results show low levels of Cs-137 (30 to $45 \mu \mathrm{R} / \mathrm{hr}$ ) over the Little Feller II area. The 1994 flyover survey detected Am-241 in the 24- to 30- $\mu \mathrm{R} / \mathrm{hr}$ range. An extensive Am-241 plume that is elongated to the north was found in and around GZ (BN, 1999).

In 1972, the NAEG began investigating the Little Feller II site by sampling surface soils. Samples were taken along a 1,500-ft transect starting at GZ and following the long axis of the approximate center of the plume (Gilbert el al., 1977). Later, 315 locations were sampled at the surface based on a grid using 200-ft spacings. Activities of Pu-239/240 and Am-241 were found at significantly higher levels than other radionuclides, with the highest value for Am-241 at $8.38 \mathrm{nCi} / \mathrm{g}$ at approximately $280 \mathrm{ft}$ northwest of GZ. The results for the Pu-239/240 activities were given in multiples of Am-241, and ranged from 8 to 24 times that of Am-241 activities. A gross gamma radiological survey determined that the highest reading was $0.3 \mathrm{mR} / \mathrm{hr}$, coinciding with the location of the highest Am-241 result. Portable alpha instrument measurements indicated a range of 200 to 50,000 cpm (300 ft northwest of GZ) along the 1,500-ft transect. Additionally, a large, man-made mound was noted to be present near GZ.

Subsequently, the NAEG surmised that the large mound of soil and rock debris (measuring $10 \mathrm{~m}$ wide, $28 \mathrm{~m}$ long, and $3 \mathrm{~m}$ high) appears have been used to store contaminated material that was removed (scrapped or dug) from the GZ area (Essington, 1981). Fourteen locations on the mound were sampled for the purpose of estimating the radionuclide inventory of the mound. Only surface 
samples were collected; the presence of large rock and the tendency of the mound to cave in during attempts to sample at depth prevented sampling of the mound interior. From analytical results, the inventory of radionuclides in the mound was estimated to be $7.7 \mathrm{Ci}$ for Pu-239/240, and 0.84 Ci for Am-241, with lesser amounts for Cs-137, Eu-152, and Co-60.

In follow-up work published for the NAEG, most of the U-239/240, Am-241, and Cs-137 activity was found to be in the top $5 \mathrm{~cm}$ of soil at most locations, with exceptions being at locations in sediment accumulations in a drainage area east and south of GZ (Essington, 1982), and in several areas of sandier soil texture to the north of GZ (Essington, 1985). Most of the total radioactivity of the soils was found to be in the 0.25 - to 2-mm size soil fraction, with the radioactive particles occurring as either spherical glass particles or as glass coatings on sand particles (Lee et al., 1985). Contamination from Am-241, defined as values more than $10 \mathrm{pCi} / \mathrm{g}$, extended to approximately $800 \mathrm{~m}$ north and $120 \mathrm{~m}$ south of GZ, with widths of $100 \mathrm{~m}$ in the south up to $400 \mathrm{~m}$ in the north (Essington, 1985). The radionuclide inventory for the site (surface soil) was estimated to be approximately $35 \mathrm{Ci}$ for Pu-239/240 and Am-241, 130 to $160 \mathrm{mCi}$ for Cs-137, and $300 \mathrm{mCi}$ for Sr-90, with calculated distributions (Block Medians, Block Means, Confidence Band on Block Medians, and Kriging Standard Deviations) of Pu-239/240 and Am-241 presented in several figures (Gilbert et al., 1985).

Other investigations include the RIDP that was conducted throughout the NTS from 1981 through 1986, and estimated the inventory of man-made radionuclides at the NTS (DRI, 1985 and 2007). Both in situ gamma spectroscopy and limited confirmatory soil sampling were implemented at the study area. Alpha-emitting radionuclides, primarily plutonium isotopes, as well as gamma-emitting radionuclides (e.g., Am-241, Co-60, Cs-137, and several europium isotopes) were identified at CAS 18-45-03.

Other CASs in the area of CAS 18-45-03 include: CAS 18-01-01, Aboveground Storage Tank; CAS 18-24-01, Batteries (Dry Cell); CAS 18-24-02, Batteries (3); CAS 18-99-02, Military Jeeps (2); CAS 18-99-03, Wax Piles/Oil Stain; and 18-99-04, Military Tank. The two military Jeeps (CAS 18-99-02) and the Military Tank (CAS 18-99-04) were associated with the Little Feller II test. The DRI archaeologists determined that CASs 18-99-02 and 18-99-04 have historical significance; recommended the Jeeps and tank be left in place, and the CASs transferred to CAU 4000, No Further Action Sites. Corrective Action Site 18-01-01, Aboveground Storage Tank, in CAU 166 is located in 
Little Feller II and consists of two metal containers containing wax and liquid, which are believed to be part of the neutron flux experiments associated with the Little Feller II test. The site will be clean closed by removing liquid from the western container and removing wax from both containers. The two metal containers will be grouted in place. Corrective Action Site 18-99-03, also in CAU 166, consists of a metal container containing wax and liquid, a metal box, and two wax piles also believed to be a part of the neutron flux experiments associated with the Little Feller II test. The metal box and wax piles are located within the fence line, and the metal container containing wax and liquid is located to the south west outside the fence line. Results from the analysis of characterization soil samples showed that $\mathrm{Am}-241, \mathrm{Pu}-238$, and $\mathrm{Pu}-239 / 240$ were present at concentrations above the FALs. All of the samples that exceeded the FALs for radionuclides were collected from within the fenced CA. No further action is required for this site; however, as a best management practice, the wax and liquid will be removed, and the metal container will be grouted in place. Corrective Action Unit 351, in the area of Little Feller II, includes CAS 18-24-01, which consists of a dry cell battery that was removed and disposed of properly. Corrective Action Site 18-24-02 consisted of three lead-acid batteries that were also removed from the site. Clean closure was verified by visual inspection and two verification soil samples analyzed for total lead that confirmed the total lead concentrations were below the FALs.

\section{A.2.3 Corrective Action Site 20-23-01, U-20k Contamination Area}

Corrective Action Site 20-23-01 consists of a release of radionuclides to the surrounding soil from the Palanquin plowshare test. A large crater is present in the southern section of the CAS is fenced and posted as a CA. Figure A.2-5 is a depiction of the CAS area.

Physical Setting and Operational History - Corrective Action Site 20-23-01 is located on Pahute Mesa in Area 20 and was the site of the Palanquin plowshare test conducted on April 14, 1965. This 4.3 kt test was part of Operation Whetstone and was designed for debris entrapment. Depth of burial of the device was approximately $279 \mathrm{ft}$ (DOE/NV, 1996b and 2000). Presently, metal towers, cables and wood debris remain at the site. The crater area is not visible from outside the CA fence line.

This CAS is a large gently sloping to flat topographic area located in Pahute Mesa in the East Thirsty Canyon and Gold Flat East Drainage Basin within the Oasis Valley Subbasin. Corrective Action 


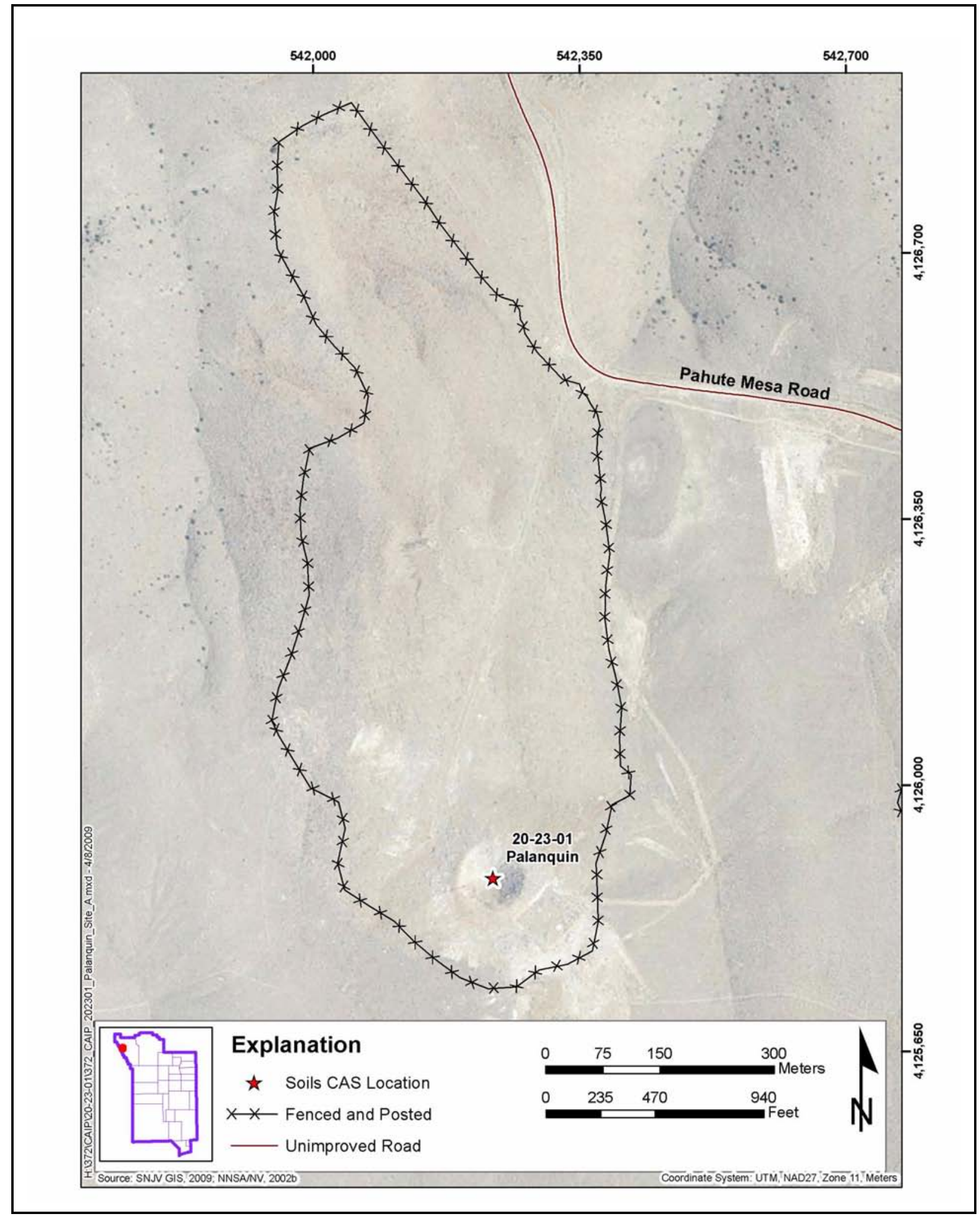

Figure A.2-5

Location of CAS 20-23-01, U-20k Contamination Area 
Site 20-23-01 is located within the comendite of Ribbon Cliff geologic unit (Slate et al., 1999). The Palanquin crater is located south and west of several north-south trending faults (USGS, 2007). According to the hydrogeologic summary, the area is comprised of $400 \mathrm{ft}$ of Thirsty Canyon Formation overlying a series of tuffs from 400 to 4,003 ft bgs (DRI, 1991).

There is an intermittent stream approximately 1,476 ft east of Palanquin crater. This stream cuts across the western boundary of the Palanquin plume and flows ultimately into Thirsty Canyon.

The nearest well, ER-20-1, is located on Pahute Mesa in Area 20 approximately $4.3 \mathrm{mi}$ south-southeast of the CAS. The well is located on a relatively flat-lying portion of the mesa at an approximate elevation of 6,168 ft. Depth to groundwater averages approximately 1,988.2 ft bgs and falls within the Tiva Canyon Tuff confined, single aquifer (USGS and DOE, 2007).

The average annual precipitation rate is approximately $7.2 \mathrm{in}$. at the nearest rain gauge, Pahute Mesa 1 (ARL/SORD, 2009). Annual PET has been estimated as $61.8 \mathrm{in}$. for the Area 3 RWMS (NNSA/NSO, 2008b).

Release Information - The release of radioactive contamination to soil from nuclear weapons testing at the site includes the fallout of fuel particles, fission products and neutron activation of soils through prompt injection, and debris in the immediate area of GZ. Multiple isotopes were detected after detonation and include: barium-140/lanthanum-140; I-131, -133 and -135; molybdenum-99; Sr-91; Tc-99; Xe-135; yttrium-91m; and Zr-95/Nb-95 and Zr-97/Nb-97. Because the short-lived isotopes identified following detonation have decayed, the expected COPCs include the long-lived isotopes: Am-241; Co-60; Cs-137; Eu-152, -154, -155; Pu-238, -239/240; Sr-90; Th-232; and U-233, -234, -235, -238. These COPCs correlate with the results of the RIDP sampling.

Previous Investigation Results - Previous investigations for CAS 20-23-01 include flyover surveys conducted in 1970, 1980, 1992, and 1994, the NAEG investigation, and the RIDP investigation. The 1970 flyover survey conducted at CAS 20-23-01 identified radiological contamination based upon gamma emissions at the site. An extensive Am-241 plume was found in and around GZ (BN, 1999). Because the Palanquin and Cabriolet GZs are relatively close together, they were not well resolved spatially during the 1970 flyover survey. The flyover survey recorded terrestrial and cosmic-ray activity levels greater than $200 \mu \mathrm{R} / \mathrm{hr}$ over the general area of the two GZs. The flyover surveys 
identified the two strongest radioisotopes in the gamma-ray spectrum from over the GZ area as manganese-54 at 835 kiloelectron volt (keV) and Co-60 at 1,173 and 1,332 keV. The 1980 flyover survey was conducted using a helicopter at a significantly lower altitude. Because this altitude was lower, the spatial resolution was improved, and maximum exposure-rate intensities were higher, because there was a much higher probability that the helicopter flew directly over the GZ. Therefore, the high-activity spots were averaged over a smaller footprint. This flyover survey reported exposure rate range at approximately $900 \mu \mathrm{R} / \mathrm{hr}(\mathrm{BN}, 1999)$.

The 1992 flyover survey, with its wide-flight line spacing, missed the centers of activity and reported much lower exposure rates with a 24- to 36- $\mu \mathrm{R} / \mathrm{hr}$ range. The results of the 1994 flyover survey were similar to the 1980 result and identified exposure rate ranges between 270 to $900 \mu \mathrm{R} / \mathrm{hr}$ (BN, 1999). The flyover survey results showed a well defined Am-241 plots at both Palanquin and Cabriolet sites.

In the mid-1970s, the NAEG began investigating the Palanquin site by sampling surface soils. Samples were taken along a transect starting at approximately $600 \mathrm{ft}$ north of GZ extending to $10,000 \mathrm{ft}$ at Palanquin and following the long axis of the approximate center of the plume (Gilbert et al., 1977). Activities of Am-241 at Palanquin ranged from approximately $60 \mathrm{nCi} / \mathrm{g}$ at approximately $600 \mathrm{ft}$ north/northwest of GZ to less than $0.003 \mathrm{nCi} / \mathrm{g}$ at approximately 10,000 ft north.

During work conducted from 1977 to early 1978, the NAEG collected a suite of samples in local washes to aid in identifying subsequent erosion of radioactive material from a recent burn across the area (Essington, 1978). However, the results were not published. Readings from an alpha radiation survey at Palanquin were the highest outside a 300-ft GZ zone at approximately $430 \mathrm{ft}$ north of GZ; the beta/gamma survey readings were highest at approximately $570 \mathrm{ft}$ north of GZ. The FIDLER readings were the highest at approximately $500 \mathrm{ft}$ north of GZ.

In 1981, the NAEG noted that the Palanquin and Cabriolet sites appeared to be quite different in radionuclide composition from safety experiment sites and Little Feller II (Essington, 1981). The Pu-238 to Pu-239/240 ratios were considerably higher than at the other sites, and the presence of considerable amounts of U-233/234 was noted.

Follow-up work published for the NAEG in 1985 presented contour graphs of the gross-beta and gross-gamma surveys at both sites, suggesting that the contributing radionuclides are distributed on 
the soil surface differently (Essington, 1985). The ratio of Pu-238 to Pu-239/240 was determined to range up to three, and considerable concentrations of U-233/234 were found in soil samples. The authors suggested that $\mathrm{Pu}-242$ and U-232 were also likely present, though samples were not analyzed for these two isotopes. Separately, the radionuclide inventory for the combined sites (surface soil) was estimated to be approximately $13 \mathrm{Ci}$ for plutonium and americium, 1.5 Ci for Cs-137, and 1.4 Ci for Sr-90, with calculated distributions (Block Medians, Block Means, Confidence Band on Block Medians, and Kriging Standard Deviations) of Pu-239/240 and Am-241, and Sr-90, presented in several figures (Gilbert et al., 1985).

The RIDP investigation identified alpha-emitting radionuclides (primarily plutonium isotopes) as well as gamma-emitting radionuclides (e.g., Am-241, Co-60, Cs-137, and several europium isotopes) at this CAS.

Investigations for other CASs conducted in the area of CAS 20-23-01 include CAU 352, CAS 20-22-06, one empty, crushed 55-gallon drum south of the U-20k crater within the posted CA. Soil sampling from the Industrial Sites Preliminary Assessment showed no contamination above action levels, and the drum was removed and the site closed. Corrective Action Site 20-24-04, also in CAU 352, consisted of four batteries removed from the site. A verification soil sample was taken and analyzed for total lead and found no contamination that exceeded the action levels and the site also was closed (EPA, 2008). Corrective Action Site 20-24-05 in CAU 87 was a battery that was removed from the CAS location. Corrective Action Site 20-22-07 in CAU 548 consists of two drums scheduled for investigation and is planned as a housekeeping site.

\section{A.2.4 Corrective Action Site 20-45-01, U-20L Crater (Cabriolet)}

Corrective Action Site 20-45-01 consists of a release of radionuclides to the surrounding soil from the Cabriolet plowshare test. A large crater is present at the site. The fenced area of the CAS is posted as a CA, and an area located southeast of the crater is posted as an HCA. These posted areas do not necessarily define the CAS boundary but meet the posting requirements of the NV/YMP RadCon Manual. Figure A.2-6 is a depiction of the CAS area.

Physical Setting and Operational History - Corrective Action Site 20-45-01 is located in Area 20 of the NTS. This CAS is located in the Pahute Mesa area in the East Thirsty Canyon and Gold Flat East 


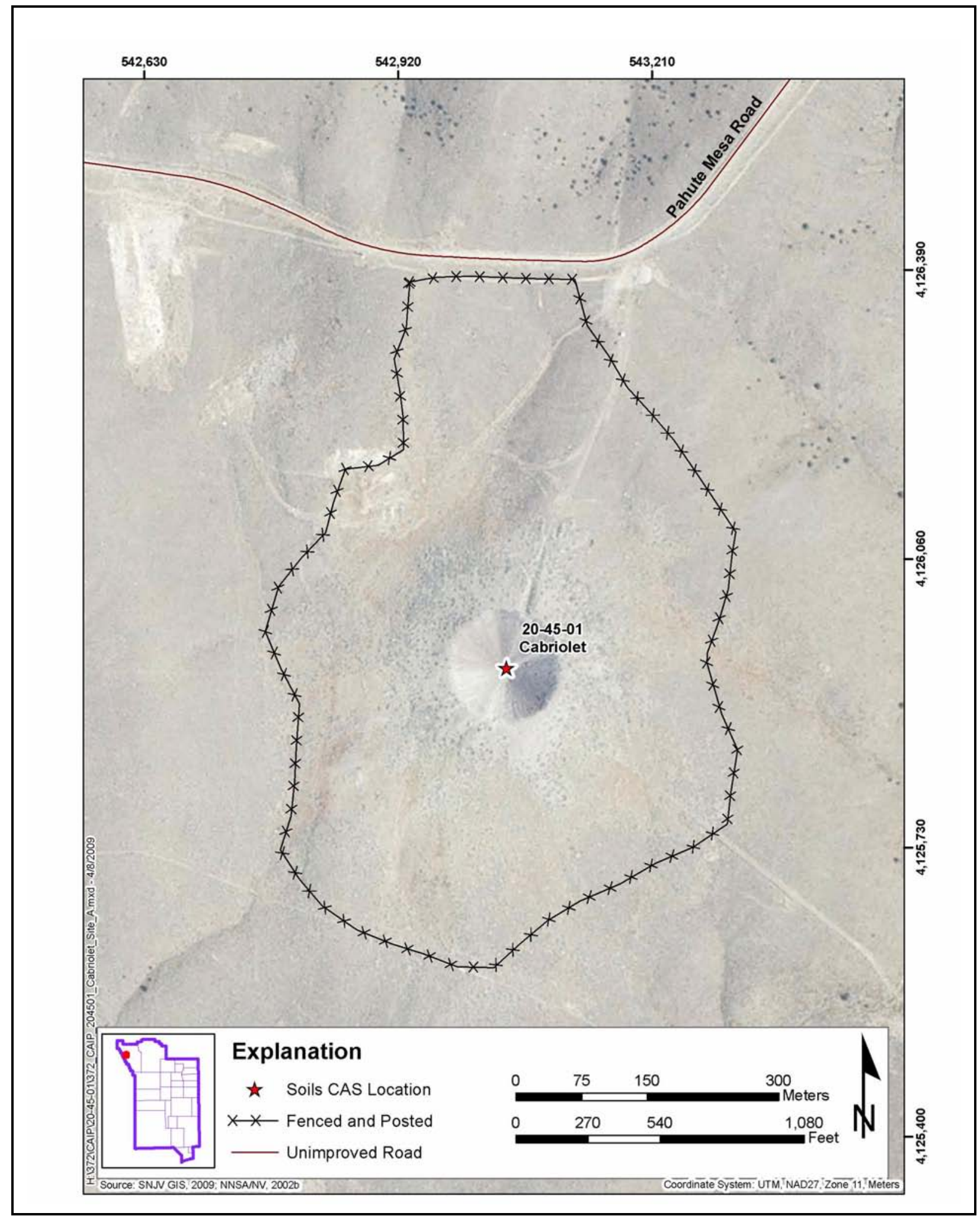

Figure A.2-6

Location of CAS 20-45-01, U-20L Crater (Cabriolet) 
drainage basins at an elevation of approximately 6,109 ft (USGS, 2007). The area was the site of the Cabriolet plowshare test conducted on January 26, 1968. This 2.3 kt test was part of Operation Crosstie and was designed as a cratering experiment. Depth of burial for the device was approximately $171 \mathrm{ft}$ (DOE/NV, 1996b and 2000). Presently, debris in the area consists of metal, cable, wood, and concrete. The area contains a large crater located in the center of the Cabriolet fence line. Several washes traverse the area.

Corrective Action Site 20-45-01 is located within the geologic unit comendite of ribbon cliff (Slate et al., 1999) There are two north-south trending fault traces that intersect the Cabriolet plume (USGS, 2007). The nearest well is ER-20-1 located on Pahute Mesa in Area 20 approximately $4.4 \mathrm{mi}$ south-southeast of CAS 20-45-01. The well is situated on a relatively flat-lying portion of the mesa at an estimated elevation of 6,168 $\mathrm{ft}$. Both to the west and south, the mesa drops off into tributary drainages of Thirsty Canyon. The area is reported to be comprised of $12 \mathrm{~m}$ of Thirsty Canyon Formation overlying a series of tuffs from 400 to 3,907 ft bgs (DRI, 1991). Depth to groundwater averages approximately 1,988 ft bgs and falls within the Tiva Canyon Tuff, confined single aquifer (DOE/NV, 1992).

Intermittent streams are present approximately 2,297 ft north and 1,640 south of the CAS location and flow southerly from the site into tributaries and ultimately into Thirsty Canyon. The average annual precipitation rate is approximately 7.2 in. at the nearest rain gauge, Pahute Mesa 1 (ARL/SORD, 2009). Annual PET has been estimated as $61.8 \mathrm{in}$. for the Area 3 RWMS (NNSA/NSO, 2009).

Release Information - The release of radioactive contamination to soil via prompt injection from nuclear weapons testing at the site include the fallout of fuel particles, fission products and the neutron activation of soils and debris in the immediate area of GZ. Multiple isotopes were identified after detonation to include: I-131, -133, -134, -135; krypton-87, -88; Ru-88; Sr-90; Te-132; tungsten-187; and Xe-133, -135. Because the short-lived isotopes identified following detonation have decayed, the expected COPCs include: Am-241; Co-60; Cs-137; Eu-152, -154, -155; Pu-238, -239/240; Sr-90; Th-232; and U-233, -234, -235, -238. These COPCs correlate with the results of the RIDP sampling. Figure A.2-3 shows a conceptual model of the ejection and the material from the crater of a nuclear explosion. 
Previous Investigation Results - Previous investigations for CAS 20-45-01 include flyover surveys conducted in 1970, 1980, 1992, and 1994; the NAEG investigation; and the RIDP investigation. The 1970 flyover survey conducted at CAS 20-45-01 identified radiological contamination based upon gamma emissions at the site. An extensive Am-241 plume was found in and around GZ (BN, 1999). Because the Palanquin and Cabriolet GZs are relatively close together, they were not well resolved spatially during the 1970 flyover survey. The flyover survey recorded terrestrial and cosmic-ray activity levels greater than $200 \mu \mathrm{R} / \mathrm{hr}$ over the general area of the two GZs. The flyover survey identified the two strongest radioisotopes in the gamma-ray septum from over the GZ area as manganese-54 at $835 \mathrm{keV}$ and Co-60 at 1,173 and 1,332 keV. The 1980 flyover survey was conducted using a helicopter at a significantly lower altitude. Because this altitude was lower, the spatial resolution was much better and maximum exposure-rate intensities were higher since there was a much higher probability that the helicopter flew directly over GZ and averaged the high-activity spots over a smaller footprint. This flyover survey reported exposure-rate range between 200 and $900 \mu \mathrm{R} / \mathrm{hr}$ (BN, 1999). With its very wide-flight line spacing, the 1992 flyover survey missed the centers of the activity and reported much lower exposure rates with the range being between 24 to $36 \mu \mathrm{R} / \mathrm{hr}$. The results of the 1994 flyover survey identified exposure rate ranges between 75 and $120 \mu \mathrm{R} / \mathrm{hr}$ (BN, 1999) with identified isotopes of Co-60, Am-241 and Cs-137. The flyover survey results showed a well defined Am-241 plume at the Cabriolet site with levels up to 2,000 cps (BN, 1999).

The Cabriolet area is listed as a site with surface soil concentrations of Pu-239/240 greater than 500 nanocuries per square meter (nCi/m²) (DRI, 1992).

In the mid-1970s, the NAEG began investigating the Cabriolet site by sampling surface soils along a transect starting approximately $150 \mathrm{ft}$ north of GZ extending to $500 \mathrm{ft}$ at Cabriolet, following the long axis of the approximate center of the plume (Essington, 1977). Activities of Am-241 and Pu-239/240 at Cabriolet ranged between approximately 0.2 and $0.9 \mathrm{nCi} / \mathrm{g}$ at the three locations sampled (Gilbert et al., 1977). Gamma readings at Cabriolet ranged from $0.7 \mathrm{mR} / \mathrm{hr}$ at $150 \mathrm{ft}$ from $\mathrm{GZ}$ to $1.5 \mathrm{mR} / \mathrm{hr}$ at $184 \mathrm{ft}$ north, then gradually declined to $0.2 \mathrm{mR} / \mathrm{hr}$ at approximately $400 \mathrm{ft}$ north.

During work conducted from 1977 to early 1978, the NAEG collected a suite of samples in local washes to aid in identifying subsequent erosion of radioactive material from a recent burn area across the area (Essington, 1978). However, results were not published. At Cabriolet, the highest readings 
from an alpha radiation survey were at the south perimeter of the 300-ft GZ zone, with the highest beta/gamma and FIDLER readings identified at several areas north, west, and south of GZ.

In 1981, the NAEG noted that the Palanquin and Cabriolet sites appeared to be relatively different in radionuclide composition than safety experiment sites and Little Feller II (Essington, 1981). The $\mathrm{Pu}-238$ to $\mathrm{Pu}-238 / 239$ ratios were considerably higher at the other sites, and the presence of considerable amounts of U-233/234 was noted.

Follow-up work published for the NAEG in 1985 presented contour graphs of the gross-beta and gross-gamma surveys at both sites, showing different distributions, which suggested that the contributing radionuclides are distributed on the soil surface differently (Essington, 1985). The ratio of $\mathrm{Pu}-238$ to $\mathrm{Pu}-239 / 240$ was determined to range up to three, and considerable concentrations of U-233/234 were found in soil samples. The authors suggested that Pu-242 and U-232 were also likely present, though samples were not analyzed for these two isotopes. Separately, the radionuclide inventory for the combined sites (surface soil) was estimated to be approximately $13 \mathrm{Ci}$ for plutonium and americium, 1.5 Ci for Cs-137, and 1.4 Ci for Sr-90, with calculated distributions (Block Medians, Block Means, Confidence Band on Block Medians, and Kriging Standard Deviations) of Pu-239/240 and Am-241, and Sr-90, presented in several figures (Gilbert et al., 1985).

The RIDP investigation identified alpha-emitting radionuclides (primarily plutonium isotopes) as well as gamma-emitting radionuclides (e.g., Am-241, Co-60, Cs-137, and several europium isotopes) at this CAS. Radionuclides at Cabriolet are a mixture of transuranics and fission products. There are extensive areas of Trinity glass around the crater area.

Investigations for other CASs conducted in the area of CAS 20-45-01 include the U-20k/Palanquin Soils site (CAS 20-23-01). Corrective Action Sites 20-22-06, 20-24-04 in CAU 352, and CAS 20-24-05 in CAU 87, consisted of debris such as crushed drums or batteries. These CASs were sampled under the Industrial Site Preliminary Assessment effort and contamination was not identified at concentrations greater than the action levels. The debris from these CASs was removed and disposed of properly. Corrective Action Site 20-22-07 consists of two drums scheduled for investigation and is planned as a housekeeping site. 


\section{A.3.0 Step 1 - State the Problem}

Step 1 of the DQO process defines the problem that requires study, identifies the planning team, and develops a conceptual model of the environmental hazard to be investigated.

The problem statement for CAU 372 is: "Existing information on the nature and extent of contamination is insufficient to evaluate and recommend corrective action alternatives for the CASs in CAU 372.”

\section{A.3.1 Planning Team Members}

The DQO planning team consists of representatives from NDEP, NNSA/NSO, SNJV, and NSTec. The DQO planning team met on February 10, 2009, for the DQO meeting. The primary decision makers are the NDEP and NNSA/NSO representatives.

\section{A.3.2 Conceptual Site Model}

The CSM is used to organize and communicate information about site characteristics. It reflects the best interpretation of available information at a point in time. The CSM is a primary vehicle for communicating assumptions about release mechanisms, potential migration pathways, or exposure routes. It provides a summary of how and where contaminants are expected to move and what impacts such movement may have. It is the basis for assessing how contaminants could reach receptors both in the present and future. The CSM describes the most probable scenario for current conditions at each site and defines the assumptions that are the basis for identifying appropriate sampling strategy and data collection methods. An accurate CSM is important as it serves as the basis for all subsequent inputs and decisions throughout the DQO process.

The CSM was developed for CAU 372 using information from the physical setting, potential contaminant sources, release information, historical background information, knowledge from similar sites, and physical and chemical properties of the potentially affected media and COPCs.

The CSM consists of:

- Potential contaminant releases, including media subsequently affected. 
- Release mechanisms (the conditions associated with the release).

- Potential contaminant source characteristics, including contaminants suspected to be present and contaminant-specific properties.

- Site characteristics, including physical, topographical, and meteorological information.

- Migration pathways and transport mechanisms that describe the potential for migration and areas where the contamination may be transported.

- Points of exposure locations where individuals or populations may come in contact with a COC associated with a CAS.

- Routes of exposure by which contaminants may enter the receptor.

If additional elements are identified during the investigation that are outside the scope of the CSM, the situation will be reviewed and a recommendation will be made as to how to proceed. In such cases, NDEP will be notified and given the opportunity to comment on, or concur with, the recommendation.

The applicability of the CSM to each CAS is summarized in Table A.3-1 and discussed below. Table A.3-2 provides information on CSM elements that will be used throughout the remaining steps of the DQO process. Figure A.3-1 represents the CSM.

\section{A.3.2.1 Contaminant Release}

The releases for CAU 372 have been divided into test releases and non-test releases. The test releases are defined as the deposition of fission products, activated products and unburned fuel at the four CASs of CAU 372. Non-test releases are defined as all other types of releases such as those resulting from spills or wastes found at the site during the investigation.

The most likely locations for deposition of contamination from the tests are at the soil surface and within the craters. Contamination is expected at the base of the crater, where present due to prompt injection, in the ejecta created from the original detonation, as well as a layer of fallout deposited from the cloud. 
Table A.3-1

Conceptual Site Model Description of Elements for Each CAS in CAU 372

\begin{tabular}{|c|c|c|c|c|}
\hline CAS Identifier & $18-45-02$ & $18-45-03$ & $20-23-01$ & $20-45-01$ \\
\hline CAS Description & $\begin{array}{l}\text { Little Feller I } \\
\text { Surface Crater }\end{array}$ & $\begin{array}{l}\text { Little Feller II } \\
\text { Surface Crater }\end{array}$ & $\begin{array}{l}\text { U-20k } \\
\text { Contamination } \\
\text { Area }\end{array}$ & $\begin{array}{l}\text { U-20L Crater } \\
\text { (Cabriolet) }\end{array}$ \\
\hline Site Status & \multicolumn{4}{|c|}{ Sites are inactive and/or abandoned } \\
\hline Exposure Scenario & \multicolumn{4}{|c|}{ Occasional Use Area } \\
\hline $\begin{array}{l}\text { Sources of Potential } \\
\text { Soil Contamination }\end{array}$ & \multicolumn{4}{|c|}{ Fallout and soil activation from surface and near surface nuclear testing } \\
\hline $\begin{array}{l}\text { Location of } \\
\text { Contaminationl } \\
\text { Release Point }\end{array}$ & \multicolumn{2}{|c|}{ Soil surface/debris, } & \multicolumn{2}{|c|}{ Deposited material from the craters } \\
\hline Amount Released & \multicolumn{4}{|c|}{ Classified } \\
\hline Affected Media & \multicolumn{4}{|c|}{ Surface and subsurface soil; debris such as concrete, and metal } \\
\hline Potential Contaminants & \multicolumn{4}{|c|}{ Fuel particles, activation and fission products } \\
\hline Transport Mechanisms & \multicolumn{4}{|c|}{$\begin{array}{l}\text { Surface water runoff may provide for the transportation of some contaminants within or } \\
\text { outside of the boundaries of the CASs. There are known intermittent drainages near the } \\
\text { Area } 20 \text { CASs. Infiltration of precipitation through subsurface media serves as a minor } \\
\text { driving force for migration of contaminants. Ejection of material from the craters provided } \\
\text { a transport mechanism at detonation. }\end{array}$} \\
\hline Migration Pathways & \multicolumn{4}{|c|}{$\begin{array}{l}\text { Lateral transport is expected to dominate over vertical transport due to the relatively large } \\
\text { PET value as compared to the annual precipitation rate. }\end{array}$} \\
\hline $\begin{array}{l}\text { Lateral and Vertical } \\
\text { Extent of } \\
\text { Contamination }\end{array}$ & \multicolumn{4}{|c|}{$\begin{array}{l}\text { Contamination, if present, is expected to be contiguous to the release points. Concentrations } \\
\text { are expected to decrease with distance and depth from the source. Groundwater } \\
\text { contamination is not expected. Lateral and vertical extent of COC contamination is assumed } \\
\text { to be within the spatial boundaries of the CAS. }\end{array}$} \\
\hline Exposure Pathways & \multicolumn{4}{|c|}{$\begin{array}{c}\text { The potential for contamination exposure is limited to industrial and construction workers, and } \\
\text { military personnel conducting training. These human receptors may be exposed to COPCs } \\
\text { through ingestion, or inhalation of soil and/or debris due to inadvertent disturbance of these } \\
\text { materials or irradiation by radioactive materials. }\end{array}$} \\
\hline
\end{tabular}




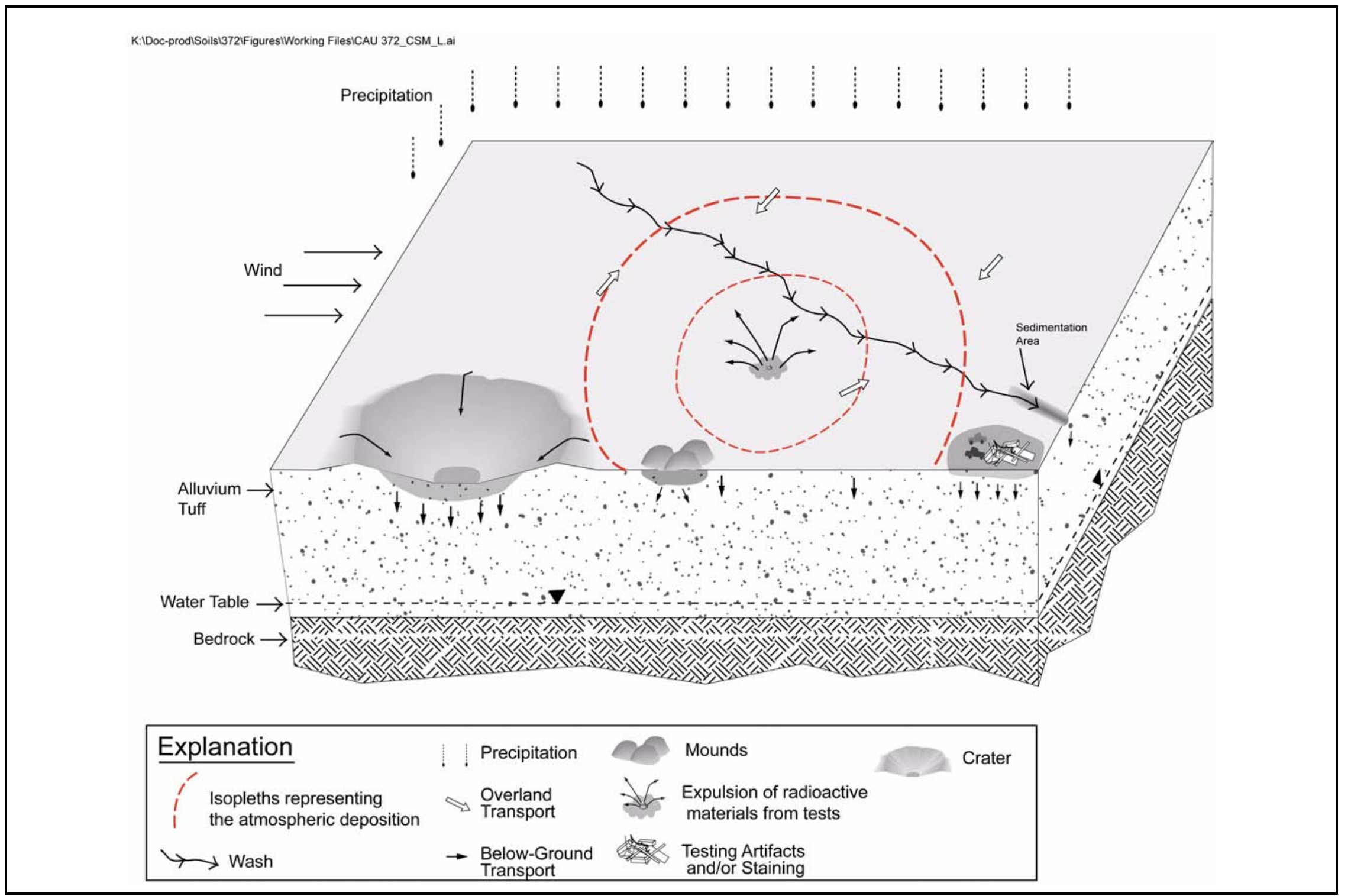

Figure A.3-1

Conceptual Site Model for CAU 372

\section{UNCONTROLLED When Printed}




\section{A.3.2.2 Potential Contaminants}

The COPCs were identified during the planning process through the review of site history, process knowledge, personal interviews, past investigation efforts (where available), and inferred activities associated with the CASs. Because complete information regarding activities performed at the CAU 372 sites is not available, contaminants detected at similar NTS sites were included in the contaminant list to reduce uncertainty. The list of COPCs is intended to encompass all of the significant contaminants that could potentially be present at each CAS. Significant contaminants are defined as COPCs that exceed PAL concentrations.

The COPCs for each CAS include: Am-241; Co-60; Cs-137; Eu-152, -154; and Pu-238, -239/240. Other radionuclides (e.g., U-233, -234, -235, and -238) may be present at low activities.

The COPCs applicable to Decision I environmental samples from each of the CASs of CAU 372 are defined as the contaminants reported from the analytical methods stipulated in Table A.3-2. Because of the limited analytical results and uncertainty with the RIDP data none of the radioisotopes identified in the flyover surveys have been identified as target analytes. However, if during the Decision I sampling isotopes are detected at concentrations that exceed the action levels, they will be considered target analytes for the Decision II sampling.

\section{A.3.2.3 Contaminant Characteristics}

Contaminant characteristics include, but are not limited to: solubility, density, and adsorption potential. In general, contaminants with low solubility, high affinity for media, and high density can be expected to be found relatively close to release points. Contaminants with small particle size, high solubility, low density, and/or low affinity for media, are found further from release points or in low areas where evaporation of ponding will concentrate dissolved contaminants.

\section{A.3.2.4 Site Characteristics}

Site characteristics are defined by the interaction of physical, topographical, and meteorological attributes and properties. Topographical and meteorological properties and attributes include slope stability, precipitation frequency and amounts, precipitation, runoff pathways, drainage channels and ephemeral streams, and evapotranspiration potential. 
Table A.3-2

Analytical Program ${ }^{a}$

\begin{tabular}{|c|c|c|c|c|c|c|c|c|}
\hline \multirow{2}{*}{ Analysis } & \multicolumn{2}{|c|}{$\begin{array}{c}\text { CAS } \\
18-45-02\end{array}$} & \multicolumn{2}{|c|}{$\begin{array}{c}\text { CAS } \\
18-45-03\end{array}$} & \multicolumn{2}{|c|}{$\begin{array}{c}\text { CAS } \\
20-23-01\end{array}$} & \multicolumn{2}{|c|}{$\begin{array}{c}\text { CAS } \\
20-45-01\end{array}$} \\
\hline & TR & NR & TR & NR & TR & NR & TR & NR \\
\hline \multicolumn{9}{|c|}{ Organic COPCs } \\
\hline Total Petroleum Hydrocarbons-Diesel-Range Organics & $\overline{--}$ & $\mathrm{X}^{\mathrm{b}}$ & $\overline{--}$ & $\mathrm{X}^{\mathrm{b}}$ & $\overline{--}$ & $\mathrm{X}^{\mathrm{b}}$ & -- & $x^{b}$ \\
\hline Total Petroleum Hydrocarbons-Gasoline-Range Organics & -- & $X^{b}$ & -- & $\mathrm{X}^{\mathrm{b}}$ & -- & $\mathrm{X}^{\mathrm{b}}$ & -- & $x^{b}$ \\
\hline Polychlorinated Biphenyls & -- & $X^{b}$ & -- & $\mathrm{X}^{\mathrm{b}}$ & -- & $\mathrm{X}^{\mathrm{b}}$ & -- & $x^{b}$ \\
\hline Semivolatile Organic Compounds & -- & $\mathrm{X}^{\mathrm{b}}$ & -- & $\mathrm{X}^{\mathrm{b}}$ & -- & $X^{b}$ & -- & $\mathrm{x}^{\mathrm{b}}$ \\
\hline Volatile Organic Compounds & -- & $x^{b}$ & -- & $\mathrm{X}^{\mathrm{b}}$ & -- & $X^{b}$ & -- & $x^{b}$ \\
\hline \multicolumn{9}{|c|}{ Inorganic COPCs } \\
\hline Resource Conservation and Recovery Act Metals & -- & $\mathrm{X}^{\mathrm{b}}$ & $\overline{--}$ & $\mathrm{X}^{\mathrm{b}}$ & -- & $\mathrm{X}^{\mathrm{b}}$ & $\overline{--}$ & $x^{b}$ \\
\hline \multicolumn{9}{|c|}{ Radionuclide COPCs } \\
\hline Gamma Spectroscopy & $\bar{x}$ & $\mathrm{X}^{\mathrm{b}}$ & $\mathrm{x}$ & $\mathrm{X}^{\mathrm{b}}$ & $\mathrm{x}$ & $\mathrm{X}^{\mathrm{b}}$ & $\mathrm{X}$ & $x^{b}$ \\
\hline Isotopic Uranium & $\mathrm{x}$ & $X^{b}$ & $\mathrm{x}$ & $\mathrm{X}^{\mathrm{b}}$ & $\mathrm{x}$ & $X^{b}$ & $\mathrm{x}$ & $\mathrm{X}^{\mathrm{b}}$ \\
\hline Isotopic Plutonium & $x$ & $\mathrm{X}^{\mathrm{b}}$ & $x$ & $\mathrm{X}^{\mathrm{b}}$ & $x$ & $\mathrm{X}^{\mathrm{b}}$ & $\mathrm{X}$ & $x^{b}$ \\
\hline Isotopic Americium & $\mathrm{x}$ & $X^{b}$ & $\mathrm{x}$ & $\mathrm{X}^{\mathrm{b}}$ & $\mathrm{x}$ & $X^{b}$ & $\mathrm{x}$ & $\mathrm{X}^{\mathrm{b}}$ \\
\hline Strontium-90 & $x$ & $X^{b}$ & $\mathrm{x}$ & $\mathrm{X}^{\mathrm{b}}$ & $\mathrm{x}$ & $\mathrm{X}^{\mathrm{b}}$ & $\mathrm{x}$ & $x^{b}$ \\
\hline
\end{tabular}

aThe COPCs are the analytes reported from the analytical methods listed.

${ }^{b}$ Selection based on type of release, indicators, process knowledge, etc.

$\mathrm{NR}=$ Non-test release

$\mathrm{TR}=$ Test release
$X=$ Required analytical method
$--=$ Not required

Corrective Action Site 18-45-02, Little Feller I, is located along a ridge in central Area 18, and the surrounding area slopes downward to the west and east. Little Feller II, CAS 18-45-03, is located in an Area 18 valley, and the surrounding area gently slopes to the south with small hills. This site has a major wash located to the east of the current CA fence line. Precipitation runoff for the Area 18 sites is into gullies and washes that generally drain to the south. This drainage can provide a migration pathway for the contaminates from within the CAS boundary.

Corrective Action Sites 18-45-02 and 18-45-03 are located within the Alkali Flat Furnace Creek Ranch Subbasin (DOE/NV, 1997), and the precipitation recharge occurs along the northern boundary at Kawich Range and Reveille Range and the northeastern boundary at Belted Range, Rainier Mesa, 
and Shoshone Mountain. Within the sub-basin, recharge occurs throughout eastern Pahute Mesa and in the southern portion of the Kawich Range. Some recharge may also occur from precipitation on Timber Mountain and the Funeral Mountains. The average annual precipitation is approximately 7.2 in. at the nearest station, Little Feller II (ARL/SORD, 2009).

Corrective Action Site 20-23-01, U-20k Contamination Area, is located on Pahute Mesa in west central Area 20. The fenced area slopes downward to the north and south, and elevation at the CAS location is approximately 1,861 m. Corrective Action Site 20-45-01, U-20L Crater (Cabriolet), is also located on Pahute Mesa in west-central Area 20. The Cabriolet area has a gentle slope to the south. Elevation is approximately 1,862 $\mathrm{m}$ at the Cabriolet location.

Corrective Action Sites 20-23-01 and 20-45-01 are located within the East Thirsty Canyon and Gold Flat East drainage basin. The average annual precipitation rate is approximately $7.2 \mathrm{in}$. at the nearest rain gauge, Pahute Mesa 1 (ARL/SORD, 2009). The closest monitoring well, ER-20-1, is located $4.4 \mathrm{mi}$ south-southeast of the sites and indicates an average groundwater depth of 1,988 ft bgs. Annual PET has been estimated as 61.8 in. for the Area 3 RWMS (NNSA/NSO, 2008b; Laczniak et al., 1996). A crater stability study was completed in 1993 by Lawrence Livermore National Laboratory (LLNL) for the Palanquin crater. Based on a technical review of existing data, LLNL believed the U-20k surface crater to be stable in its current configuration (LLNL, 1993). The average crater depth for Palanquin is $78.7 \mathrm{ft}$ with a radius of $118.1 \mathrm{ft}$ (LLNL, 1965), and $114 \mathrm{ft}$ deep with a radius of $180.5 \mathrm{ft}$ for Cabriolet (LRL, Date Unknown).

\section{A.3.2.5 Migration Pathways and Transport Mechanisms}

Migration pathways include the lateral migration of potential contaminants across soil/sediments and vertical migration of potential contaminants into subsurface soils. Erosion of material contaminated by fallout, prompt injection within the crater formed from the detonation or throw out ejecta from the test are all subject to this migration pathway. At the CAU 372 CASs migration pathways include the surface runoff as sheet flow downslope from the source of the radioactivity and the intermittent flow in the various drainages within the area of deposition. Contaminants released into ephemeral washes in the vicinity of the tests are subject to higher potential for migration than contaminants released to other surface areas. These washes are generally dry but are subject to infrequent, potentially intense, stormwater flows that provide a periodic mechanism for both vertical and horizontal transport of 
contaminants. Contaminated sediments entrained by these stormwater events would be carried to locations where the flowing water loses energy and the sediments fall out of suspension. These locations are readily identifiable as sedimentation areas.

The atmospheric deposition of radionuclides is limited to the top $5 \mathrm{~cm}$ of undisturbed soil, while the depth of radiological contamination from depositions other than atmospheric is largely dependent upon its original placement. Radionuclides, with multi-year half-lives, that have been distributed at the NTS from above ground nuclear testing have been found to be concentrated in the upper $5 \mathrm{~cm}$ of undisturbed soil (DRI, 1983 and 1985; Gilbert et al., 1977; Tamura, 1977).

Contaminants migrating from a CAS, regardless of physical or chemical characteristics, are generally expected to exist in the soil adjacent to the area of soil-particle activation, fallout deposition in lateral directions and at the base of the crater created by the detonation. For the CASs in CAU 372, activated soil formed during the nuclear explosion is expected to contain activation products (i.e., europium and cobalt isotopes), and to be most concentrated closest to GZ, with distribution in an annular pattern rotating out from GZ. Concentrations are generally expected to decrease with horizontal and vertical distance from the source. Contamination is expected to be contiguous to the release point and the annual distribution may have been affected by the wind direction during the test.

For the CASs in CAU 372, contamination may also have been transported in washes and the original deposition may not be contiguous to the undisturbed contaminant plume. For CASs 18-45-02 and 18-45-03, intermittent streams in the area flow south, through the Fortymile Wash drainage basin, toward Jackass Flats. For CASs 20-23-01 and 20-45-01 intermittent streams in the area flow south into Thirsty Canyon. Surface migration of contaminants at the CASs due to lateral migration during stormwater run-off events occurs infrequently, but may be significant as drainages are present around the sites.

Other minor potential transport mechanisms for contamination may include wind-borne material and material pushed along dirt roads within the deposition area in the area (e.g., moved during road maintenance). 


\section{A.3.2.6 Exposure Scenarios}

Human receptors may be exposed to COPCs through dermal contact, oral ingestion, or inhalation of soil or debris due to inadvertent disturbance of these materials or irradiation by radioactive materials. The land-use and exposure scenarios for the CAU 372 CASs are listed in Table A.3-3 and are based on NTS current and future land use (DOE/NV, 1998). All of the CAU 372 CASs are at locations without site improvements and where no regular work is performed. There is still a possibility, however, that site workers could occupy these locations on an occasional and temporary basis, such as military exercises. Therefore, these sites are classified as occasional work areas.

Table A.3-3

Land-Use and Exposure Scenarios

\begin{tabular}{||c|c|c||}
\hline CAS & Record of Decision Land-Use Zone & Exposure Scenario \\
\hline \hline 18-45-02 & $\begin{array}{c}\text { Reserved Zone } \\
\text { This area includes land and facilities that provide } \\
\text { widespread flexible support for diverse short-term } \\
\text { testing and experimentation. The reserved zone is } \\
\text { also used for short duration exercises and training } \\
\text { such as nuclear emergency response and Federal } \\
\text { Radiological Monitoring and Assessment Center } \\
\text { training and U.S. Department of Defense } \\
\text { land-navigation exercises and training. }\end{array}$ & $\begin{array}{c}\text { Worker will be exposed to the site occasionally } \\
\text { (up to 100 hours per year for 5 years). Site } \\
\text { structures are not present for shelter and } \\
\text { comfort of the worker. }\end{array}$ \\
\hline 20-23-01 & $\begin{array}{c}\text { Nuclear Test } \\
\text { This area is reserved for dynamic experiments, } \\
\text { hydrodynamic tests, and underground nuclear } \\
\text { weapons and weapons effects tests. This zone } \\
\text { includes compatible defense and nondefense } \\
\text { research, development, and testing activities. }\end{array}$ & $\begin{array}{c}\text { Worker will be exposed to the site occasionally } \\
\text { (up to 100 hours per year for 5 years). Site } \\
\text { structures are not present for shelter and } \\
\text { comfort of the worker }\end{array}$ \\
\hline
\end{tabular}




\section{A.4.0 Step 2 - Identify the Goal of the Study}

Step 2 of the DQO process states how environmental data will be used in meeting objectives and solving the problem, identifies study questions or decision statement(s), and considers alternative outcomes or actions that can occur upon answering the question(s).

\section{A.4.1 Decision Statements}

The Decision I statement for test releases is: "Is radioactivity associated with the CAS present in environmental media that could result in a dose exceeding 25 mrem/yr?” Any plot for which the 95 percent UCL of the mean TED exceeds $25 \mathrm{mrem} / \mathrm{yr}$ will be defined as containing a COC. If a COC is not present, the investigation for that release is complete.

The Decision I statement for non-test releases is: "Is any COC associated with the CAS present in environmental media?” Any analytical result for a COPC above a FAL will result in that COPC being designated as a COC.

A corrective action will be determined for any site containing a COC. The evaluation of the need for corrective action will include the potential for wastes that are present at a site to cause the future contamination of site environmental media if the wastes were to be released.

A COC may also be defined as a contaminant that, in combination with other like contaminants, is determined to jointly pose an unacceptable risk based on a multiple contaminant analysis (NNSA/NSO, 2006). If a COC is detected, then Decision II must be resolved. If a COC is not detected, then the investigation for that release is complete.

The Decision II statement is: "If a COC is present, is sufficient information available to evaluate potential corrective action alternatives?” Sufficient information is defined to include:

- The lateral and vertical extent of COC contamination

- The information needed to determine potential remediation waste types

- The information needed to evaluate the feasibility of remediation alternatives 
If sufficient information is not available to evaluate potential corrective action alternatives then site conditions will be re-evaluated and additional samples will be collected (as long as the scope of the investigation is not exceeded and any CSM assumption has not been shown to be incorrect).

\section{A.4.2 Alternative Actions to the Decisions}

This section identifies actions that may be taken to solve the problem depending on the possible outcomes of the investigation.

\section{A.4.2.1 Alternative Actions to Decision I}

If no COC associated with a release from the CAS is detected, then further assessment of the CAS is not required. If a COC associated with a release from the CAS is detected, then the extent of COC contamination will be determined and additional information required to evaluate potential corrective action alternatives will be collected.

\section{A.4.2.2 Alternative Actions to Decision II}

If sufficient information is available to evaluate potential corrective action alternatives, then further assessment of the CAS is not required. If sufficient information is not available to evaluate potential corrective action alternatives, then additional samples will be collected. 


\section{A.5.0 Step 3 - Identify Information Inputs}

Step 3 of the DQO process identifies the information needed, determines sources for information, and identifies sampling and analysis methods that will allow reliable comparisons with FALs.

\section{A.5.1 Information Needs}

\section{A.5.1.1 Test Releases}

To resolve Decision I at the test releases (determine whether a COC associated with the CAS is present [dose exceeding $25 \mathrm{mrem} / \mathrm{yr}$ ), samples will be collected and analyzed following these criteria:

- To determine that dose exceeds the FAL, samples will be collected in a plot that exceeds a 25-mrem/yr-dose rate.

- To determine that dose exceeding the FAL does not exist at the CAS, samples must be collected in a plot located in an area most likely to exceed a 25-mrem/yr-dose rate. Samples must accurately represent contamination within the plots (probabilistic sampling).

- The analytical methods and in situ measurements must be sufficient to detect a 25-mrem/yr dose.

To resolve Decision II, dose measurements from bounding plots need to be collected and analyzed to meet the following criterion:

- A decreasing trend of TED rates from more than 25-mrem/yr to less than $25 \mathrm{mrem} / \mathrm{yr}$ along each vector needs to be established sufficiently to determine a boundary area that encompasses the area exceeding the FAL.

\section{A.5.1.2 Non-Test Releases}

To resolve Decision I at non-test releases (determine whether a COC associated with the CAS is present), samples need to be collected and analyzed according to the following criteria:

- Samples must be collected in areas most likely to contain a COC (judgmental sampling)

- The analytical suite selected must be sufficient to identify any COCs present in the samples. 
To resolve Decision II (determine whether sufficient information is available to evaluate potential corrective action alternatives at each CAS), samples shall be collected and analyzed to meet the following criteria:

- Samples must be collected in areas contiguous to the COC contamination but where contaminant concentrations are below FALs.

- Samples of the waste or environmental media must provide sufficient information to determine potential remediation waste types.

- The analytical suites selected must be sufficient to detect contaminants at concentrations equal to or less than their corresponding FALs.

\section{A.5.2 Sources of Information}

For test releases, information to satisfy Decision I and Decision II will be generated by collecting environmental samples using randomized composite sampling (systematic triangular grid with a random start location), grab sampling, hand augering, backhoe excavation, or other appropriate sampling methods. For non-test releases, information to satisfy Decision I and Decision II will be generated using a judgmental sampling approach. Sampling locations will be based on the results of field screening, visual observations or the presence of potential source material. Sample collection and handling activities will follow standard procedures. All samples will be submitted to analytical laboratories meeting the quality criteria stipulated in the Industrial Sites QAPP (NNSA/NV, 2002a). Screening data (e.g., radiological surveys and visual surveys) will be used to guide the detailed sampling; however, only validated data from analytical laboratories will be used to support all DQO decisions.

For test releases, data collected will be used to estimate the TED at each plot. The TED will be determined by summing the internal and external dose components. For internal dose, sample results will be used to calculate internal dose using RESRAD. External dose will be determined by collecting in situ measurements using TLDs. Decision criteria is based on the 95 percent UCL of the average TED estimates. Information on decreasing TED rate trends will be generated by calculating TED rates from each plot, and correlating the dose with distance from the point of release, as described in Section A.9.0. 


\section{A.5.2.1 Sample Locations}

Design of the sampling approaches for CAU 372 must ensure that the data collected are sufficient for selection and evaluation of the corrective action alternatives (EPA, 2002). To meet this objective, samples from within the plots will be randomly located (probabilistic samples), while the plots will be judgmentally (biased) located where COCs are most likely to be found.

\section{A.5.2.1.1 Test Releases}

An investigation of contamination from the test releases will be implemented through a combination of judgmental and probabilistic sampling. The establishment of sample plots will be conducted judgmentally. The sample locations within the plots will be randomly selected.

The plot locations will be determined based upon the results of the radiological surveys and the applicable data from the NAEG and RIDP sampling efforts. The Decision I plot will be established in an area likely to exceed a 25-mrem/yr dose (Figures A.9-2 through A.9-5).

For Decision II at all CASs, three sample plots will be located (based upon the 1994 flyover survey), along three sampling vectors, outward from GZ (Section A.9.0) (BN, 1999). For each sampling vector, at least one sample plot will be placed at a location where the TED is expected to be less than the 25-mrem/yr-dose FAL.

\section{Sample Collection Scheme}

The data needed to make DQO decisions requires the measurement of TED at several discreet areas throughout the CAS. To accomplish this, sample plots will be established to represent what is essentially a $100-\mathrm{m}^{2}$ exposure unit. This is a conservative estimate of exposure as it is not reasonable to assume that any worker would be assigned to work exclusively in such a small area. The size of this area was chosen such that results will be comparable to RIDP estimates that also were designed to provide an integrated estimate of radioactivity. The objective is to obtain dose measurements that accurately represent the true dose of each sample plot. To meet this objective, the samples 
collected from the plots must be representative of the entire $100-\mathrm{m}^{2}$ area. This can be accomplished in two ways:

1. Simple Random Sampling - The entire area is represented through multiple samples that individually represent discrete locations within the area. The results from the individual locations are then averaged to generate a value representative of the area. The statistic (e.g., upper confidence limits) generated from these samples is based on the variability between samples. The variability between simple random samples is a combination of the spatial variability within the plot area and the variability associated with sampling and measurement errors. With the simple random sampling approach, these two sources of variability cannot be distinguished.

2. Composite Sampling - Composite samples represent the entire area through physical averaging of multiple individual aliquots collected across the area. Each aliquot must contribute equally to the total sample without bias. To accomplish this, equal size aliquots (typically nine) will be collected from random locations, which are constrained to an evenly spaced grid that covers the entire plot (i.e., random start, systematic triangular grid). Each sample, which is comprised of several aliquots, represent the entire area. The only inherent differences between the samples is associated with sampling and measurement errors (i.e., does not include spatial variability).

A summary of the differences between simple random and composite sampling is provided in Table A.5-1.

The major difference between simple random and composite sampling schemes is that:

- Spatial variability and variability from sampling and measurement errors cannot be distinguished using a simple random sampling scheme.

- Spatial variability is virtually eliminated and the resulting variability between samples is largely only attributable to sampling and measurement error using a composite sampling scheme.

Information on the spatial variability (i.e., true subexposure unit variability) of dose is not important as the DQO decisions are made at the exposure unit level. Subexposure unit variability can be significant as soil contamination from radionuclides is generally not homogenous. This is especially true for the actinides, which exhibit very small, insoluble particle sizes of high specific activity (Lee and Straight, 1978). 
Table A.5-1

Characteristics of Simple Random Sampling and Composite

\begin{tabular}{|c|c|c|}
\hline Characteristic & Composite Sampling & Simple Random Sampling \\
\hline Representativeness & Represents the population average. & $\begin{array}{l}\text { Represents the sample } \\
\text { collection location. }\end{array}$ \\
\hline Population Mean & $\begin{array}{l}\text { Because the compositing physically averages } \\
\text { the individual samples, averaging the analytical } \\
\text { results of a few composites can produce an } \\
\text { estimated mean that is as precise as one based } \\
\text { on many more individual sample results. }\end{array}$ & $\begin{array}{l}\text { Estimate variability within the } \\
\text { population. Ability to estimate mean is } \\
\text { related to the number of samples. }\end{array}$ \\
\hline Variability & $\begin{array}{l}\text { Minimizes effects of within-population spatial } \\
\text { variability. Variability primarily due to } \\
\text { measurement error. }\end{array}$ & $\begin{array}{l}\text { Includes information on } \\
\text { within-population spatial variability. } \\
\text { Variability due to measurement error as } \\
\text { well as spatial variability. }\end{array}$ \\
\hline Cost & $\begin{array}{c}\text { Achieves approximately the same precision of } \\
\text { an estimated mean at a lower cost or provides } \\
\text { more coverage (better representation) of the } \\
\text { population at the same cost. }\end{array}$ & $\begin{array}{l}\text { More samples (analyses) are required } \\
\text { to provide comparable results. }\end{array}$ \\
\hline
\end{tabular}

This distinction is important because the variability between samples is used to calculate the 95 percent UCL of the average dose at each plot that is needed to resolve the DQO decisions. The objective of the investigation is to generate a measurement of TED that is representative of the true average dose of the area at each plot (i.e., the exposure unit). Therefore, variability associated with sampling and measurement error is used to establish the confidence in the TED measurements (EPA, 2006a).

Composite sampling minimizes the effects of spatial variability and more accurately represents the variability associated with sampling and measurement errors. It was chosen as the preferred sampling scheme for each plot (4 samples with 9 aliquots per sample) and provides an estimate of the average dose of each plot equivalent to collecting and analyzing 36 simple random samples.

\section{Computation of Minimum Sample Size}

The minimum number of samples required to compute a UCL will be calculated from the TED measurements within each plot to verify that sufficient samples were collected. The minimum sample sizes will be calculated using EPA methodologies (EPA, 2006a). 
The input parameters to be used in calculating the minimum sample size are:

- A confidence level that a false negative error will not occur will be set at 95 percent.

- A confidence level that a false positive error will not occur will be set at 80 percent.

- A gray region width of 50 percent of the FAL (12.5 mrem/yr).

- The standard deviation of the TED.

The location of subsamples within the plot will be determined using a triangular grid pattern, based on a starting location that is chosen randomly. If it is determined that additional samples need to be collected based on the determination of minimum sample size using actual sample results, additional sample(s) will be collected using the same methodology. An example of subsample locations within a plot is presented in Section A.9.0. A more detailed discussion of the computation of the UCL is presented in Appendix C.

\section{A.5.2.1.2 Non-Test Releases}

Decision I sample locations for non-test releases will be determined based upon the likelihood of the soil containing a COC, if present at the CAS. These locations will be selected based on field-screening techniques, biasing factors, the CSM, and existing information. Analytical suites for Decision I samples will be based on existing site information and site conditions discovered during the investigation. The following factors will be considered in selecting locations for analytical samples at CAU 372:

- $\quad$ Documented process knowledge on source and location of release (e.g., volume of release).

- Elevated radiation: Any location identified during radiological surveys that had alpha/beta/gamma levels significantly higher than surrounding soil. This includes areas such as washes or Am-241 plumes.

- Drums, containers, equipment, or debris: Materials of interest that may have been used at, or added to, a location, and that may have contained or come in contact with hazardous or radioactive substances at some point during their use.

- Visual indicators such as discoloration, textural discontinuities, disturbance of native soils, or any other indication of potential contamination.

- Other biasing factors: Factors not previously defined for the CAI that become evident once the investigation of the site is in progress. 
Decision II sample step-out locations will be selected based on the CSM, biasing factors, and existing data. Analytical suites will include those parameters that exceeded FALs (i.e., COCs) in prior samples. Biasing factors to support Decision II sample locations include Decision I biasing factors plus available analytical results.

\section{A.5.2.2 Analytical Methods}

Analytical methods are available to provide the data needed to resolve the decision statements. The analytical methods and laboratory requirements (e.g., detection limits, precision, and accuracy) are provided in Table 3-2. 


\section{A.6.0 Step 4 - Define the Boundaries of the Study}

Step 4 of the DQO process defines the target population of interest and its relevant spatial boundaries, specifies temporal and other practical constraints associated with sample/data collection, and defines the sampling units on which decisions or estimates will be made.

\section{A.6.1 Target Populations of Interest}

\section{A.6.1.1 Test Releases}

The population of interest to resolve Decision I ("Is any COC associated with the CAS present in environmental media?”) is any location or area within the CAS that contains a COC. The populations of interest to resolve Decision II ("If a COC is present, is sufficient information available to evaluate potential corrective action alternatives?’) are:

- Each one of a set of locations bounding contamination in lateral and vertical directions.

- Investigation waste and potential remediation waste.

\section{A.6.2 Spatial Boundaries}

Spatial boundaries are the maximum lateral and vertical extent of expected contamination supported by the CSM at each CAS. These spatial boundaries are intended to function as a conceptual stopping point during the CAI. It is established as a $1 \mathrm{mi}$ downgradient, lateral buffer outward from GZ. Vertical boundaries are established as $2 \mathrm{ft}$ bgs for test releases and $15 \mathrm{ft}$ bgs for non-test releases. Contamination found beyond these boundaries may indicate a flaw in the CSM and require re-evaluation of the CSM before the investigation could continue. Each CAS is considered geographically independent.

\section{A.6.3 Practical Constraints}

Practical constraints associated with the investigation of CAU 372 are activities at the NTS, which may pose access restrictions affecting the ability to investigate this site, such as military exercises. Additional constraints include topography and steep crater slopes. 


\section{A.6.4 Define the Sampling Units}

The scale of decision-making in Decision I is defined as the CAS. Any COC detected at a location within the CAS will cause the determination that the CAS is contaminated and needs further evaluation. The scale of decision-making for Decision II is defined as a contiguous area contaminated with any COC originating from the CAS. Resolution of Decision II requires this contiguous area to be bounded. 


\section{A.7.0 Step 5 - Develop the Analytic Approach}

Step 5 of the DQO process specifies appropriate population parameters for making decisions, defines action levels, and generates an "If ... then ... else" decision rule that involves it.

\section{A.7.1 Population Parameters}

\section{A.7.1.1 Test Releases}

For probabilistic sampling results (used for the test releases), the population parameter is the true average TED of the plot. Resolution of the DQO Decision I and Decision II statements associated with the probabilistic sampling design requires determining, with a specified degree of confidence, whether the true average TED at the plot exceeds the FAL. Because the average TED from the plot measurements is an estimate of the true (unknown) average TED, it is uncertain how well the estimated TED represents the true TED at the plot. If the measured estimate of the TED was compared directly to the FAL, a significant difference between the estimated TED and the true TED could lead to making a decision error. To reduce the probability of making a false negative decision error (while increasing the probability of making a false positive decision error), a conservative estimate of the true TED will be used to compare to the FAL. This conservative estimate (overestimation) of the true TED will be calculated as the 95 percent UCL of the estimated TED. By definition, there will be a 95 percent probability that the true average TED is less than the 95 percent UCL of the estimated TED.

The computation of appropriate UCLs depends upon the data distribution, the number of samples, the variability of the dataset, and the skewness associated with the dataset. An evaluation will be conducted to determine the appropriate probability distribution (e.g., normal, lognormal, gamma) and/or a suitable nonparametric distribution-free method will be defined and then used to compute appropriate UCLs.

Computation of an appropriate UCL for the TED requires that:

- A minimum number of samples be collected from random locations at each site.

- The data originate from a symmetric, but not necessarily normally distributed, population. 
The population parameter for Decision II is the location along each vector that corresponds to the estimated 95 percent UCL of the 25-mrem/yr dose, based on a correlation of the TED, as a function of distance along each vector.

\section{A.7.1.2 Non-Test Releases}

For judgmental sampling results (used for non-test releases), the population parameter is the observed concentration of each contaminant from each individual analytical sample. Each sample result will be compared to the FAL on a point-by-point basis to determine the appropriate resolution to Decision I and Decision II.

\section{A.7.2 Action Levels}

The PALs presented in this section are to be used for site screening purposes. They are not necessarily intended to be used as cleanup action levels or FALs. However, they are useful in screening out contaminants that are not present in sufficient concentrations to warrant further evaluation and, therefore, streamline the consideration of remedial alternatives. The RBCA process used to establish FALs is described in Industrial Sites Project Establishment of Final Action Levels (NNSA/NSO, 2006). This process conforms with NAC Section 445A.227, which lists the requirements for sites with soil contamination (NAC, 2006a). For the evaluation of corrective actions, NAC Section 445A.22705 (NAC, 2006b) requires the use of ASTM Method E 1739-95 (ASTM, 1995) to "conduct an evaluation of the site, based on the risk it poses to public health and the environment, to determine the necessary remediation standards (i.e., FALs) or to establish that corrective action is not necessary.”

This RBCA process defines the following three tiers (or levels) of evaluation involving increasingly sophisticated analyses:

- Tier 1 evaluation - Sample results from source areas (highest concentrations) are compared to action levels based on generic (non-site-specific) conditions (i.e., the PALs established in the CAIP). The FALs may then be established as the Tier 1 action levels, or the FALs may be calculated using a Tier 2 evaluation.

- Tier 2 evaluation - Conducted by calculating Tier 2 SSTLs using site-specific information as inputs to the same or similar methodology used to calculate Tier 1 action levels. The Tier 2 SSTLs are then compared to individual sample results from reasonable points of exposure 
(as opposed to the source areas as is done in Tier 1) on a point-by-point basis. Total TPH concentrations will not be used for risk-based decisions under Tier 2 or Tier 3. Rather, the individual chemical constituents of the TPH will be compared to the SSTLs.

- $\quad$ Tier 3 evaluation - Conducted by calculating Tier 3 SSTLs on the basis of more sophisticated risk analyses using methodologies described in Method E1739-95 that consider site-, pathway-, and receptor-specific parameters.

The comparison of laboratory results to FALs and the evaluation of potential corrective actions will be included in the CADD. The FALs will be defined (along with the basis for their definition) in the CADD.

\section{A.7.2.1 Chemical PALs}

Except as noted herein, the chemical PALs are defined as the EPA Region 9 Risk-Based Preliminary Remediation Goals (PRGs) for chemical contaminants in industrial soils (EPA, 2008). Background concentrations for RCRA metals and zinc will be used instead of PRGs when natural background concentrations exceed the PRG, as is often the case with arsenic on the NTS. Background is considered the average concentration plus two standard deviations of the average concentration for sediment samples collected by the Nevada Bureau of Mines and Geology throughout the Nevada Test and Training Range (formerly the Nellis Air Force Range) (NBMG, 1998; Moore, 1999). For detected chemical COPCs without established PRGs, the protocol used by the EPA Region 9 in establishing PRGs (or similar) will be used to establish PALs. If used, this process will be documented in the CADD.

\section{A.7.2.2 Total Petroleum Hydrocarbon PALs}

The PAL for TPH is $100 \mathrm{mg} / \mathrm{kg}$ as listed in NAC 445A.2272 (NAC, 2006c).

\section{A.7.2.3 Radionuclide PALs}

The radiological PAL for the test releases is established as the 25-mrem/yr TED based on the modified industrial area exposure scenario. This modified approach includes a $100-\mathrm{m}^{2}$ sample area with $5 \mathrm{~cm}$ depth of contamination.

The PALs for radiological contaminants for the non-test releases are based on the NCRP Report No. 129 recommended screening limits for construction, commercial, industrial land-use scenarios 
(NCRP, 1999) scaled to 25-mrem/yr-dose constraint (Murphy, 2004) and the generic guidelines for residual concentration of radionuclides in DOE Order 5400.5 (DOE, 1993). These PALs are based on the construction, commercial, and industrial land-use scenario provided in the guidance and are appropriate for the NTS based on future land-use scenarios as presented in Section A.3.2.

\section{A.7.3 Decision Rules}

The decision rule applicable to both Decision I and Decision II is:

- If COC contamination is inconsistent with the CSM or extends beyond the spatial boundaries identified in Section A.6.2, then work will be suspended and the investigation strategy will be reconsidered, else the decision will be to continue sampling.

The decision rules for Decision I are:

- If the population parameter of any COPC in the Decision I population of interest (defined in Step 4) exceeds the corresponding FAL, then that contaminant is identified as a COC, and Decision II samples will be collected, else no further investigation is needed for that COPC in that population.

- If a COC exists at any CAS, then a corrective action will be determined, else no further action will be necessary.

- If a waste is present that, if released, has the potential to cause the future contamination of site environmental media, then a corrective action will be determined, else no further action will be necessary.

The decision rule for Decision II (test release) is:

- If a flyover survey isopleth exists that bounds all locations determined to exceed the 25-mrem/yr TED, then the isopleth will be established as the corrective action boundary; else the radiation survey area will be increased until that boundary is defined.

The decision rule for Decision II (non-test releases) is:

- If the population parameter (the observed concentration of any COC) in the Decision II population of interest (defined in Step 4) exceeds the corresponding FAL in any bounding direction or potential remediation waste types have not been adequately defined, then additional samples will be collected to complete the Decision II evaluation, else the extent of the COC contamination has been defined. 


\section{A.8.0 Step 6 - Specify Performance or Acceptance Criteria}

Step 6 of the DQO process defines the decision hypotheses, specifies controls against false rejection and false acceptance decision errors, examines consequences of making incorrect decisions from the test, and places acceptable limits on the likelihood of making decision errors.

\section{A.8.1 Decision Hypotheses}

The baseline condition (i.e., null hypothesis) and alternative condition for Decision I are:

- $\quad$ Baseline condition - A COC is present.

- Alternative condition - A COC is not present.

The baseline condition (i.e., null hypothesis) and alternative condition for Decision II are:

- $\quad$ Baseline condition - The extent of a COC has not been defined.

- Alternative condition - The extent of a COC has been defined.

Decisions and/or criteria have false negative or false positive errors associated with their determination. The impact of these decision errors and the methods that will be used to control these errors are discussed in the following subsections. In general terms, confidence in DQO decisions based on judgmental sampling results will be established qualitatively by:

- The development and concurrence of the CSM (based on process knowledge) by stakeholder participants during the DQO process.

- Validity testing of CSMs based on investigation results.

- Evaluation of the data quality based on DQI parameters.

\section{A.8.2 False Negative Decision Error}

The false negative decision error would mean deciding that a COC is not present when it actually is (Decision I), or deciding that the extent of a COC has been defined when it has not (Decision II). In both cases, the potential consequence is an increased risk to human health and environment. 


\section{A.8.2.1 False Negative Decision Error for Judgmental Sampling}

In judgmental sampling, the selection of the number and location of samples is based on knowledge of the feature or condition under investigation and on professional judgment (EPA, 2002).

Judgmental sampling conclusions about the target population depend upon the validity and accuracy of professional judgment.

The false negative decision error (where consequences are more severe) for judgmental sampling designs is controlled by meeting these criteria:

- For Decision I, having a high degree of confidence that the sample locations selected will identify COCs if present anywhere within the CAS. For Decision II, having a high degree of confidence that the sample locations selected will identify the extent of COCs.

- Having a high degree of confidence that analyses conducted will be sufficient to detect any COCs present in the samples.

- Having a high degree of confidence that the dataset is of sufficient quality and completeness.

To satisfy the first criterion, Decision I samples must be collected in areas most likely to be contaminated by COCs (supplemented by random samples where appropriate). Decision II samples must be collected in areas that represent the lateral and vertical extent of contamination (above FALs). The following characteristics must be considered to control decision errors for the first criterion:

- Source and location of release

- Chemical nature and fate properties

- Physical transport pathways and properties

- Hydrologic drivers

These characteristics were considered during the development of the CSM and selection of sampling locations. The field-screening methods and biasing factors listed in Section A.5.2.1 will be used to further ensure that appropriate sampling locations are selected to meet these criteria. Radiological survey instruments and field-screening equipment will be calibrated and checked in accordance with the manufacturer's instructions and approved procedures. The CADD will present an assessment on the DQI of representativeness that samples were collected from those locations that best represent the populations of interest as defined in Section A.6.1. 
To satisfy the second criterion, Decision I samples will be analyzed for the chemical and radiological parameters listed in Section 3.2. Decision II samples will be analyzed for those chemical and radiological parameters that identified unbounded COCs. The DQI of sensitivity will be assessed for all analytical results to ensure that all sample analyses had measurement sensitivities (detection limits) that were less than or equal to the corresponding FALs. If this criterion is not achieved, the affected data will be assessed (for usability and potential impacts on meeting site characterization objectives) in the CADD.

To satisfy the third criterion, the entire dataset, as well as individual sample results, will be assessed against the DQIs of precision, accuracy, comparability, and completeness as defined in the QAPP (NNSA/NV, 2002a) and in Section 6.2.2. The DQIs of precision and accuracy will be used to assess overall analytical method performance as well as to assess the need to potentially “flag” (qualify) individual contaminant results when corresponding QC sample results are not within the established control limits for precision and accuracy. Data qualified as estimated for reasons of precision or accuracy may be considered to meet the analyte contaminant performance criteria based on an assessment of the data. The DQI for completeness will be assessed to ensure that all data needs identified in the DQO have been met. The DQI of comparability will be assessed to ensure that all analytical methods used are equivalent to standard EPA methods so that results will be comparable to regulatory action levels that have been established using those procedures. Strict adherence to established procedures and QA/QC protocol protects against false negatives. Site-specific DQIs are discussed in more detail in Section 6.2.2.

To provide information for the assessment of the DQIs of precision and accuracy, the following QC samples will be collected as required by the QAPP (NNSA/NV, 2002a):

- Field duplicates (minimum of 1 per matrix per 20 environmental samples)

- Laboratory QC samples (minimum of 1 per matrix per 20 environmental samples)

\section{A.8.2.2 False Negative Decision Error for Probabilistic Sampling}

The false negative error rate for probabilistic sampling was established by the DQO meeting participants at 0.05 (or 5 percent probability). Upon validation of the analytical results, statistical 
parameters will be calculated for each COC identified at each site. Maintenance of a 0.05 false negative error rate is contingent upon:

- Population distribution

- Sample size

- Actual variability

- Measurement error

Control of the false negative decision error for probabilistic sampling designs is, therefore, accomplished by ensuring that:

- The population distributions fit the applied UCL determination method.

- A sufficient sample size was collected.

- The actual standard deviation is calculated.

- Analyses conducted were sufficient to detect any COCs present in samples.

If these criteria cannot be met, the false negative decision error can also be controlled by assuming that COCs exist at the CAS.

\section{A.8.3 False Positive Decision Error}

The false positive decision error would mean deciding that a COC is present when it is not, or a COC is unbounded when it is, resulting in increased costs for unnecessary sampling and analysis.

False positive results are typically attributed to laboratory and/or sampling/handling errors that could cause cross contamination. To control against cross contamination, decontamination of sampling equipment will be conducted according to established and approved procedures, and only certified clean sample containers will be used. To determine whether a false positive analytical result may have occurred, the following QC samples will be collected as required by the QAPP (NNSA/NV, 2002a) for chemical samples only (if collected):

- Trip blanks (1 per sample cooler containing VOC environmental samples)

- Equipment blanks (1 per sampling event for each type of decontamination procedure)

- $\quad$ Source blanks (1 per source lot per sampling event)

- Field blanks (minimum of 1 per CAS, additional if field conditions change)

- Field duplicates (minimum of 1 per matrix per 20 environmental samples) 
For probabilistic sampling, false positive decision error was established by the DQO meeting participants at 0.20 (or 20 percent probability). Protection against this decision error is also afforded by the controls listed in Section A.8.2 for probabilistic sampling designs. 


\section{A.9.0 Step 7 - Develop the Plan for Obtaining Data}

Step 7 of the DQO process selects and documents a design that will yield data that will best achieve performance or acceptance criteria. Judgmental sampling schemes will be implemented to select the sample plot locations for the test releases. Probabilistic sampling schemes will be implemented to select nine sample locations for each of four composite samples per sample plot. Judgmental sampling will also be used to investigate any non-test releases based on site biasing factors (staining, historical knowledge, debris). Sections A.9.1 through A.9.2.2 contain general information about collecting samples under judgmental and probabilistic sample designs, and Decision II sampling.

\section{A.9.1 Sampling of Test Releases}

A combination of judgmental and probabilistic sampling approaches will be implemented for the investigation of the annular distribution of contamination at the CASs in CAU 372.

The judgmental location of sample plots will meet the following criteria:

- Decision I sample plots will be biased to the areas likely to have a dose greater than $25 \mathrm{mrem} / \mathrm{yr}$ as determined during the radiological surveys.

- Decision II sample plots will also be biased with the biasing factors that one plot will have a dose of less than $25 \mathrm{mrem} / \mathrm{yr}$.

- Decision II sample plots will be biased to establish a minimum of three plots along each of three vectors.

The probabilistic collection and evaluation of samples within each plot will meet the following criteria:

- Aliquot (i.e., subsample) locations within each plot for each composite sample will be determined using a random start, triangular grid pattern, thereby giving an unbiased selection of sampled locations.

- $\quad$ Statistics (i.e., average, standard deviation, and 95 percent UCL of the average) from the data will be used to determine minimum sample size and compare to FALs. 


\section{A.9.1.1 Decision I Sampling}

The TED will be determined by summing the internal and external dose components. The RESRAD code will be used to derive the Residual Radioactive Material Guidelines (RRMGs). Soil samples are compared to RRMGs to calculate the internal dose. External dose will be determined by collecting in situ measurements using TLDs or other dose measurement devices. External dose measurements will be taken at the approximate center of each sample plot at a height of $3.3 \mathrm{ft}(1 \mathrm{~m})$.

Sample plot locations will be based judgmentally on radiological surveys and applicable historical sampling results. These data may include the 1994 aerial radiological flyover survey (BN, 1999), GPS-assisted gamma walkover surveys, NAEG data, and RIDP data. These data will be used to establish patterns of contaminant distribution at each CAS. One sample plot will be established judgmentally at a location most likely to exceed a 25-mrem/yr-dose constraint determined from the radiological surveys and historical data at each CAS.

The radiological surveys will also be conducted over potential migration pathways (i.e., drainages). Judgmental sampling locations will be selected from along the major drainages where sediment has accumulated after rainfall events that may have transported radioactivity down stream from within the CAS. The results of these radiological surveys and existing historical data will be used to determine the need for additional sample plots along these potential migration pathways.

For the probabilistic sampling approach at the sample plots:

- Each composite sample will be comprised of nine aliquots taken from randomly selected locations within each plot. These locations will be predetermined using a random start with a triangular grid pattern.

- Samples will be sieved to eliminate material (e.g., Trinity glass) greater than 0.25 in.

- The entire volume of the composited material collected will be submitted to the laboratory for analysis.

A minimum number of samples (i.e., composite samples) is required to compute the UCL. This number will be calculated based on the TED results (comprised of individual internal dose rates associated with each of the four composite samples added to the external dose rates from each plot). 
If a predetermined location cannot feasibly be sampled (e.g., rock, caliche or concrete), the Site Supervisor will establish an alternate sampling location at the nearest place that can be sampled.

Determination of the minimum sample size cannot be accomplished until after the data has been generated. However, based on the input parameters below, and the variability of the data from CAU 372, a minimum of three would be required. After the data evaluation is complete, the required number of samples will be calculated.

The input parameters to be used in calculating the minimum sample size are:

- A confidence level that a false negative error will not occur will be set at 95 percent.

- A confidence level that a false positive error will not occur will be set at 80 percent.

- A gray region width equal to 50 percent of the FAL (12.5 mrem/yr).

- The standard deviation of the TEDs at each plot.

If the criteria established in this section results in a determination that the minimum sample size was not met for a plot, one of the following actions may be taken:

- Additional composite sample(s) may be collected.

- Conservatively assume that the TED for the plot exceeds the FAL. This would not be acceptable for the plot that is determined to be outside the $25-\mathrm{mrem} / \mathrm{yr}$ boundary. Justifications for use of the resulting TED without meeting the criteria will be made in the CADD.

An example of the four composite samples and nine locations per sample plot for the CAU 372 CASs is shown in Figure A.9-1. Values/setting used for the computation of the composite sample locations for the plots are listed in Table A.9-1.

In addition to the plot sampling, soil/sediment samples will be collected from sediment accumulation areas in the drainages that provide major migration pathways from the site. These biased locations will be identified based on the results of radiological survey and visual identification of areas of sediment accumulation. Initially, samples will be collected from two of the largest sediment traps identified to be outside the estimated 25-mrem/yr boundary. Each sediment location will be sampled in 5-cm lifts throughout the entire thickness of the sediment (up to a thickness of $2 \mathrm{ft}$ ). If the thickness of the sediments exceeds $2 \mathrm{ft}$, the sampling interval may be increased based on the field-screening results and the Site Supervisor's judgment. The intervals should not be increased 


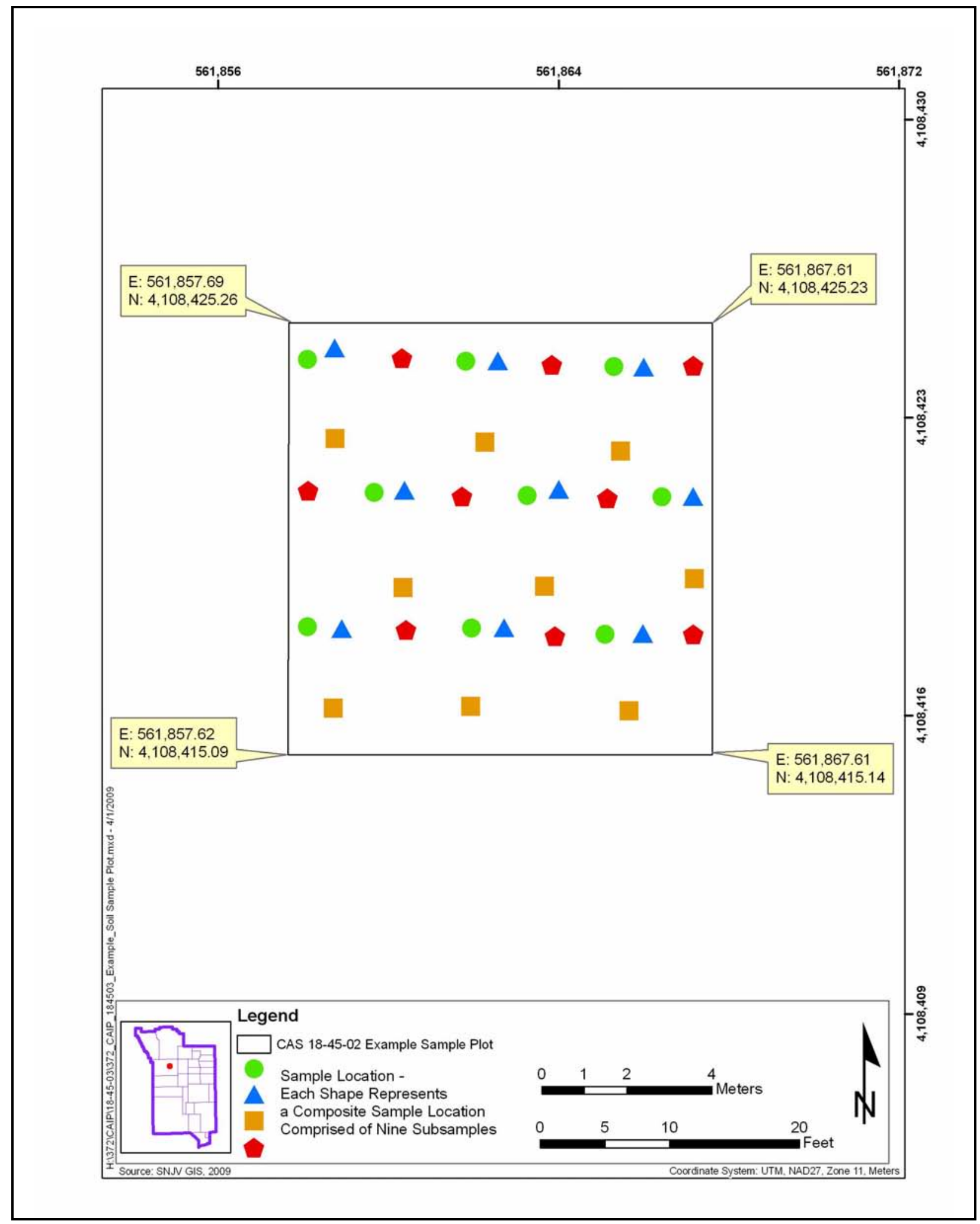

Figure A.9-1

Example Sample Plot 
Table A.9-1

Placement of Random Composite Sample Locations

\begin{tabular}{||c|c||}
\hline Type of sampling design & Ordinary - predetermined number of samples \\
\hline Sample aliquot placement (location) in the field & Systematic with a random start location \\
\hline Estimated initial number of sample aliquots & 9 \\
\hline Total number of composite samples per plot & $100 \mathrm{~m}^{2}$ \\
\hline Size of sample plot & Triangular \\
\hline Grid pattern & \\
\hline
\end{tabular}

beyond $1 \mathrm{ft}$. In addition, based on the result of this initial sampling, additional samples may be collected laterally based on the Site Supervisor's professional judgment and the result of the radiological screening.

\section{A.9.1.2 Decision II Sampling}

For Decision II at the CAU 372 CASs, three additional 100- $\mathrm{m}^{2}$ sample plots will be established along each of three vectors. The approximate proposed sampling vectors and sample plots are shown in Figures A.9-2 through A.9-5. Because there is high confidence that the FAL will be exceeded at the Decision I sample plot, Decision II sample plots will be located and sampled at the CAU 372 CASs during the initial field effort.

The area exceeding the FAL will be calculated using the 95 percent UCL TEDs from each plot along each vector. A relationship will be established of the measured dose with distance along each vector such that a point along each vector can be established that corresponds to the $25 \mathrm{mrem} / \mathrm{yr}$ FAL (see Figure C.3-1). To conservatively assure that this point will be beyond locations exceeding the FAL, the 95 percent UCL TEDs will be used as the estimate of dose for establishing the relationship of dose to distance. An isopleth from a radiological survey that encompasses the locations along each vector that correspond to the FAL will be chosen as the corrective action boundary. Any additional areas containing contamination exceeding the FAL (e.g., from the migration of contamination in drainages) will be added to the corrective action boundary. 


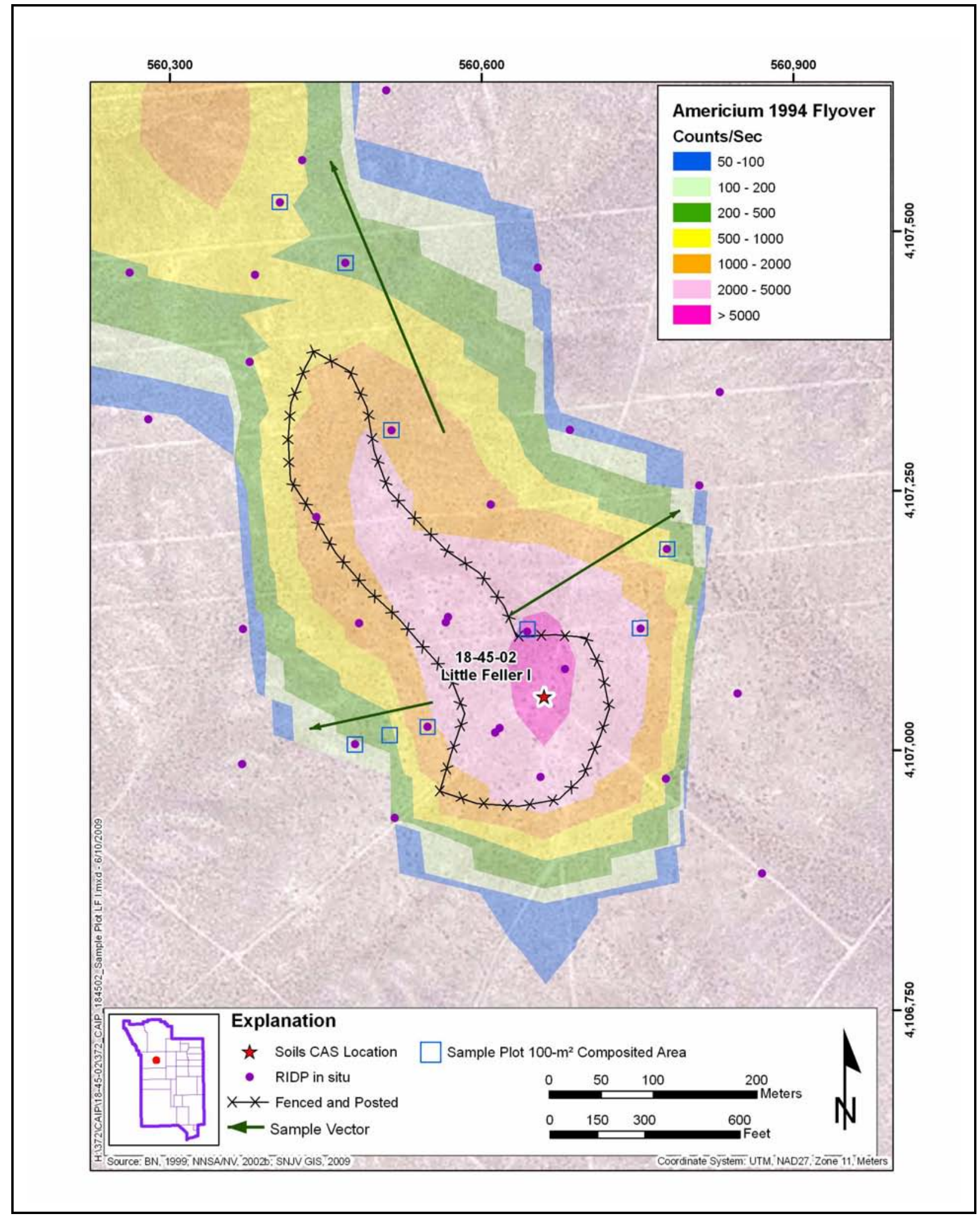

Figure A.9-2

Proposed Sample Locations at CAS 18-45-02, Little Feller I Surface Crater 


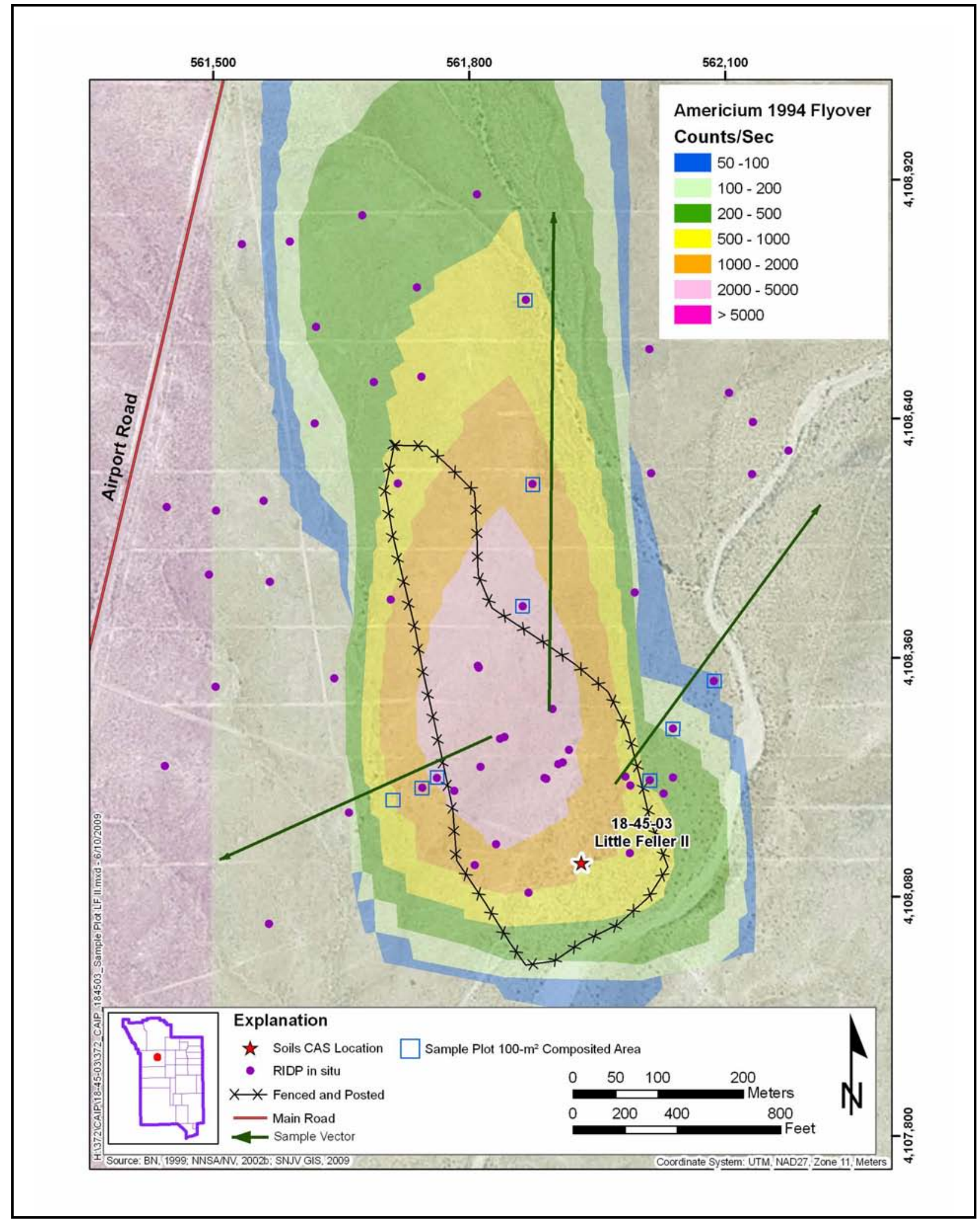

Figure A.9-3

Proposed Sample Locations at CAS 18-45-03, Little Feller II Surface Crater 


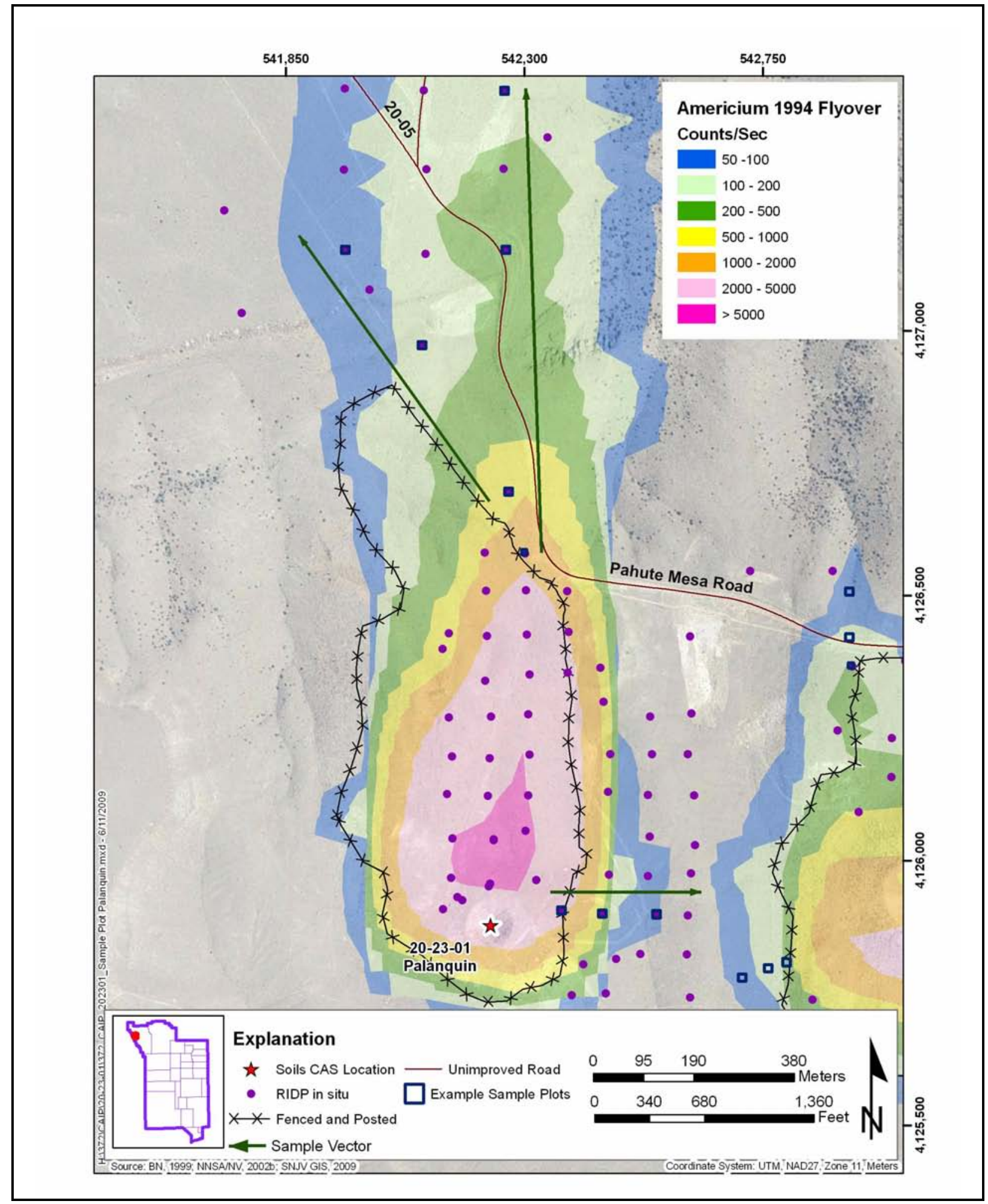

Figure A.9-4

Proposed Sample Locations at CAS 20-23-01, U-20k Contamination Area 


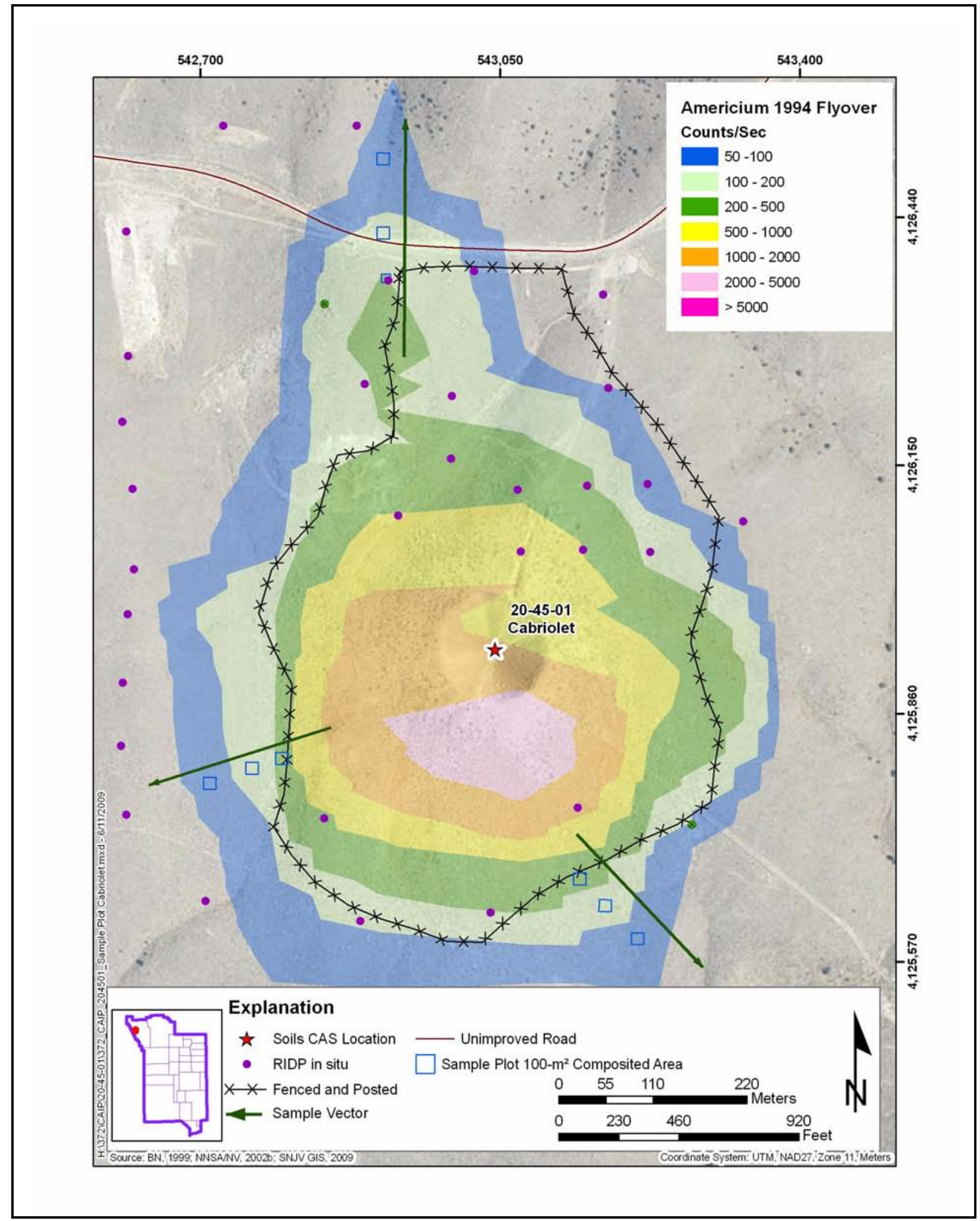

Figure A.9-5

Proposed Sample Locations at CAS 20-45-01, U-20L Crater (Cabriolet) 


\section{A.9.2 Non-Test Releases}

\section{A.9.2.1 Decision I}

A judgmental sampling approach will be implemented for the Decision I investigation of non-test releases at the CAU 372 CASs.

The investigation of non-test releases includes locations of potential chemical contamination identified during the CAI (i.e., debris, lead bricks, stains, areas with anomalous radiation survey readings) at all CASs.

If potential chemical contamination is identified, grab samples will be collected and submitted to the laboratory for analysis based on existing site information and site conditions discovered during the investigation. The following factors will be considered in selecting locations for analytical samples at CAU 372:

- Documented process knowledge on source and location of release (e.g., volume of release).

- Stains: Any spot or area on the soil surface that may indicate the presence of a potentially hazardous liquid. Typically, stains indicate an organic liquid (e.g., an oil) has reached the soil, and may have spread out vertically and horizontally

- Elevated radiation: Locations identified during radiological surveys that had alpha/beta/gamma levels significantly higher than surrounding background soil.

- Drums, containers, equipment, or debris: Materials of interest that may have been used at, or added to, a location, and that may have contained or come in contact with hazardous or radioactive substances at some point during their use.

- Visual indicators such as discoloration, textural discontinuities, disturbances of native soils, or other indications of potential contamination.

- Presence of PSM.

- Physical and chemical characteristics of contaminants.

- Other biasing factors: Factors not defined previously for the CAI that become evident once the investigation of the site is in progress. 


\section{A.9.2.2 Decision II}

To meet the DQI of representativeness, Decision II samples will be collected from locations that represent the population of interest as defined in Section A.6.1. Judgmental sampling locations at each CAS will be selected based on locations where COCs were detected, the CSM, and other field screening and biasing factors listed in Section A.5.2. In general, sample locations will be arranged in a triangular pattern around the area containing COCs; at distances based on site conditions, process knowledge, and biasing factors. If COCs extend beyond the initial step-outs, Decision II samples will be collected from incremental step-out locations. Initial step-out samples will be at least as deep as the vertical extent of contamination defined at the Decision I location and the depth of the incremental step-out samples will be based on the deepest contamination observed at all locations. A clean sample (i.e., COCs less than FALs) collected from each step-out direction (lateral or vertical) will define extent of contamination in that direction. The number, location, and spacing of step-out samples may be modified by the Site Supervisor, as warranted by site conditions, but only if the modified locations meet the decision needs and criteria stipulated in this DQO. 


\section{A.10.0 References}

ARL/SORD, see Air Resources Laboratory/Special Operations and Research Division.

Air Resources Laboratory/Special Operation and Research Division. 2007. "NTS Climatological

Rain Gauge Data, “as accessed at http://www.sord.nv.doe.gov/raingage/Monthly on

4 October 2008.

Air Resources Laboratory/Special Operations and Research Division. 2009. "NTS Climatological

Rain Gauge Data,” as accessed at http://www.sord.nv.doe.gov/raingage/Monthly on 18 February.

ASTM, see American Society for Testing and Materials.

American Society for Testing and Materials. 1995. Standard Guide for Risk-Based Corrective Action Applied at Petroleum Release Sites, ASTM E 1739-95 (Reapproved 2002). Philadelphia, PA.

BN, see Bechtel Nevada.

Bechtel Nevada. 1999. An Aerial Radiological Survey of the Nevada Test Site, DOE/NV/11718-324.

Prepared for U.S. Department of Energy, Nevada Operations Office. Las Vegas, NV: Remote

Sensing Laboratory.

DOE, see U.S. Department of Energy.

DOE/NV, see U.S. Department of Energy, Nevada Operations Office.

DRI, see Desert Research Institute.

Desert Research Institute. 1983. Radionuclide Inventory and Distribution Program: The Galileo Area, DOE/NV/10162-14. December. Las Vegas, NV: Desert Research Institute, University of Nevada System, Water Resources Center.

Desert Research Institute. 1985. Nevada Test Site Radionuclide Inventory and Distribution Program: Report \#2, Areas 2 and 4, DOE/NV/10162-20. Prepared by R.D. McArthur and J.F. Kordas. Las Vegas, NV.

Desert Research Institute. 1991. Hydrogeologic Summary for Groundwater Characterization Well ER-20-1 (Southwest Area 20). August. Las Vegas, NV: Water Resources Center.

Desert Research Institute. 1992. Letter to R. Smiecinski (DOE/NV) from R.D. McArthur (DRI) with attached document entitled, "An Estimate of the Amount of Land on the Nevada Test Site That is Contaminated to Greater Than 10 PCi/G of 239, 240Pu,” 31 July. Prepared by the Water Resources Center. 
Desert Research Institute. 2007. Radionuclide Inventory and Distribution Program (RIDP) Database, Rev. 2. April. Prepared by K. Gray, D.S. Shafer, K. Self, C. Martin, and R. McArthur. Las Vegas, NV.

EPA, see U.S. Environmental Protection Agency.

Essington, E.H. 1978. "Soil Radioactivity Distribution Studies for the Nevada Applied Ecology Group.” In: Selected Environmental Plutonium Research Reports of the NAEG, NVO-192. pp. 177-243. June. M.G. White, P.B. Dunaway, and D.L. Wireman, eds. Las Vegas, NV: U.S. Department of Energy, Nevada Operations Office.

Essington, E.H. 1981. Progress of Soil Radionuclide Distribution Studies for Nevada Applied Ecology Group - 1981, LA-UR-81-1585. Los Alamos, NM: Los Alamos Scientific Laboratory.

Essington, E.H. 1982. "Progress of Soil Radionuclide Distribution Studies for the Nevada Applied Ecology Group.” In: The Radioecology of Transuranics and Other Radionuclides in Desert Ecosystems, NVO-224. pp. 145-184. December. W.A. Howard, P.B. Dunaway, and R.G. Fuller, eds. Las Vegas, NV: U.S. Department of Energy, Nevada Operations Office.

Essington, E.H. 1985. "Soil Radionuclide Distribution Studies for the Nevada Applied Ecology Group-1981.” In: The Dynamics of Transuranics and Other Radionuclides in Natural Environments, NVO-272. pp. 123-195. December. W.A. Howard and R.G. Fuller, eds. Las Vegas, NV: U.S. Department of Energy, Nevada Operations Office.

Gilbert, R.O., E.H. Essington, D.N. Brady, P.G. Doctor, and L.L Eberhardt. 1977. "Statistical Activities During 1976 and the Design and Initial Analysis of Nuclear Site Studies.” In: Transuranics in Desert Ecosystems, NVO-181. pp. 331-366. November. Las Vegas, NV: U.S. Department of Energy, Nevada Operations Office.

Gilbert, R.O., J.C. Simpson, E.W. Engel, and R.R. Kinnison. 1985. “Estimating Isotopic Ratios, Spatial Distribution, and Inventory of Radionuclides at Nuclear Sites.” The Dynamics of Transuranics and Other Radionuclides in Natural Environments, NVO-272. pp. 381-429 December. W.A. Howard and R.G. Fuller, eds. Las Vegas, NV: U.S. Department of Energy, Nevada Operations Office.

LLNL, see Lawrence Livermore National Laboratory.

LRL, see Lawrence Radiation Laboratory.

Lee, K.D., and R.J. Straight. 1978. "Sequential Separation of Sr 90, Pu 239, and Am 241.” In: Selected Plutonium Research Reports of the NAEG, NVO-192. Nevada Applied Ecology Group. Vol. 1. pp. 315-318. Las Vegas, NV: U.S. Department of Energy, Nevada Operations Office. 
Lee, S.Y., T. Tamura, and I.L. Larsen. 1985. "Characterization of Nuclear Site 201 Soils from the Nevada Test Site.” In: The Dynamics of Transuranics and Other Radionuclides in Natural Environments, NVO-272. pp. 99-113. December. W.A. Howard and R.G. Fuller, eds. Las Vegas, NV: U.S. Department of Energy, Nevada Operations Office.

Lawrence Livermore National Laboratory. 1965. Gamma Fallout Fields, Project Palanquin. April. Livermore, CA.

Lawrence Livermore National Laboratory. 1993. Crater Stability Study Documentation. January. Livermore, CA.

Lawrence Radiation Laboratory. Date Unknown. Description of Craters, Nevada Test Site. Unknown. Livermore, CA.

Moore, J., Science Applications International Corporation. 1999. Memorandum to M Todd (SAIC) entitled, "Background Concentrations for NTS and TTR Soil Samples,” 3 February. Las Vegas, NV: IT Corporation.

Murphy, T., Bureau of Federal Facilities. 2004. Letter to R. Bangerter (NNSA/NSO) entitled, "Review of Industrial Sites Project Document Guidance for Calculating Industrial Sites Project Remediation Goals for Radionuclides in Soil Using the Residual Radiation (RESRAD) Computer Code," 19 November. Las Vegas, NV.

NAC, see Nevada Administrative Code.

NBMG, see Nevada Bureau of Mines and Geology.

NCRP, see National Council on Radiation Protection and Measurements.

NNSA/NSO, see U.S. Department of Energy, National Nuclear Security Administration Nevada Site Office.

NNSA/NV, see U.S. Department of Energy, National Nuclear Security Administration Nevada Operations Office.

National Council on Radiation Protection and Measurements. 1999. Recommended Screening Limits for Contaminated Surface Soil and Review of Factors Relevant to Site-Specific Studies, NCRP Report No. 129. Bethesda, MD.

Nevada Administrative Code. 2006a. NAC 445A.227, “Contamination of Soil: Order by Director for Corrective Action; Factors To Be Considered in Determining Whether Corrective Action Required.” Carson City, NV. As accessed at http://www.leg.state.nv.us/nac on 22 October 2008.

Nevada Administrative Code. 2006b. NAC 445A.22705, “Contamination of Soil: Evaluation of Site by Owner or Operator; Review of Evaluation by Division.” Carson City, NV. As accessed at http://www.leg.state.nv.us/nac on 22 October 2008. 
Nevada Administrative Code. 2006c. NAC 445A.2272, "Contamination of Soil: Establishment of Action Levels.” Carson City, NV. As accessed at http://www.leg.state.nv.us/nac on 22 October 2008.

Nevada Bureau of Mines and Geology. 1998. Mineral and Energy Resource Assessment of the Nellis Air Force Range, Open-File Report 98-1. Reno, NV.

SNJV GIS, see Stoller-Navarro Joint Venture Geographic Information Systems. 2009. ESRI ArcGIS Software.

Slate, J.L., M.E. Berry, P.D. Rowley, C.J. Fridrich, K.S Morgan, J.B. Workman, O.D. Young, G.L. Dixon, V.S. Williams, E.H. McKee, D.A. Ponce, T.G. Hildenbrand, W.C. Swadley, S.C. Lundstrom, E.B. Ekren, R.G. Warren, J.C. Cole, R.J. Fleck, M.A. Lanphere, D.A. Sawyer, S.A. Minor, D.J. Grunwald, R.J. Laczniak, C.M. Menges, J.C. Yount, and A.S. Jayko. 1999. Part A. Digital Geologic Map of the Nevada Test Site and Vicinity, Nye, Lincoln, and Clark Counties, Nevada and Inyo County California, Revision 4. Open-file Report 99-554-A, scale 1:120,000. Denver, CO: U.S. Geological Survey.

Stoller-Navarro Joint Venture Geographic Information Systems.

Shott, G.J., V. Yucel, M.J. Sully, L.E. Barker, S.E. Rawlinson, and B.A. Moore. 1997. Performance Assessment/Composite Analysis for the Area 3 Radioactive Waste Management Site at the Nevada Test Site, Nye County, Nevada, Rev. 2.0. Las Vegas, NV.

Stoller-Navarro Joint Venture Geographic Information Systems. 2009. ESRI ArcGIS Software.

Tamura, T. 1977. Plutonium Distribution in a Desert Pavement-Desert Mound Soil System in Area 11. In: Environmental Plutonium on the Nevada Test Site and Environs, NVO-171. June. Nevada Applied Ecology Group. Las Vegas, NV: U.S. Energy Research and Development Administration.

USGS, see U.S Geological Survey.

U.S. Geological Survey and U.S. Department of Energy.

U.S. Department of Energy. 1993. Radiation Protection of the Public and the Environment, DOE Order 5400.5, Change 2. Washington, DC: U.S. Government Printing Office.

U.S. Department of Energy, National Nuclear Security Administration Nevada Operations Office. 2002a. Industrial Sites Quality Assurance Project Plan, Nevada Test Site, Nevada, Rev. 3, DOE/NV--372. Las Vegas, NV.

U.S. Department of Energy, National Nuclear Security Administration Nevada Operations Office. 2002b. Nevada Test Site Orthophoto Site Atlas, DOE/NV/11718--604. Prepared by Bechtel Nevada. Las Vegas, NV. 
U.S. Department of Energy, National Nuclear Security Administration Nevada Site Office. 2006. Industrial Sites Project Establishment of Final Action Levels, Rev. 0, DOE/NV--1107. Las Vegas, NV.

U.S. Department of Energy, Nevada Operations Office. 1992. Remedial Investigation and Feasibility Study for the Plutonium Contaminated Soils at Nevada Test Site, Nellis Air Force Range and Tonopah Test Range. April. Las Vegas, NV.

U.S. Department of Energy, Nevada Operations Office. 1997. Performance Assessment/Composite Analysis for the Area 3 Radioactive Waste Management Site at the Nevada Test Site, Nye County, Nevada, Rev. 2.0. September. Las Vegas, NV.

U.S. Department of Energy, Nevada Operations Office. 1998. Nevada Test Site Resource Management Plan. DOE/NV-518, Las Vegas, NV.

U.S. Environmental Protection Agency. 2002. Guidance for Quality Assurance Project Plans, EPA QA/G5. Washington, DC.

U.S. Environmental Protection Agency. 2006a. Data Quality Assessment: Statistical Methods for Practitioners, EPA QA/G-9S. Washington, DC.

U.S. Environmental Protection Agency. 2006b. Guidance on Systematic Planning Using the Data Quality Objectives Process, EPA QA/G-4. Washington, DC.

U.S. Environmental Protection Agency. 2008. Region 9: Superfund, Preliminary Remediation Goals, Screening Levels for Chemical Contaminants. As accessed at http://www.epa.gov/region09/waste/sfund/prg/index.html on 15 May. Prepared by EPA Office of Superfund and Oak Ridge National Laboratory.

U.S. Geological Survey. 2007. “Rock-Property Information from the Core Library and Data Center at Mercury and Nevada Water Science Center Office in Henderson, Nevada; Rock-Property Database.” As accessed at http://nevada.usgs.gov/mercury/rock.html on 9 October 2008. Mercury, NV.

U.S Geological Survey, 2008. “Data Repository.” As accessed at http://seamless.usgs.gov on 4 October.

U.S. Geological Survey and U.S. Department of Energy. 2008. “USGS/USDOE Cooperative Studies in Nevada; Water-Level Wells, Nevada Test Site.” As accessed at http://nevada.usgs.gov/doe_nv/ntsmap.htm on 4 October. 


\section{Appendix B}

\section{Project Organization}




\section{B.1.0 Project Organization}

The NNSA/NSO Acting Federal Sub-Project Director is Kevin Cabble. He can be contacted at (702) 295-5000.

The identification of the project Health and Safety Officer and the Quality Assurance Officer can be found in the appropriate plan. However, personnel are subject to change, and it is suggested that the DOE Federal Sub-Project Director be contacted for further information. The Task Manager will be identified in the FFACO Monthly Activity Report before the start of field activities. 


\section{Appendix C}

\section{Determination of the Number and Location of Random Samples}




\section{C.1.0 Probabilistic Sampling Plan}

\section{C.1.1 Purpose}

This appendix describes the probabilistic sampling plan used to generate information needed to resolve the two DQO decisions for the investigation of atmospheric distributions. For both Decision I and Decision II, information is needed on the TED at each plot (i.e., the sample TED from all contributing radionuclides present within the sample plot). For Decision II, information is also needed to identify the location along each vector that corresponds to a 25-mrem/yr dose. 


\section{C.2.0 Computation of Total Effective Dose Equivalent}

Determination of the radiological dose (i.e., TED) at each sample plot requires evaluating, with a specified degree of confidence, whether the true TED for the sample plot exceeds the 25-mrem/yr FAL. The TED calculated from the results of composited samples at each plot (i.e., the average TED, comprised of TEDs calculated from individual, composited samples) combined with the external dose measurements is an estimation of the true TED at the plot location. The average TED calculated from sample results and external dose measurements is only an estimate of the true (unknown) TED. It is uncertain how well the average TED actually represents the true TED. If an average TED was directly compared to the FAL, any significant difference between the true TED and the sample TED could lead to decision errors. To reduce the probability of making a false negative decision error (thus increasing the probability of making a false positive decision error), a conservative estimate of the true TED is used to compare the FAL. This conservative estimate (overestimation) of the true TED will be calculated as the 95 percent UCLs of the average TED calculated from the respective individual TEDs associated with each composite sample. By definition, there will be a 95 percent probability that the true TED is less than the 95 percent UCL of the calculated average TED.

\section{C.2.1 Computation of the Upper Confidence Limit}

The computation of appropriate UCLs depends upon the data distribution, the number of samples, the variability of the dataset, and skewness associated with the dataset. Statistical methods consistent with EPA methodologies (EPA, 2006) will be used to:

- Determine the appropriate probability distribution (e.g., normal, lognormal, gamma) and/or a suitable nonparametric distribution-free method.

- $\quad$ Test for outliers.

- $\quad$ Compute appropriate UCLs.

To ensure that the appropriate UCL computational method is used, the sample data will be tested for goodness-of-fit to all of the parametric and nonparametric UCL computation methods described in Office of Solid Waste and Emergency Response EPA guidelines (EPA, 2002). 
A UCL of the TED will be calculated for each plot. Computation of an appropriate UCL for the TED requires that:

- A minimum number of samples be collected from random locations at each site.

- The data originate from a population that fits a modeled distribution.

- The estimation of the variability is reasonable and representative of the population being sampled.

- The population values are not temporally or spatially correlated.

\section{C.2.2 Sample Size}

A minimum number of samples (i.e., composite samples) is required to compute a UCL. This number will be calculated from the individual TEDs associated with each of the four composite samples from each plot. The Visual Sample Plan (VSP) software will be used to calculate minimum sample sizes (PNNL, 2005). This software was developed by Pacific Northwest National Laboratory for the DOE and EPA to determine the minimum number of samples needed to characterize a site based on the type of test to be performed, the distribution of the data, the variability of the data, and the acceptable false positive and false negative error rates.

The input parameters to be used in calculating the minimum sample size are:

- A confidence level that a false negative error will not occur will be set at 95 percent.

- A confidence level that a false positive error will not occur will be set at 80 percent.

- A gray region width of 50 percent of the FAL (25 mrem/yr).

- The average TED at each plot.

- The standard deviation of the TEDs at each plot.

Because the minimum number of composite samples needed to perform the UCL comparison tests cannot be determined until after investigation results are obtained, the number of composite samples to be collected during the CAI must be estimated. The initial number of composite samples was estimated to be four from each plot. 
If the criteria established in this section results in a determination that the minimum sample size was not met for any plot, one of the following actions may be taken:

- Additional samples may be collected.

- It may be conservatively assumed that the average TED for the plot exceeds the FAL.

- Justification for use of the resulting average TED without meeting the criteria will be made in the investigation report.

\section{C.2.3 Sample Location Selection}

The location of initial CAI samples which comprise each composite sample will be determined using the VSP software. The software was constrained to nine sample locations on a random-start, systematic, triangular grid pattern with a random starting location. If it is determined that additional composite samples need to be collected, based on the determination of minimum sample size using actual composite sample results, additional sample locations will be determined using the same methodology.

Values/settings used in VSP for the computation of the composite sample locations for each of the sample plots (i.e., 3 plots on 3 vectors) are listed in Table C.2-1. An example of 4 sets (9 locations per set/composite) of sample location coordinates is also listed in Table C.2-1.

Table C.2-1

VSP Placement of Random Composite Sample Locations

\begin{tabular}{||c|c|}
\hline Primary objective of design & Nonstatistical \\
\hline Type of sampling design & Ordinary-predetermined number of samples \\
\hline Sample placement (location) in the field & Systematic with a random start location \\
\hline Estimated initial number of samples & 9 \\
\hline Size of sample plot & $100 \mathrm{~m}^{2}$ \\
\hline Grid pattern & Triangular \\
\hline
\end{tabular}




\section{C.3.0 Computation of the Area Exceeding the FAL}

The area exceeding the FAL will be calculated using the 95 percent UCL TEDs from each plot along each vector. A relationship will be established of the measured dose with distance along each vector such that a point along each vector can be established that corresponds to the $25 \mathrm{mrem} / \mathrm{yr}$ FAL

(Figure C.3-1). To conservatively assure that this point will be beyond locations exceeding the FAL, the 95 percent UCL TEDs will be used as the estimate of dose for establishing the relationship of dose to distance. An isopleth from a radiological survey that encompasses the locations along each vector that correspond to the FAL will be chosen as the corrective action boundary. Any additional areas containing contamination exceeding the FAL (e.g., from the migration of contamination in drainages) will be added to the corrective action boundary.

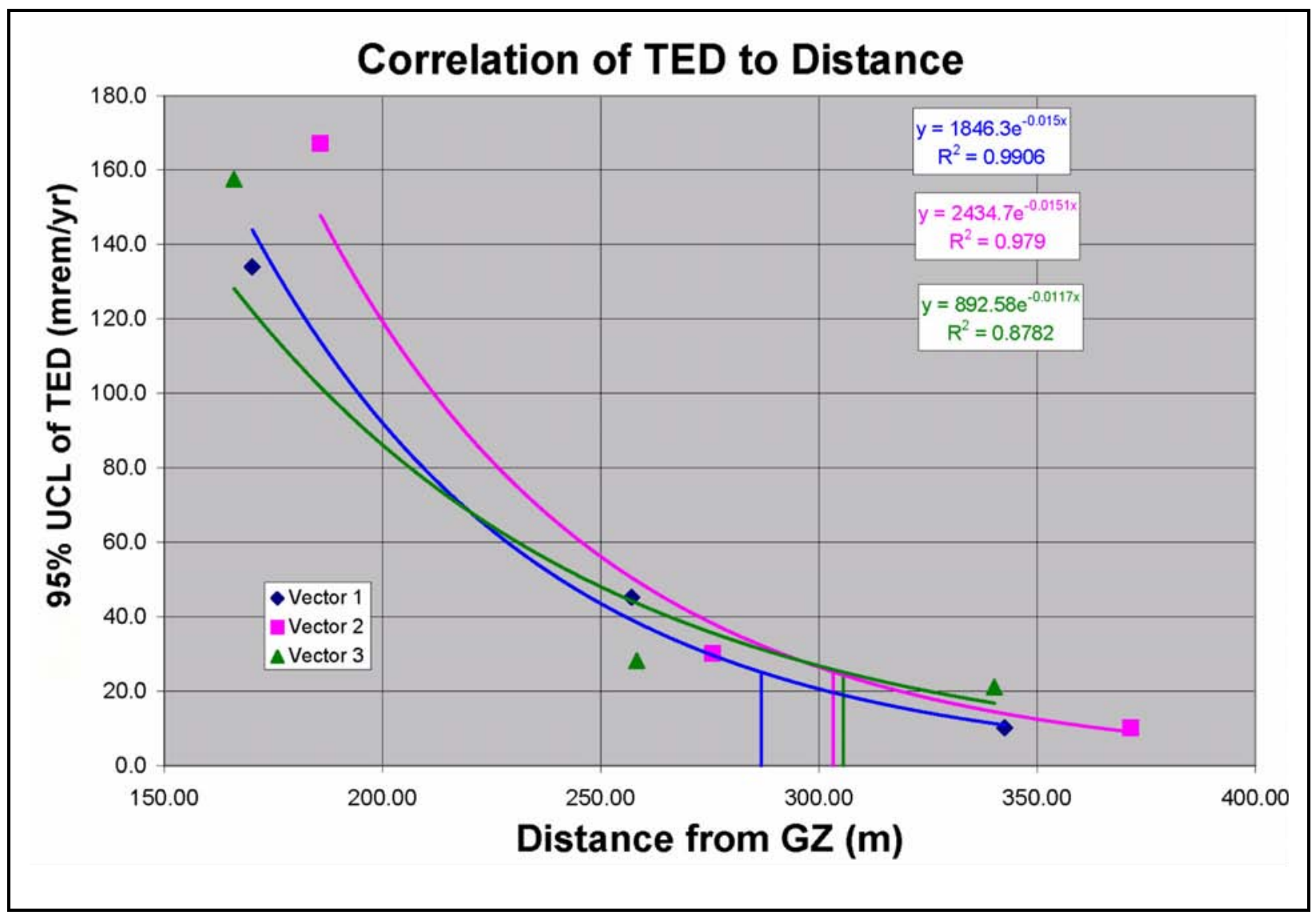

Figure C.3-1

Correlation of TED to Distance

(Formula for lines [y-values] and regression coefficients [R-values] are used as examples) 


\section{C.4.0 References}

BN, see Bechtel Nevada.

Bechtel Nevada. 1999. An Aerial Radiological Survey of the Nevada Test Site, DOE/11718-324. Prepared for U.S. Department of Energy, Nevada Operations Office. Nellis Air Force Base, NV: Remote Sensing Laboratory.

EPA, see U.S. Environmental Protection Agency.

PNNL, see Pacific Northwest National Laboratory.

Pacific Northwest National Laboratory. 2005. Visual Sample Plan, Version 4.0 User's Guide, PNNL-15247. Richland, WA.

U.S. Environmental Protection Agency. 2002. Calculating Upper Confidence Limits for Exposure Point Concentrations at Hazardous Waste Sites, OSWER 9285.6-10. December.

Washington, DC: Office of Solid Waste and Emergency Response.

U.S. Environmental Protection Agency. 2006. Data Quality Assessment: Statistical Methods for Practitioners, EPA QA/G-9S. Washington, DC. 


\title{
Appendix D
}

\section{Nevada Division of Environmental Protection Comment Responses}

\author{
(9 Pages)
}




\section{NEVADA ENVIRONMENTAL RESTORATION PROJECT \\ DOCUMENT REVIEW SHEET}

\begin{tabular}{|c|c|c|c|c|c|c|}
\hline \multicolumn{2}{|c|}{ 1. Document Title/Number: } & \multicolumn{2}{|c|}{$\begin{array}{l}\text { Draft Corrective Action Investigation Plan for Corrective Action Unit 372: Area } 20 \\
\text { Cabriolet/Palanquin Unit Craters, Nevada Test Site, Nevada }\end{array}$} & \multirow{2}{*}{\begin{tabular}{|l|} 
2. Document Date: \\
4. Originator/Organization:
\end{tabular}} & \multicolumn{2}{|l|}{$4 / 17 / 2009$} \\
\hline \multicolumn{2}{|l|}{ 3. Revision Number: } & \multicolumn{2}{|l|}{0} & & \multicolumn{2}{|l|}{ Stoller-Navarro } \\
\hline \multicolumn{2}{|c|}{$\begin{array}{l}\text { 5. Responsible NNSA/NSO Federal } \\
\text { Sub-Project Director: }\end{array}$} & \multicolumn{2}{|l|}{ Kevin J. Cabble } & 6. Date Comments Due: & \multicolumn{2}{|l|}{$5 / 18 / 2009$} \\
\hline \multicolumn{2}{|l|}{ 7. Review Criteria: } & \multicolumn{2}{|l|}{ Full } & & & \\
\hline \multicolumn{2}{|c|}{ 8. Reviewer/Organization/Phone No: } & : Jeff MacDougall, NDEP, 486-2850, ext. 233 & & 9. Reviewer's Signature: & & \\
\hline \begin{tabular}{|l|} 
10. Comment \\
Number/Location
\end{tabular} & 11. Type* & 12. Comment & \multicolumn{3}{|c|}{ 13. Comment Response } & 14. Accept \\
\hline 1.) General & Mandatory & $\begin{array}{l}\text { The document uses the term Total Effective Dose (TED). } \\
\text { During a recent discussion of the CAU } 370 \text { CADD/CR the } \\
\text { term TED was replaced with TED Equivalent (TEDE) for a } \\
\text { technical reason. Does this same reason apply to CAU } \\
372 \text { and if so, should the term TEDE be used throughout } \\
\text { the document instead of TED? Does Appendix C need } \\
\text { modification? }\end{array}$ & \multicolumn{3}{|c|}{$\begin{array}{l}\text { The reviewer is correct in that there is a difference in terms } \\
\text { between CAU } 370 \text { and CAU } 372 \text {. The term TEDE is not } \\
\text { being used in CAU } 372 \text {, and the dose is now referred to as } \\
\text { TED. Although the term TEDE has previously been used, } \\
10 \text { CFR Part } 835 \text { was revised in June } 2007 \text {. The revision } \\
\text { incorporated new terminology for internal and external } \\
\text { dosimetry, including a transition from the term TEDE to the } \\
\text { term TED. In order to reflect the most current terminology } \\
\text { contained within } 10 \text { CFR Part } 835 \text {, future soils CAUs, } \\
\text { including CAU } 372 \text {, will use the term TED. }\end{array}$} & \\
\hline 2.) General & Mandatory & $\begin{array}{l}\text { Section C.2.0 states that the ProUCL statistical package } \\
\text { will be used for statistical analysis. Section A.3.5 } \\
\text { Deviations bullet item } 6 \text { of the CAU } 370 \text { CADD/CR } \\
\text { mentions that, instead of the ProUCL software, the } \\
\text { statistical formulas in the EPA } 2006 \text { publication Data } \\
\text { Assessment Methods for Practitioners were used to } \\
\text { compute the UCL. Please specify which method will be } \\
\text { used for calculating UCLs for CAU } 372 \text {. }\end{array}$ & \multicolumn{3}{|c|}{$\begin{array}{l}\text { The statistical analysis for CAU } 372 \text { will adhere to the EPA } \\
2006 \text { publication Data Quality Assessment: Statistical } \\
\text { Methods for Practitioners to compute the UCL. The text in } \\
\text { Section C.2.1, first paragraph, second sentence, has been } \\
\text { changed to read, "Statistical methods consistent with EPA } \\
\text { methodologies (EPA, 2006a) will be used to..." }\end{array}$} & \\
\hline 3.) Table 2-1 & Mandatory & $\begin{array}{l}\text { This is an excellent table. Is this just based on } 5 \text { years of } \\
\text { data? Twenty-five or more years would appear to be more } \\
\text { appropriate. Please clarify. }\end{array}$ & \multicolumn{3}{|c|}{$\begin{array}{l}\text { Precipitation data for Area } 18 \text { (Little Feller II rain gauge) } \\
\text { has been updated in Table } 2-1 \text { and in text throughout the } \\
\text { document to include data from } 1977 \text { to } 2008 \text {. Precipitation } \\
\text { data for Area } 20 \text { (Pahute Mesa rain gauge) has been } \\
\text { updated in Table } 2-1 \text { and in text throughout the document } \\
\text { to include data from } 1964 \text { to } 2008 \text {. Potential } \\
\text { evapotranspiration data has not been edited, as all } \\
\text { available data on PET has already been presented in the } \\
\text { CAIP. }\end{array}$} & \\
\hline
\end{tabular}




\section{NEVADA ENVIRONMENTAL RESTORATION PROJECT}

DOCUMENT REVIEW SHEET

\begin{tabular}{|c|c|c|c|c|c|c|}
\hline \multicolumn{2}{|c|}{ 1. Document Title/Number: } & \multicolumn{2}{|c|}{$\begin{array}{l}\text { Draft Corrective Action Investigation Plan for Corrective Action Unit 372: Area } 20 \\
\text { Cabriolet/Palanquin Unit Craters, Nevada Test Site, Nevada }\end{array}$} & \multirow{2}{*}{\begin{tabular}{|l|} 
2. Document Date: \\
4. Originator/Organization:
\end{tabular}} & \multicolumn{2}{|l|}{$4 / 17 / 2009$} \\
\hline \multicolumn{2}{|l|}{ 3. Revision Number: } & \multicolumn{2}{|l|}{0} & & \multicolumn{2}{|l|}{ Stoller-Navarro } \\
\hline \multicolumn{2}{|c|}{$\begin{array}{l}\text { 5. Responsible NNSA/NSO Federal } \\
\text { Sub-Project Director: }\end{array}$} & \multicolumn{2}{|l|}{ Kevin J. Cabble } & 6. Date Comments Due: & \multicolumn{2}{|l|}{$5 / 18 / 2009$} \\
\hline \multicolumn{2}{|l|}{ 7. Review Criteria: } & \multicolumn{2}{|l|}{ Full } & & & \\
\hline \multicolumn{2}{|c|}{ 8. Reviewer/Organization/Phone No: } & Jeff MacDougall, NDEP, 486-2850, ext. 233 & & 9. Reviewer's Signature: & & \\
\hline $\begin{array}{l}\text { 10. Comment } \\
\text { Number/Location }\end{array}$ & 11. Type* & 12. Comment & \multicolumn{3}{|c|}{ 13. Comment Response } & 14. Accept \\
\hline $\begin{array}{l}\text { 4.) Section 2.5.2, } \\
\text { 1st Paragraph, } \\
\text { 1st Sentence }\end{array}$ & Mandatory & $\begin{array}{l}\text { Typo - ...of } 2,000 \text { at } 5,000 \mathrm{cps} . . . \text { should read } \ldots 2,000 \text { to } \\
5,000 \mathrm{cps} \ldots\end{array}$ & \multicolumn{3}{|c|}{$\begin{array}{l}\text { Section } 2.5 .2, " 2,000 \text { at } 5,000 \text { " has been changed to read, } \\
\text { "2,000 to } 5,000 . "\end{array}$} & \\
\hline
\end{tabular}


NEVADA ENVIRONMENTAL RESTORATION PROJECT

DOCUMENT REVIEW SHEET

\begin{tabular}{|c|c|c|c|c|c|c|}
\hline \multicolumn{2}{|c|}{ 1. Document Title/Number: } & \multicolumn{2}{|c|}{$\begin{array}{l}\text { Draft Corrective Action Investigation Plan for Corrective Action Unit 372: Area } 20 \\
\text { Cabriolet/Palanquin Unit Craters, Nevada Test Site, Nevada }\end{array}$} & \multirow{2}{*}{$\begin{array}{l}\text { 2. Document Date: } \\
\text { 4. Originator/Organization: }\end{array}$} & \multicolumn{2}{|l|}{$4 / 17 / 2009$} \\
\hline \multicolumn{2}{|l|}{ 3. Revision Number: } & 0 & & & \multicolumn{2}{|l|}{ Stoller-Navarro } \\
\hline \multicolumn{2}{|c|}{$\begin{array}{l}\text { 5. Responsible NNSA/NSO Federal } \\
\text { Sub-Project Director: }\end{array}$} & Kevin J. Cabble & & 6. Date Comments Due: & \multicolumn{2}{|l|}{$5 / 18 / 2009$} \\
\hline \multicolumn{2}{|l|}{ 7. Review Criteria: } & Full & & & & \\
\hline \multicolumn{2}{|c|}{ 8. Reviewer/Organization/Phone No: } & Jeff MacDougall, NDEP, 486-2850, ext. 233 & & 9. Reviewer's Signature: & & \\
\hline $\begin{array}{l}\text { 10. Comment } \\
\text { Number/Location }\end{array}$ & 11. Type* & 12. Comment & \multicolumn{3}{|c|}{ 13. Comment Response } & 14. Accept \\
\hline $\begin{array}{l}\text { 5.) Section } \\
\text { 3.1.4.2, 2nd } \\
\text { Paragraph }\end{array}$ & Mandatory & $\begin{array}{l}\text { This seems to provide justification for the need of an } \\
\text { updated flyover analysis... has it been determined to what } \\
\text { level of detail the washes will be investigated? }\end{array}$ & \multicolumn{3}{|c|}{ 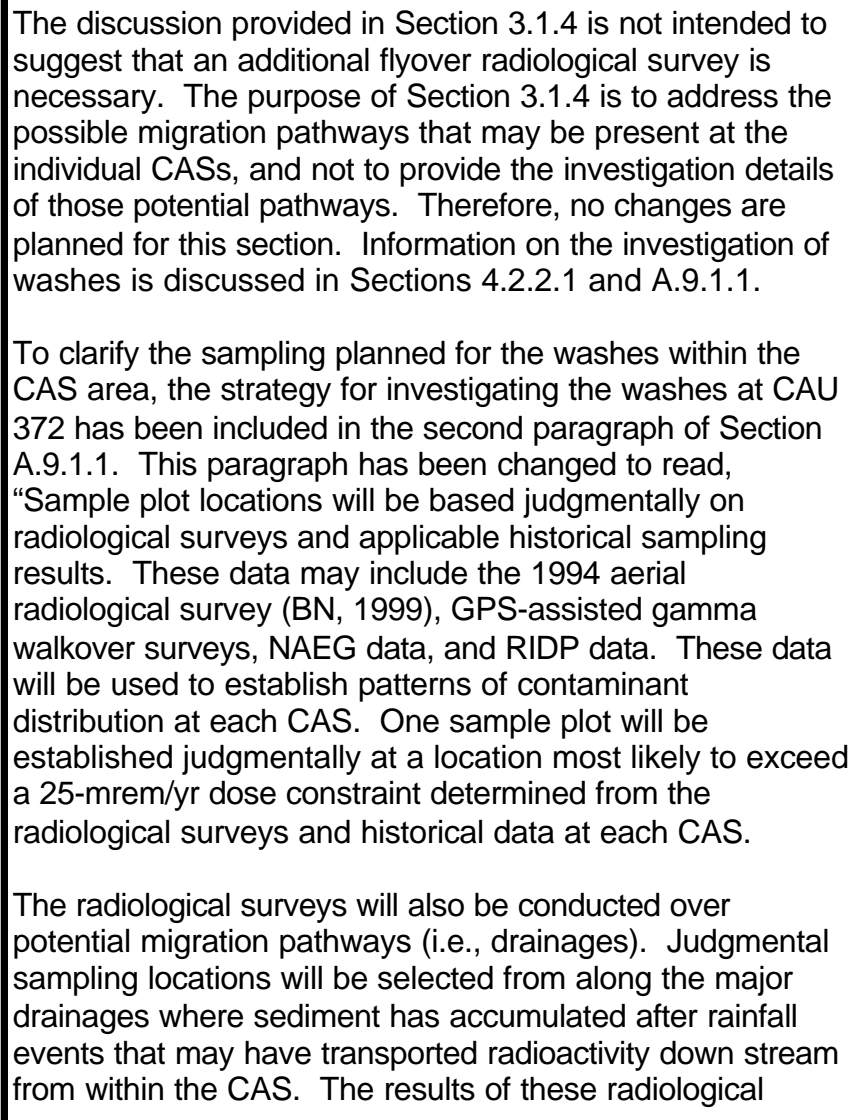 } & \\
\hline
\end{tabular}


NEVADA ENVIRONMENTAL RESTORATION PROJECT

DOCUMENT REVIEW SHEET

\begin{tabular}{|c|c|c|c|c|c|c|}
\hline \multicolumn{2}{|c|}{ 1. Document Title/Number: } & \multicolumn{2}{|c|}{$\begin{array}{l}\text { Draft Corrective Action Investigation Plan for Corrective Action Unit 372: Area } 20 \\
\text { Cabriolet/Palanquin Unit Craters, Nevada Test Site, Nevada }\end{array}$} & \multirow{2}{*}{\begin{tabular}{|l|} 
2. Document Date: \\
4. Originator/Organization: \\
\end{tabular}} & \multicolumn{2}{|l|}{$4 / 17 / 2009$} \\
\hline \multicolumn{2}{|l|}{ 3. Revision Number: } & \multicolumn{2}{|l|}{0} & & \multicolumn{2}{|l|}{ Stoller-Navarro } \\
\hline \multicolumn{2}{|c|}{$\begin{array}{l}\text { 5. Responsible NNSA/NSO Federal } \\
\text { Sub-Project Director: }\end{array}$} & \multicolumn{2}{|l|}{ Kevin J. Cabble } & 6. Date Comments Due: & \multicolumn{2}{|l|}{$5 / 18 / 2009$} \\
\hline \multicolumn{2}{|l|}{ 7. Review Criteria: } & \multirow{2}{*}{\multicolumn{2}{|c|}{\begin{tabular}{|l|} 
Full \\
Jeff MacDougall, NDEP, 486-2850, ext. 233
\end{tabular}}} & & & \\
\hline \multicolumn{2}{|c|}{ 8. Reviewer/Organization/Phone No: } & & & 9. Reviewer's Signature: & & \\
\hline \multirow[t]{2}{*}{$\begin{array}{l}\text { 10. Comment } \\
\text { Number/Location }\end{array}$} & 11. Type* & 12. Comment & \multicolumn{3}{|c|}{ 13. Comment Response } & 14. Accept \\
\hline & Mandatory & & \multicolumn{3}{|c|}{$\begin{array}{l}\text { surveys and existing historical data will be used to } \\
\text { determine the need for additional sample plots along these } \\
\text { potential migration pathways." } \\
\text { The following has been added as the last paragraph in } \\
\text { Section A.9.1.1: "In addition to the plot sampling, } \\
\text { soil/sediment samples will be collected from sediment } \\
\text { accumulation areas in the drainages that provide major } \\
\text { migration pathways from the site. These biased locations } \\
\text { will be identified based on the results of radiological survey } \\
\text { and visual identification of areas of sediment } \\
\text { accumulation. Initially samples will be collected from two of } \\
\text { the largest sediment traps identified to be outside the } \\
\text { estimated 25-mrem/yr boundary. Each sediment location } \\
\text { will be sampled in 5-cm lifts throughout the entire thickness } \\
\text { of the sediment up to a thickness of two feet. If the } \\
\text { thickness of the sediments exceeds two feet the sampling } \\
\text { interval may be increased based on the field screening } \\
\text { results and the Site Supervisor's judgment. The intervals } \\
\text { should not be increased beyond } 1 \text { foot. In addition, based } \\
\text { on the result of this initial sampling, additional samples may } \\
\text { be collected laterally based on the Site Supervisor's } \\
\text { professional judgment and the result of the radiological } \\
\text { screening." } \\
\text { The following has been added as the last paragraph in } \\
\text { Section 4.2.2.1: "In addition to the probabilistic sampling, } \\
\text { biased samples will be collected from the drainages that } \\
\text { transect the sites. These samples will be located based on } \\
\text { radiological walkover data and visual evidence of sediment } \\
\text { accumulation." }\end{array}$} & \\
\hline
\end{tabular}




\section{NEVADA ENVIRONMENTAL RESTORATION PROJECT DOCUMENT REVIEW SHEET}

\begin{tabular}{|c|c|c|c|c|c|c|}
\hline \multicolumn{2}{|c|}{ 1. Document Title/Number: } & \multicolumn{2}{|c|}{$\begin{array}{l}\text { Draft Corrective Action Investigation Plan for Corrective Action Unit 372: Area } 20 \\
\text { Cabriolet/Palanquin Unit Craters, Nevada Test Site, Nevada }\end{array}$} & \multirow{2}{*}{\begin{tabular}{|l|} 
2. Document Date: \\
4. Originator/Organization:
\end{tabular}} & \multicolumn{2}{|l|}{$4 / 17 / 2009$} \\
\hline \multicolumn{2}{|l|}{ 3. Revision Number: } & \multicolumn{2}{|l|}{0} & & \multicolumn{2}{|l|}{ Stoller-Navarro } \\
\hline \multicolumn{2}{|c|}{$\begin{array}{l}\text { 5. Responsible NNSA/NSO Federal } \\
\text { Sub-Project Director: }\end{array}$} & \multicolumn{2}{|l|}{ Kevin J. Cabble } & 6. Date Comments Due: & \multicolumn{2}{|l|}{$5 / 18 / 2009$} \\
\hline \multicolumn{2}{|l|}{ 7. Review Criteria: } & \multicolumn{2}{|l|}{ Full } & & & \\
\hline \multicolumn{2}{|c|}{ 8. Reviewer/Organization/Phone No: } & Jeff MacDougall, NDEP, 486-2850, ext. 233 & & 9. Reviewer's Signature: & & \\
\hline $\begin{array}{l}\text { 10. Comment } \\
\text { Number/Location }\end{array}$ & 11. Туре* & 12. Comment & \multicolumn{3}{|c|}{ 13. Comment Response } & 14. Accept \\
\hline 6.) General & Mandatory & $\begin{array}{l}\text { In setting the } 25 \text { mrem/yr boundary, which is used: is it the } \\
\text { last isopleth boundary, with a }>25 \mathrm{mrem} / \mathrm{yr} \text { value? Or, is it } \\
\text { the first isopleth outer boundary, with a }<25 \text { mrem/yr } \\
\text { value? Please clarify. } \\
\text { Follow-up clarification requested on June } 9,2009 \text {. I was } \\
\text { looking for more of the explanation that was given in the } \\
\text { recent presentation in our offices. Basically verifying my } \\
\text { assumption below. Since a relatively small area of each } \\
\text { isopleth is being sampled they are taking a linear } \\
\text { extrapolation for each vector to determine the } 25 \text { mrem/yr } \\
\text { points. Then use the outer boundary of the isopleth } \\
\text { containing those points as the CAS boundary. The } \\
\text { extrapolated points and not the sample plots are the } \\
\text { decision-info used to define the boundary. }\end{array}$ & \multicolumn{3}{|c|}{$\begin{array}{l}\text { To clarify the process to be used to establish the corrective } \\
\text { action boundary, the second and third paragraphs, and } \\
\text { single bullet, of Section A.9.1.2 beginning with the text "The } \\
\text { area exceeding the FAL ..." on page A-50, and all text in } \\
\text { Section C.3.0, have been replaced by the following text: } \\
\text { The area exceeding the FAL will be calculated using the } 95 \\
\text { percent UCL TEDs from each plot along each vector. A } \\
\text { relationship will be established of the measured dose with } \\
\text { distance along each vector such that a point along each } \\
\text { vector can be established that corresponds to the } 25 \\
\text { mrem/yr FAL (Figure C.3-1). To conservatively assure that } \\
\text { this point will be beyond locations exceeding the FAL, the } \\
95 \text { percent UCL TEDs will be used as the estimate of dose } \\
\text { for establishing the relationship of dose to distance. An } \\
\text { isopleth from a radiological survey that encompasses the } \\
\text { locations along each vector that correspond to the FAL will } \\
\text { be chosen as the corrective action boundary. Any } \\
\text { additional areas containing contamination exceeding the } \\
\text { FAL (e.g., from the migration of contamination in } \\
\text { drainages) will be added to the corrective action boundary. }\end{array}$} & \\
\hline
\end{tabular}

\section{UNCONTROLLED When Printed}




\section{NEVADA ENVIRONMENTAL RESTORATION PROJECT \\ DOCUMENT REVIEW SHEET}

\begin{tabular}{|c|c|c|c|c|c|c|}
\hline \multicolumn{2}{|c|}{ 1. Document Title/Number: } & \multicolumn{2}{|c|}{$\begin{array}{l}\text { Draft Corrective Action Investigation Plan for Corrective Action Unit 372: Area } 20 \\
\text { Cabriolet/Palanquin Unit Craters, Nevada Test Site, Nevada }\end{array}$} & \multirow{2}{*}{$\begin{array}{l}\text { 2. Document Date: } \\
\text { 4. Originator/Organization: }\end{array}$} & \multicolumn{2}{|l|}{$4 / 17 / 2009$} \\
\hline \multicolumn{2}{|l|}{ 3. Revision Number: } & \multicolumn{2}{|l|}{0} & & \multicolumn{2}{|l|}{ Stoller-Navarro } \\
\hline \multicolumn{2}{|c|}{$\begin{array}{l}\text { 5. Responsible NNSA/NSO Federal } \\
\text { Sub-Project Director: }\end{array}$} & \multicolumn{2}{|l|}{ Kevin J. Cabble } & 6. Date Comments Due: & \multicolumn{2}{|l|}{$5 / 18 / 2009$} \\
\hline \multicolumn{2}{|l|}{ 7. Review Criteria: } & \multicolumn{2}{|l|}{ Full } & & & \\
\hline \multicolumn{2}{|c|}{ 8. Reviewer/Organization/Phone No: } & Jeff MacDougall, NDEP, 486-2850, ext. 233 & & 9. Reviewer's Signature: & & \\
\hline $\begin{array}{l}\text { 10. Comment } \\
\text { Number/Location }\end{array}$ & 11. Type* & 12. Comment & \multicolumn{3}{|c|}{ 13. Comment Response } & 14. Accept \\
\hline $\begin{array}{l}\text { 7.) Throughout } \\
\text { Document }\end{array}$ & & $\begin{array}{l}\text { Although not done in response to specific comments from } \\
\text { NDEP, additional information has been added to a few } \\
\text { sections of the document to add to the completeness and } \\
\text { clarity of the document. These changes have not affected } \\
\text { the sampling strategy or approach to closing CAU } 372 \text { but } \\
\text { have been included to provide addition detail and historical } \\
\text { documentation related to the previous sampling conducted } \\
\text { at the CASs or to provide additional explanation of } \\
\text { concepts or ideas. }\end{array}$ & \multicolumn{3}{|c|}{$\begin{array}{l}\text { 1. Additional information concerning the Nevada Applied } \\
\text { Ecology Group (NAEG) and RDIP sampling will be added } \\
\text { to the Previous Investigation Results sub-section for each } \\
\text { CAS in CAU } 372 \text {. This addition will provide a brief } \\
\text { discussion of the sampling and results to aid in the } \\
\text { completeness of the available information. } \\
\text { The following documents have been reviewed and short } \\
\text { summaries of the findings and results will be included in } \\
\text { the identified sections. } \\
\text { Transuranics in Desert Ecosystems, NAEG Nov } 1977 \text { NV- } \\
\text { 181, MG White, P.B. Dunaway, \& D.L. Wireman (Eds) } \\
\text { USDOE/NOO, Las Vegas, NV } \\
\text { Section 2.0 Investigation Background, } \\
\text { Sec. 2.5.2 CAS 18-45-03 Little Feller II } \\
\text { Sec. 2.5.3 CAS 20-23-01 U-20k Contamination Area } \\
\text { Sec. 2.5.4 CAS 20-45-01 U-20L (Cabriolet) } \\
\text { Section A.2.0 Background Information } \\
\text { Sec. A.2.2 CAS 18-45-03 Little Feller II, Previous } \\
\text { Investigation Results } \\
\text { Sec. A.2.3 CAS 20-23-01 U-20k Contamination Area, } \\
\text { Previous Investigation Results } \\
\text { Sec. A.2.3 CAS 20-45-01 U-20L Crater (Cabriolet), } \\
\text { Previous Investigation Results } \\
\text { The Dynamics of Transuranics and Other Radionuclides in } \\
\text { Natural Environments, Dec 1985, NVO-272, W.A; Howard } \\
\text { and R.G Fuller (Eds) Characterization of Nuclear Site } 201 \\
\text { Soils from the Nevada Test Site. S.Y. Lee, T. Tamura, and }\end{array}$} & \\
\hline
\end{tabular}


NEVADA ENVIRONMENTAL RESTORATION PROJECT

DOCUMENT REVIEW SHEET

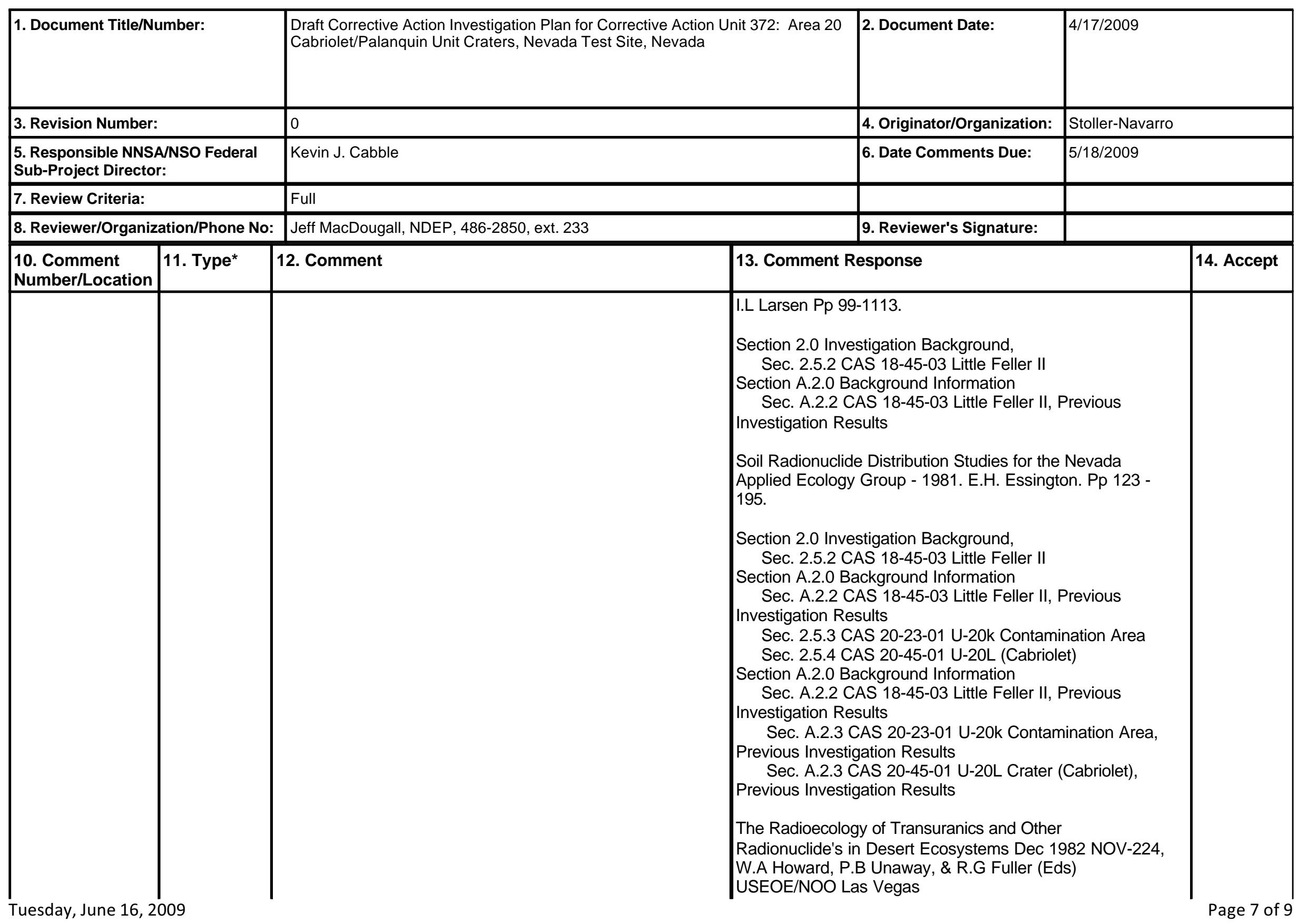

\section{UNCONTROLLED When Printed}


NEVADA ENVIRONMENTAL RESTORATION PROJECT

DOCUMENT REVIEW SHEET

\begin{tabular}{|c|c|c|c|c|c|c|}
\hline \multicolumn{2}{|c|}{ 1. Document Title/Number: } & \multicolumn{2}{|c|}{$\begin{array}{l}\text { Draft Corrective Action Investigation Plan for Corrective Action Unit 372: Area } 20 \\
\text { Cabriolet/Palanquin Unit Craters, Nevada Test Site, Nevada }\end{array}$} & \multirow{2}{*}{\begin{tabular}{|l|} 
2. Document Date: \\
4. Originator/Organization: \\
\end{tabular}} & \multicolumn{2}{|l|}{$4 / 17 / 2009$} \\
\hline \multicolumn{2}{|l|}{ 3. Revision Number: } & \multicolumn{2}{|l|}{0} & & \multicolumn{2}{|l|}{ Stoller-Navarro } \\
\hline \multicolumn{2}{|c|}{$\begin{array}{l}\text { 5. Responsible NNSA/NSO Federal } \\
\text { Sub-Project Director: }\end{array}$} & \multicolumn{2}{|l|}{ Kevin J. Cabble } & 6. Date Comments Due: & \multicolumn{2}{|l|}{$5 / 18 / 2009$} \\
\hline \multicolumn{2}{|l|}{ 7. Review Criteria: } & Full & & & & \\
\hline \multicolumn{2}{|c|}{ 8. Reviewer/Organization/Phone No: } & Jeff MacDougall, NDEP, 486-2850, ext. 233 & & 9. Reviewer's Signature: & & \\
\hline \multirow[t]{2}{*}{$\begin{array}{l}\text { 10. Comment } \\
\text { Number/Location }\end{array}$} & 11. Type* & 12. Comment & \multicolumn{3}{|c|}{ 13. Comment Response } & 14. Accept \\
\hline & & & \multicolumn{3}{|c|}{$\begin{array}{l}\text { Progress of Soil Radionuclide distribution Studies for the } \\
\text { Nevada Applied Ecology Group. E. H Essington. Pp } 145 \text { - } \\
\text { 184. } \\
\text { Section 2.0 Investigation Background, } \\
\text { Sec. 2.5.2 CAS 18-45-03 Little Feller II } \\
\text { Section A.2.0 Background Information } \\
\text { Sec. A.2.2 CAS 18-45-03 Little Feller II, Previous } \\
\text { Investigation Results } \\
\text { Progress of Soil Radionuclide Distribution Studies for } \\
\text { NAEG. 1981 To be presented at NAEG Annual Meeting, } \\
\text { May 27-28, 1981, by P.B. Dunaway. LA-UR-81-1585 E.H. } \\
\text { Essington (Author) Los Alamos Scientific Laboratory, Los } \\
\text { Alamos, NM } \\
\text { Section 2.0 Investigation Background, } \\
\text { Sec. 2.5.2 CAS 18-45-03 Little Feller II } \\
\text { Sec. 2.5.3 CAS 20-23-01 U-20k Contamination Area } \\
\text { Sec. 2.5.4 CAS 20-45-01 U-20L (Cabriolet) } \\
\text { Section A.2.0 Background Information } \\
\text { Sec. A.2.2 CAS 18-45-03 Little Feller II, Previous } \\
\text { Investigation Results } \\
\text { Sec. A.2.3 CAS 20-23-01 U-20k Contamination Area, } \\
\text { Previous Investigation Results } \\
\text { Sec. A.2.3 CAS 20-45-01 U-20L Crater (Cabriolet), } \\
\text { Previous Investigation Results } \\
\text { Selected Environmental Plutonium Research Reports of } \\
\text { the NAEG June 1978 NVO-192 M.G. White, P.B. } \\
\text { Dunaway, \& D.L. Wireman (Eds) USDOE/NOO Las }\end{array}$} & \\
\hline
\end{tabular}




\section{NEVADA ENVIRONMENTAL RESTORATION PROJECT \\ DOCUMENT REVIEW SHEET}

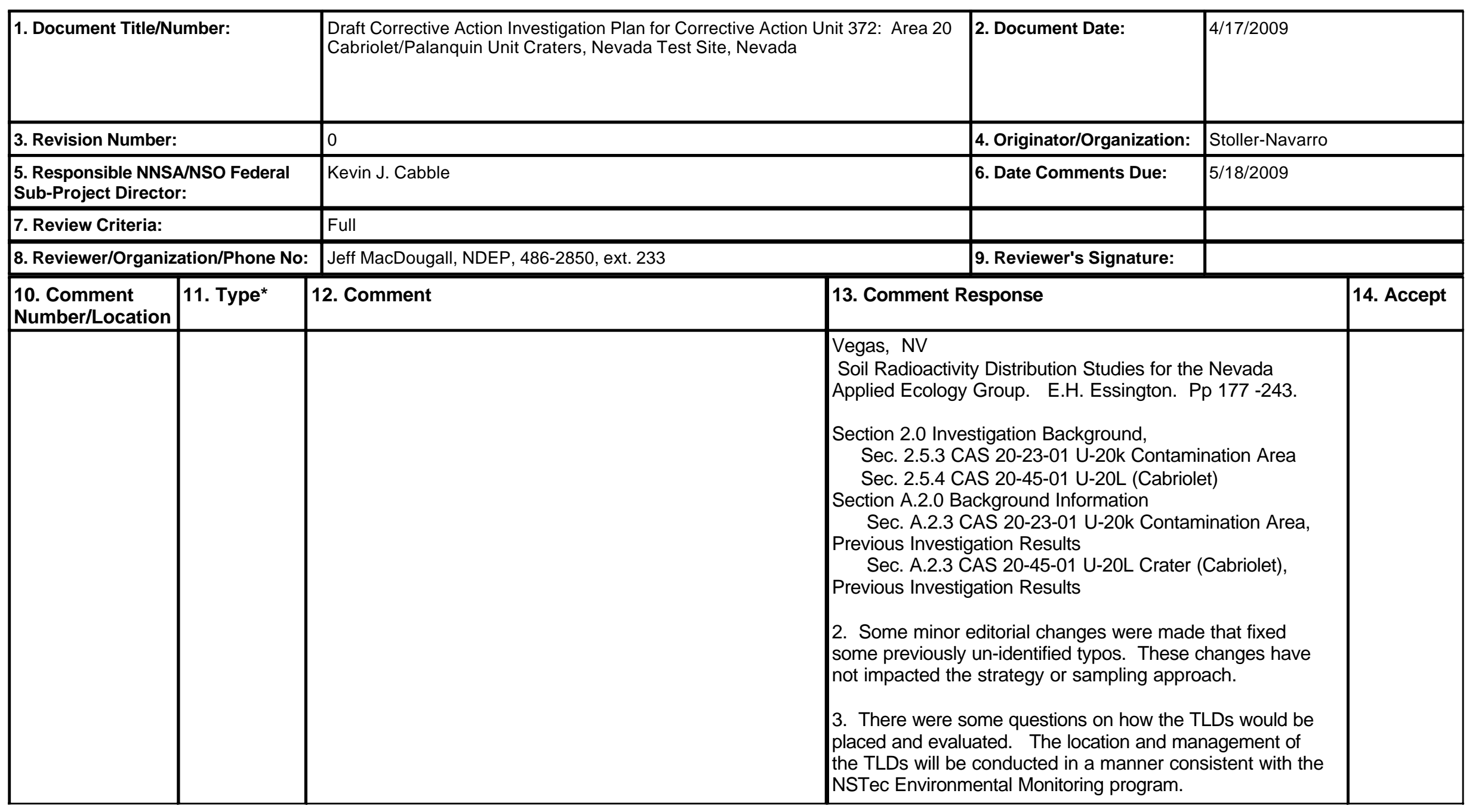




\title{
Library Distribution List
}

\author{
$\underline{\text { Copies }}$ \\ U.S. Department of Energy \\ 1 (Uncontrolled, electronic copy) \\ National Nuclear Security Administration \\ Nevada Site Office \\ Technical Library \\ P.O. Box 98518, M/S 505 \\ Las Vegas, NV 89193-8518 \\ U.S. Department of Energy \\ Office of Scientific and Technical Information \\ 1 (Uncontrolled, electronic copy) \\ P.O. Box 62 \\ Oak Ridge, TN 37831-0062 \\ Southern Nevada Public Reading Facility \\ 2 (Uncontrolled, electronic copies) \\ c/o Nuclear Testing Archive \\ P.O. Box 98521, M/S 400 \\ Las Vegas, NV 89193-8521 \\ Manager, Northern Nevada FFACO \\ 1 (Uncontrolled, electronic copy) \\ Public Reading Facility \\ c/o Nevada State Library \& Archives \\ 100 N Stewart Street \\ Carson City, NV 89701-4285
}

